\title{
De Novo Organelle Biogenesis in the Cyanobacterium TDX16 Released from the Green Alga Haematococcus pluvialis
}

\author{
Qinglin Dong*, Xiangying Xing, Yang Han, Xiaolin Wei, Shuo Zhang \\ Department of Bioengineering, Hebei University of Technology, Tianjin, China \\ Email: *qldong@hebut.edu.cn
}

How to cite this paper: Dong, Q.L., Xing, X.Y., Han, Y., Wei, X.L. and Zhang, S. (2020) De Novo Organelle Biogenesis in the Cyanobacterium TDX16 Released from the Green Alga Haematococcus pluvialis. CellBio, 9, 29-84.

https://doi.org/10.4236/cellbio.2020.91003

Received: February 17, 2020

Accepted: March 17, 2020

Published: March 20, 2020

Copyright $\odot 2020$ by author(s) and Scientific Research Publishing Inc. This work is licensed under the Creative Commons Attribution International License (CC BY 4.0).

http://creativecommons.org/licenses/by/4.0/

\begin{abstract}
It is believed that eukaryotes arise from prokaryotes, which means that organelles can form de novo in prokaryotes. Such events, however, had not been observed previously. Here, we report the biogenesis of organelles in the endosymbiotic cyanobacterium TDX16 (prokaryote) that was released from its senescent/necrotic host cell of green alga Haematococcus pluvialis (eukaryote). Microscopic observations showed that organelle biogenesis in TDX16 initiated with cytoplasm compartmentalization, followed by de-compartmentalization, DNA allocation, and re-compartmentalization, as such two composite organelles-the primitive chloroplast and primitive nucleus sequestering minor and major fractions of cellular DNA respectively were formed. Thereafter, the eukaryotic cytoplasmic matrix was built up from the matrix extruded from the primitive nucleus; mitochondria were assembled in and segregated from the primitive chloroplast, whereby the primitive nucleus and primitive chloroplast matured into the nucleus and chloroplast respectively. While mitochondria subsequently turned into double-membraned vacuoles after matrix degradation. Results of pigment analyses, $16 \mathrm{~S}$ rRNA and genome sequencing revealed that TDX16 is a phycocyanin-containing cyanobacterium resembling Chroococcidiopsis thermalis, which had acquired 9,017,401 bp DNAs with 10,301 genes from its host. Accordingly, we conclude that organelle biogenesis in TDX16 is achieved by hybridizing the acquired eukaryotic DNAs with its own one and expressing the hybrid genome. The formation of organelles in cyanobacterium TDX16 is the first case of organelle biogenesis in prokaryotes observed so far, which sheds an unprecedented light on eukaryotes and their connections with prokaryotes, and thus has broad implications on biology.
\end{abstract}

\section{Keywords}

Organelle Biogenesis, Cyanobacterium, DNA Acquisition, Hybridization, Transition 


\section{Introduction}

All cells are structurally categorized into two groups: eukaryotic cells and prokaryotic cells. Eukaryotic cells contain membrane-bounded organelles. These organelles were once thought to develop only by fission of the preexisting ones, while recent studies show that Golgi apparatus [1], peroxisomes [2] [3] [4], lysosomes [5] [6] [7] and vacuoles [8] [9] form de novo. By contrast, prokaryotic cells have no organelle, but are believed to be the ancestors of eukaryotic cells, which means that organelles can develop from scratch in prokaryotic cells (the first place) to create eukaryotic cells (eukaryogenesis). Such events, however, had not been observed previously for unknown reasons. As a result, how organelles form in prokaryotic cells remains an unsolved puzzle in biology, which could not be studied experimentally in cell biology, but was inferred extensively in evolutionary biology with the outcome of numerous hypotheses. Since no extant cell remains in a true intermediate state between prokaryotic and eukaryotic cells, it is postulated that organelle biogenesis in prokaryotic cells occurred only once in ancient times. However, on the contrary, there is another possibility that organelle formations in prokaryotic cells still occur at the present time in a manner different from the hypothetical ways, which proceed rapidly and finish in a short time rather than gradually in a long time as usually speculated, result in sudden transition of the prokaryotic cells into eukaryotic cells, and thus are hard to capture.

Haematococcus pluvialis is a unicellular astaxanthin-producing green alga [10], which reproduces by binary fission and generating aplanospores in the conditions of high light and low temperature (Figure 1). By contrast, when growing in the adverse conditions of high temperature and low irradiance $H$. pluvialis cells underwent senescence and no longer divided or generated aplanospores, but unexpectedly we found that the senescent/necrotic $H$. pluvialis cells burst and liberated countless small blue cells (Figure 2). Initially, we mistook this phenomenon for a novel reproduction way of $H$. pluvialis. However, subsequent studies revealed that the newly released small blue cells from the ruptured $H$. pluvialis cells were indeed cyanobacterial cells (TDX16) [11]. Transmission electron microscopic observations showed that before liberation the tiny premature TDX16 cells with unique electron-dense heterogenous globular bodies (HGBs) multiplied by asymmetric division within the enclosing sheaths (sporangia) in the senescent/necrotic $H$. pluvialis cell (host) and subsequently grew up into small thylakoids-less endospore-producing TDX16 cells filling up the dead host's cellular space (Figure 3). The liberated TDX16 cells are highly abnormal, which remain relatively stable in the dim light, but turn readily into small green algal cells as light intensity elevated [12]. The time required for TDX16's transition is short and inversely correlated with light intensity, which is about 10 days at $60 \mu \mathrm{mol}$ photons $\mathrm{m}^{-2} \cdot \mathrm{s}^{-1}$. Whereas irradiance above $60 \mu \mathrm{mol}$ photons $\mathrm{m}^{-2} \cdot \mathrm{s}^{-1}$ is lethal to TDX16, causing massive cell death. 


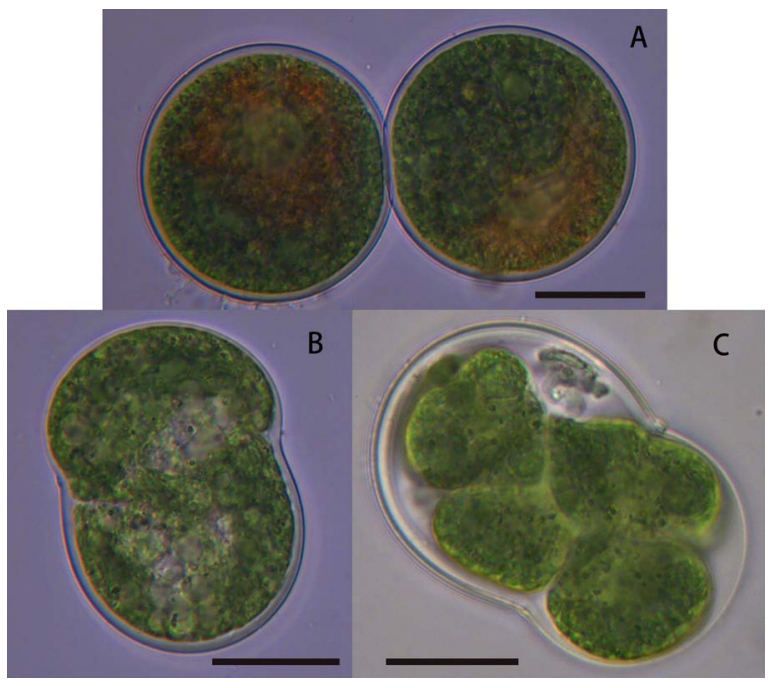

Figure 1. Reproduction of Haematococcus pluvialis. (A) Binary fission of $H$. pluvialis cell. (B) Differentiation of a $H$. pluvialis cell into an aplanosporangium. (C) Development of aplanospores within the aplanosporangium. Scale bars $10 \mu \mathrm{m}$. Cells were observed with a light microscope BK6000 (Optec, China). Microphotographs were taken under the objective lens (40×) using a DV E3 630 camera.
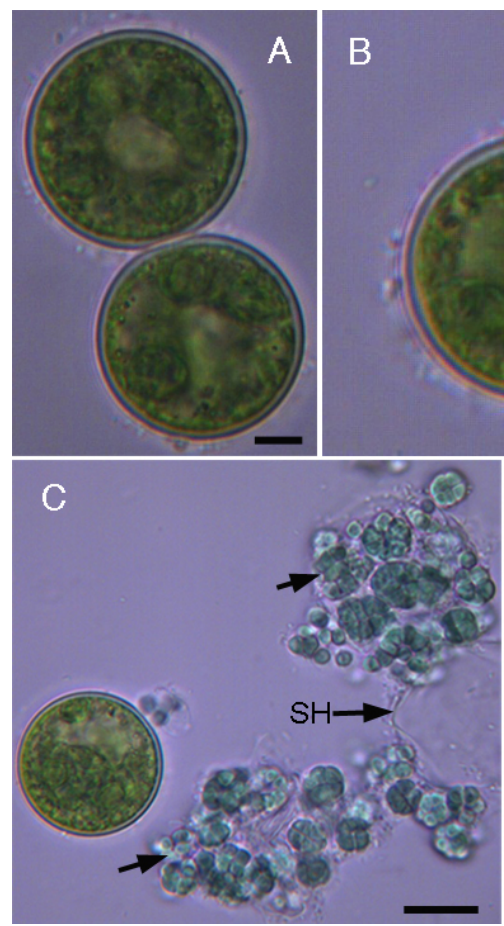
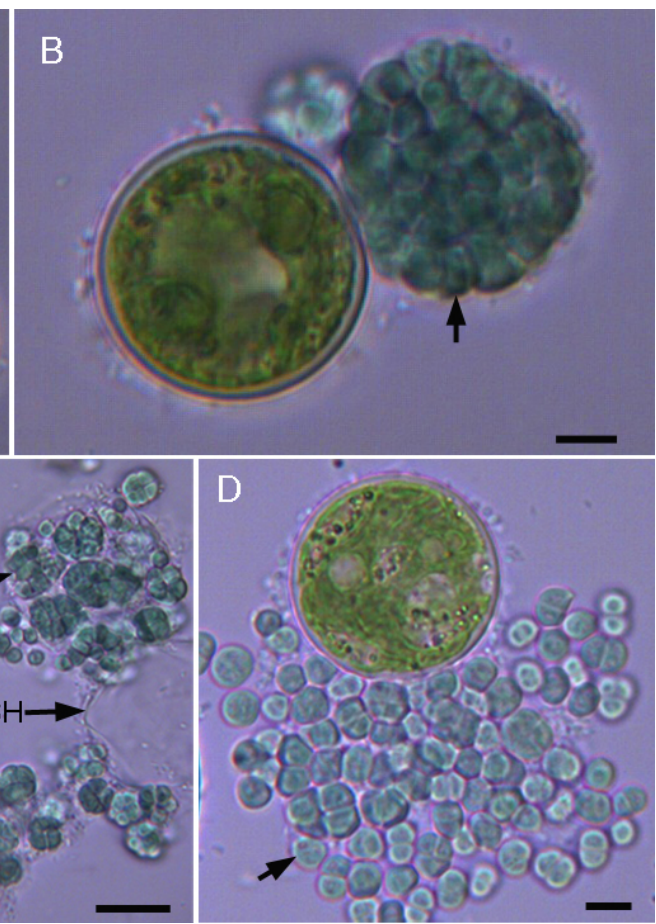

Figure 2. Liberation of TDX16 from the senescent/necrotic $H$. pluvialis cell. (A) Two large senescent/necrotic $H$. pluvialis cells, scale bar $5 \mu \mathrm{m}$. (B) The cell wall of one senescent/necrotic $H$. pluvialis cell suddenly burst and liberated a massive equal-sized blue spheroid (arrow) consisting of countless TDX16 cells, scale bar $5 \mu \mathrm{m}$. (C) The transparent covering sheath ( $\mathrm{SH}$ ) (cytoplasmic membrane of $H$. pluvialis cell) of the blue spheroid ruptured, and thus the blue spheroid collapsed into many cell clumps (arrow), scale bar $10 \mu \mathrm{m}$. (D) The compacted TDX16 cells in the cell clumps disaggregated, which were enclosed within the sporangia (arrow), scale bar $5 \mu \mathrm{m}$. Microphotographs were taken in the same way as Figure 1. 

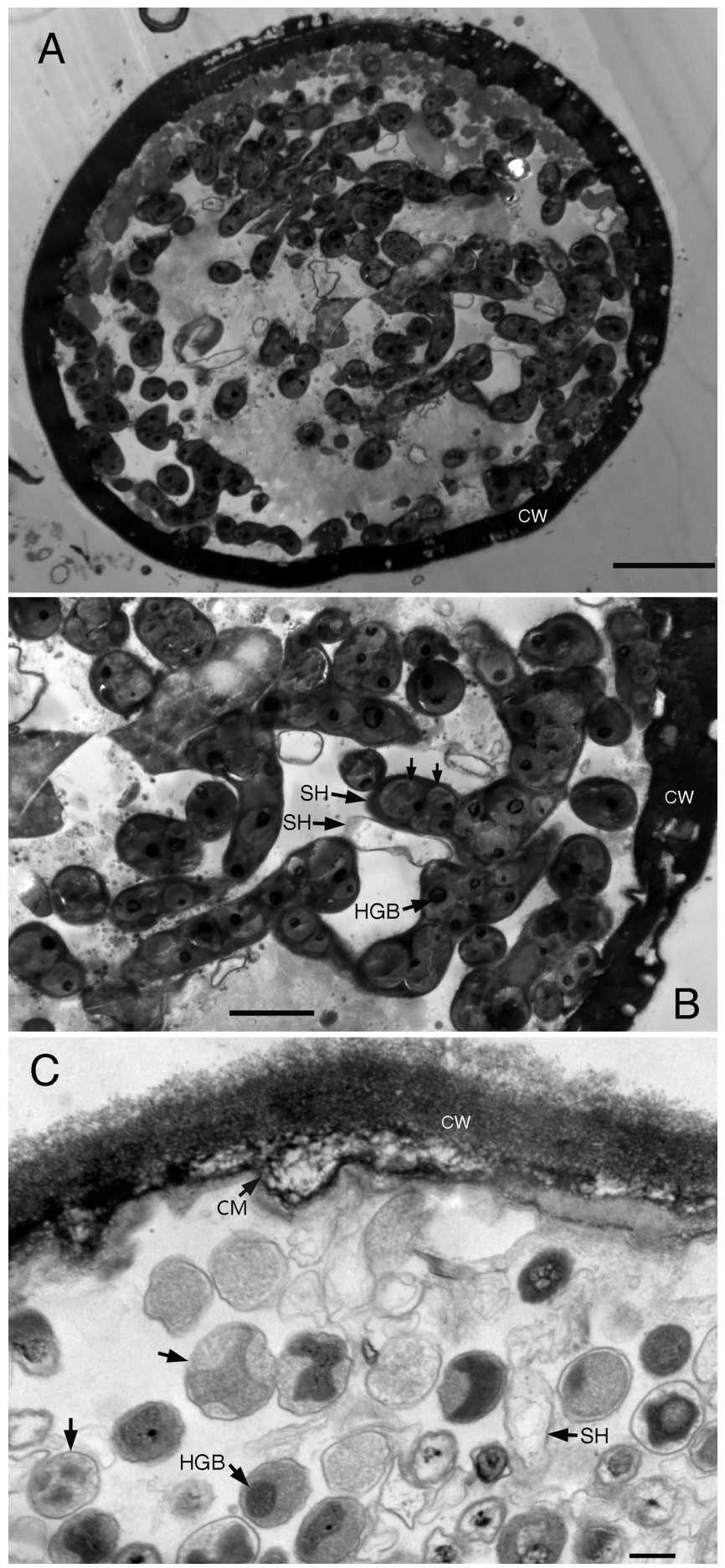

Figure 3. Proliferation and development of TDX16 in the senescent/necrotic $H$. pluvialis cell. (A) Tiny premature TDX16 cells proliferated within a senescent/necrotic $H$. pluvialis cell, whose cell wall (CW) remained intact but organelles dissolved, scale bar $5 \mu \mathrm{m}$. (B) Detail from (A), tiny TDX16 cells (arrow) with electron-dense heterogenous globular bodies (HGBs) multiplied by asymmetric division within and escaped from the enclosing sheaths (SH) (sporangia), scale bar $2 \mu \mathrm{m}$. (C) Tiny TDX16 cells grew up into small thylakoid-less DTX16 cells filling up the cellular space of the dead $H$. pluvialis cell whose cell wall (CW) and cytoplasmic membrane (CM) still remained intact. The small TDX16 cells multiplied by formation of endospores within the sporangia (arrow), scale bar $0.2 \mu \mathrm{m}$. 
The transition of cyanobacterium TDX16 cells into green algal cells is the first case of prokaryote-to-eukaryote transition observed so far, which provides the opportunity and platform to solve the puzzle of organelle biogenesis in prokaryotic cells. Hence, this study aims to investigate how and why organelles form in cyanobacterium TDX16.

\section{Materials and Methods}

\subsection{Strain and Cultivation}

Pure TDX16 cells were collected from the $H$. pluvialis cultures, in which all $H$. pluvialis cells burst and released TDX16 cells [11], and maintained in sterile BG-11 liquid medium [13] at $25^{\circ} \mathrm{C}, 12 \mu \mathrm{mol}$ photons $\mathrm{m}^{-2} \cdot \mathrm{s}^{-1}$ in the illumination incubator. Axenic TDX16 was prepared according to the method [14] with some modifications. Briefly, pure TDX16 culture was treated with antibiotics nystatin $(100 \mu \mathrm{g} / \mathrm{ml})$ and cycloheximide $(150 \mu \mathrm{g} / \mathrm{ml})$ for $18 \mathrm{~h}$, then the culture was diluted 10 fold with sterile distilled water and plated onto BG-11 solid medium in petri dishes supplemented $(\mathrm{w} / \mathrm{v})$ with glucose $(0.5 \%)$, peptone $(0.3 \%)$ and yeast extracts $(0.2 \%)$. The petri dishes were sealed with parafilm and incubated in an inverted position in the illumination incubator at $25^{\circ} \mathrm{C}, 12 \mu \mathrm{mol}$ photons $\mathrm{m}^{-2} \cdot \mathrm{s}^{-1}$ for one month. The colonies (Figure 4) were picked and transferred into autoclaved 250-ml flasks containing $100 \mathrm{ml}$ BG-11 medium and cultivated under the same conditions as described above.

The obtained axenic TDX16 cultures were used in experiments: $10 \mathrm{ml}$ axenic TDX16 culture was inoculated into each autoclaved 250-ml flask containing 100 $\mathrm{ml} \mathrm{BG}-11$ medium and illuminated with continuous light of $60 \mu \mathrm{mol}$ photons $\mathrm{m}^{-2} \cdot \mathrm{s}^{-1}$ at $25^{\circ} \mathrm{C}$ in the incubator.

\subsection{Microscopy Observations}

Light microscopy: TDX16 cells in cultures were examined each day with a light microscope BK6000 (Optec, China). Photomicrographs were taken under the oil immersion objective lens $(100 \times)$ using a DV E3 630 camera. Cell sizes were measured with a micrometer eyepiece.

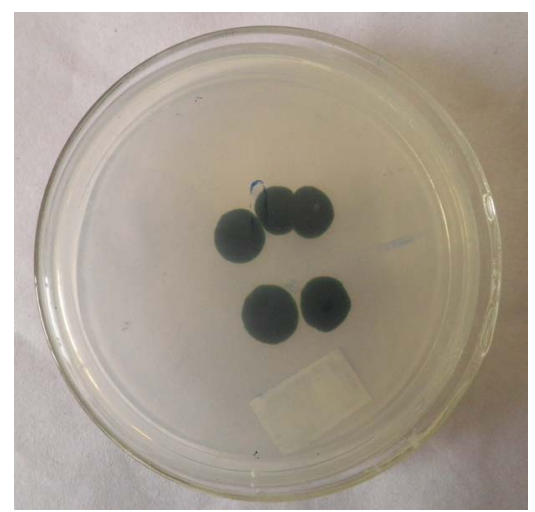

Figure 4. TDX16 colonies in an inverted Petri dish. 
Transmission electron microscopy: TDX16 cells were harvested each day by centrifugation (3000 rpm, $10 \mathrm{~min}$ ) and fixed overnight in $2.5 \%$ glutaraldehyde (50 mM phosphate buffer, pH7.2) and $1 \%$ osmium tetroxide (the same buffer) for $2 \mathrm{~h}$ at room temperature. After dehydration with ascending concentrations of ethanol, the fixed cells were embedded in Spurr's resin at $60^{\circ} \mathrm{C}$ for $24 \mathrm{~h}$. Ultrathin sections ( 60 to $80 \mathrm{~nm}$ ) were cut with a diamond knife, mounted on a copper grid, double-stained with $3 \%$ uranyl acetate and $0.1 \%$ lead citrate, and examined using a JEM1010 electron microscope (JEOL, Japan).

\subsection{Pigment Analyses}

In vivo absorption spectra: Cell suspensions were scanned with Ultraviolet-Visible Spectrophotometer Cary 300 (Agilent, USA), the spectra were normalized to give an equal absorbance of chlorophyll a at $440 \mathrm{~nm}$.

Fluorescence emission spectra: Water soluble pigments were extracted with $0.75 \mathrm{M} \mathrm{K}$-phosphate buffer $(\mathrm{pH}=6.8)$. Lipid soluble pigments were extracted with pure acetone and diluted 50-fold into ethanol. Both extracts were analyzed on Fluorescence Spectrophotometer F-4500 (Hitachi, Japan) at room temperature with excitations of $580 \mathrm{~nm}$ and $478 \mathrm{~nm}$ respectively.

Pigment separation and identification: Chlorophyll $b$ and lutein was separated by thin-layer chromatography according to the method [15]. Phycocyanin was extracted and purified following the procedures described by Adams [16]. All pigments were analyzed with Ultraviolet-Visible Spectrophotometer Cary 300 (Agilent, USA), and identified by spectroscopic matching with the published data.

\subsection{S rRNA Sequence}

DNA samples were prepared according to the method described previously [17]. 16S rRNAs were amplified using the primers 8 - $27 \mathrm{f}$ (AGAGTTTGATCCTGGCTCAG) and $1504-1486$ r (CTTGTTACGACTTCACCCC) [18]. Fragments were cloned into the pMD18-T vector and amplified using M13 forward and reverse universal primers. The PCR products were digested with restriction enzymes BamH1/SalI, and sequenced on ABI 3730 DNA analyzer (PerkinElmer Biosystems, USA).

\subsection{Genome Sequence of TDX16}

TDX16 cells were harvested by centrifugation at $3000 \mathrm{rpm}$ for $10 \mathrm{~min}$, and washed twice with $5 \mathrm{M} \mathrm{NaCl}$ solution and sterile water alternately. The pelleted cells were frozen in liquid nitrogen and then grinded with sterile glass beads $(0.5 \mathrm{~mm}$ diameter). The slurry was transferred into $5 \mathrm{ml}$ centrifuge tube with TE buffer (1 $\mathrm{mM}$ EDTA, $10 \mathrm{mM}$ Tris- $\mathrm{HCl}, \mathrm{pH}=8.0$ ), supplemented with $1.0 \mathrm{ml}$ lysozyme solution $(20 \mathrm{mg} / \mathrm{ml})$ and incubated at $37^{\circ} \mathrm{C}$ for $60 \mathrm{~min}$, then added CTAB (Cetyltrimethyl ammonium bromide) solution (10\% CTAB, $0.7 \mathrm{M} \mathrm{NaCl})$ and heated to $65^{\circ} \mathrm{C}$ for $30 \mathrm{~min}$ in a water bath. After centrifugation $(12,000 \mathrm{rpm}, 10 \mathrm{~min})$, the supernatant was extracted with one volume of phenol-chloroform-isoamyl alcohol $(25: 24: 1, \mathrm{~V} / \mathrm{V})$, and DNA was precipitated overnight at $-20^{\circ} \mathrm{C}$ after the addi- 
tion of 2/3 volume of cold isopropanol and 1/10 volume of $3 \mathrm{M}$ sodium acetate, dried and resuspended in TE buffer. The extracted DNA was first subjected to quality assay and then sheared ultrasonically into fragments, with their overhangs being converted into blunt ends applying T4 DNA polymerase, Klenow Fragment and T4 Polynucleotide Kinase. Subsequently, adapters were ligated to the 3' ends of DNA fragments that were introduced with " $A$ " bases. The obtained fragments were purified via gel-electrophoresis and PCR-amplified for preparing the sequencing library of DNA clusters. Paired-end sequencing was carried out on an Illumina HiSeq 4000 platform, yielding 1.132 Mb raw data. After removal of the low quality reads, $1.009 \mathrm{Mb}$ clean data was assembled with SOAPdenovo.

\section{Results}

\subsection{Light Microscopic Observation of TDX16-to-Alga Transition}

At the beginning, TDX16 cells were blue in color and reproduced by binary fission within the sporangia, containing more or less small grey vesicles (day 1, Figure 5(A)). In the following day (day 2, Figure 5(B)) TDX16 cells turned pale blue-green and began to escape from the ruptured sporangia leaving remnant sheaths (ruptured sporangia). With time, all TDX16 cells escaped from the sporangia, which no longer divided but enlarged, rounded up and turned a little bit more blue, while the intracellular grey vesicles became nearly indistinguishable (Figure 5(C), day 3). Subsequently, TDX16 cells turned slightly yellow, in which small white vesicles began to form (Figure 5(D), day 4) and increase in number and size (Figure 5(E), day 5). As such most TDX16 cells contained several small or medium-sized white vesicles, and occasionally a newly-formed small blue vesicle (Figure 5(F), day 6). Radical changes occurred on day 7 (Figure 5(G)): TDX16 cells turned green, in which large blue vesicles and large white vesicles formed. Thereafter, the large blue and white vesicles shrank and disappeared in TDX16 cells, while parietal chloroplasts similar to those of green algae developed in some of the last type cells (day 8 , Figure $5(\mathrm{H})$ ). When the large blue and white vesicles disappeared completely, chloroplasts formed in most TDX16 cells but were still under development in the rest ones (day 9, Figure 5(I)). Ultimately, all TDX16 cells turned into green algal cells (TDX16-DE), containing one single giant chloroplast and multiplying by formation of autospores (autosporulation) (day 10, Figure $5(J))$. Such that, the color of TDX16 cultures changed from blue (day 1) to green (day 10) (Figure $5(\mathrm{~K})$ ).

\subsection{Transmission Electron Microscopic Observation of Organelle Biogenesis in TDX16}

Consistent with our previous studies, light microscopic observation (Figure 5) showed unequivocally the transition of TDX16 cells into green algal cells as evidenced by the formation of chloroplast as well as the changes of cell color, morphology and reproduction mode. So, there is no doubt that during the 10-day 


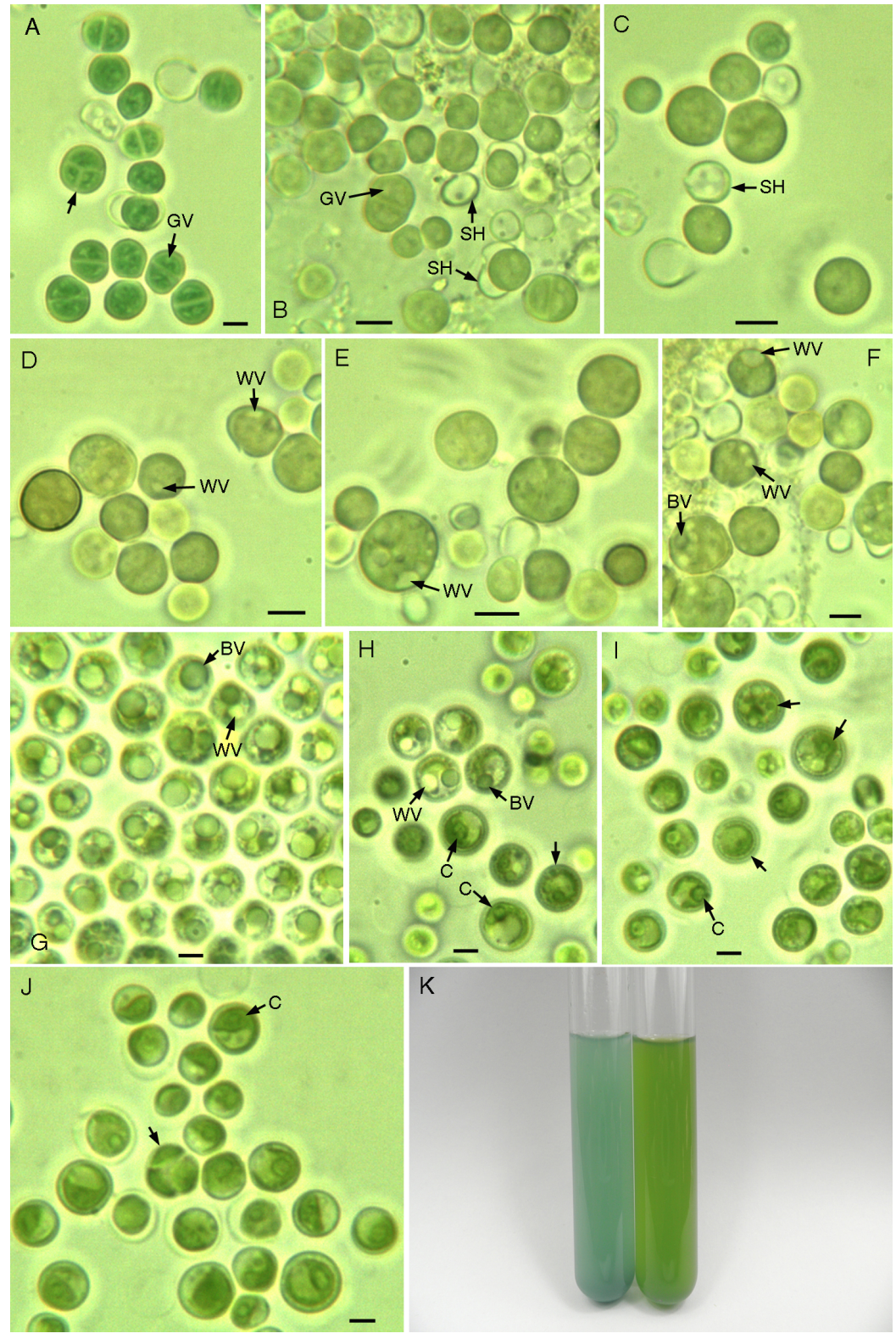

Figure 5. Light microscopic images of cyanobacterium TDX16-to-alga transition. (A) The newly inoculated blue TDX16 cells reproduced by binary fission within the sporangia (arrow) containing small grey vesicles (GV) (day 1). (B) TDX16 cells turned pale blue-green, some of which escaped from the sporangia leaving the remnant sheath ( $\mathrm{SH}$ ) (day 2). (C) All TDX16 cells escaped from the sporangia, increased in size, rounded up and turned a little bit more blue (day 3). (D) TDX16 cells turned slightly yellow, in which white vesicle (WV) began to form (day 4), and increased in size and number (E) (day 5). (F) TDX16 cells contained several small or one medium-sized white vesicles and occasionally a newly-formed small blue vesicles (BV) (day 6). (G) TDX16 cells turned green, in which large blue vesicles and large white vesicles formed (day7). $(\mathrm{H})$ Large blue vesicles and large white vesicles shrunk in part of TDX16 cells and vanished in the rest ones (arrow), and in some of the latter type cells parietal chloroplasts (C) developed (day 8). (I) Chloroplasts formed in most TDX16 cells, but were under development in other ones (arrow) (day 9). (J) All TDX16 cells turned into green algal cells (TDX16-DE), containing a single chloroplast and reproducing by autosporulation (arrow) in day 10. (K) Image of TDX16 culture samples on day 1 (left) and day 10 (right). Scale bars $2 \mu \mathrm{m}$. 
transition process other organelles aside from chloroplast and compartments also formed through previously unknown intermediates and subtle changes in ultrastructure, which cannot be visualized directly and tracked in real time, but can only be detected discontinuously with the conventional transmission electron microscopy (TEM). Whereas, it is a formidable task to elucidate the complex and dynamic process of organelle biogenesis based on the static TEM images. Since TDX16 cells originally contained only heterogenous globular bodies (Figure 3 ), all organelles developed from scratch. That is to say, changes of TDX16 initiated from a definite start-point and progressed irreversibly in one direction towards organelle biogenesis. In this unique situation, we sequenced TEM images according to sampling time, and reconstructed the general process of organelle biogenesis based on the connections (overlaps) and coherences of intermediates and changes in ultrastructure. However, the time for each change could not be determined owing to the unsynchronized states of cells, and thus time intervals were showed in the figure legends.

\subsubsection{Initial Structure of TDX16 Cells}

Initially, TDX16 cells (day 1) were surrounded by thick sheaths and enclosed within the sporangia (Figure 6 and Figure 7), resembling the endospores (baeocytes) of cyanobacterium Chroococcidiopsis sp. [19] and Chroococcidiopsis thermalis [20]. TDX16 cells in the same or different sporangia remained at different states with some different inclusions (Figure 6 and Figure 7). As shown in Figure 6, three different-sized cells in a multilayered sporangium contained no thylakoid but unique membrane-bounded heterogenous globular bodies (HGB) and cyanobacterial inclusions, including carboxysomes (CX) [21], polyphosphate bodies (PB) [22] and osmiophilic granules (OG) [23]. The heterogenous globular bodies sequestered DNA-like electron-dense granules and filaments (resembling compacted chromatin fibers) and situated in the nucleoids (NU), where DNA fibers (DF) [24] and ribosomes (RB) [25] scattered. The prominent difference among these cells was that some small swirly and rod-shaped electron-transparent vesicles (EV) were being developed in the left large cell. Similarly, in a five-celled sporangium (Figure 7), the bottom cell contained osmiophilic granules and a polyphosphate body, while many large different-shaped electron-transparent vesicles were being developed in the three middle cells, and several thylakoid-like structures were built up in the upper cell. These results confirmed the light microscopic observations that TDX16 cells were hypersensitive to light and highly variable in nature, whose change could not be suppressed completely even in the dim light.

The electron-transparent vesicles developed from osmiophilic granules, because: 1) osmiophilic granule was the only membranous cyanobacterial inclusion prior to electron-transparent vesicles, 2) osmiophilic granules presented in electron-transparent vesicles, some of which were not in the section plane and thus invisible, and 3) as electron-transparent vesicles enlarged, osmiophilic granules turned into 


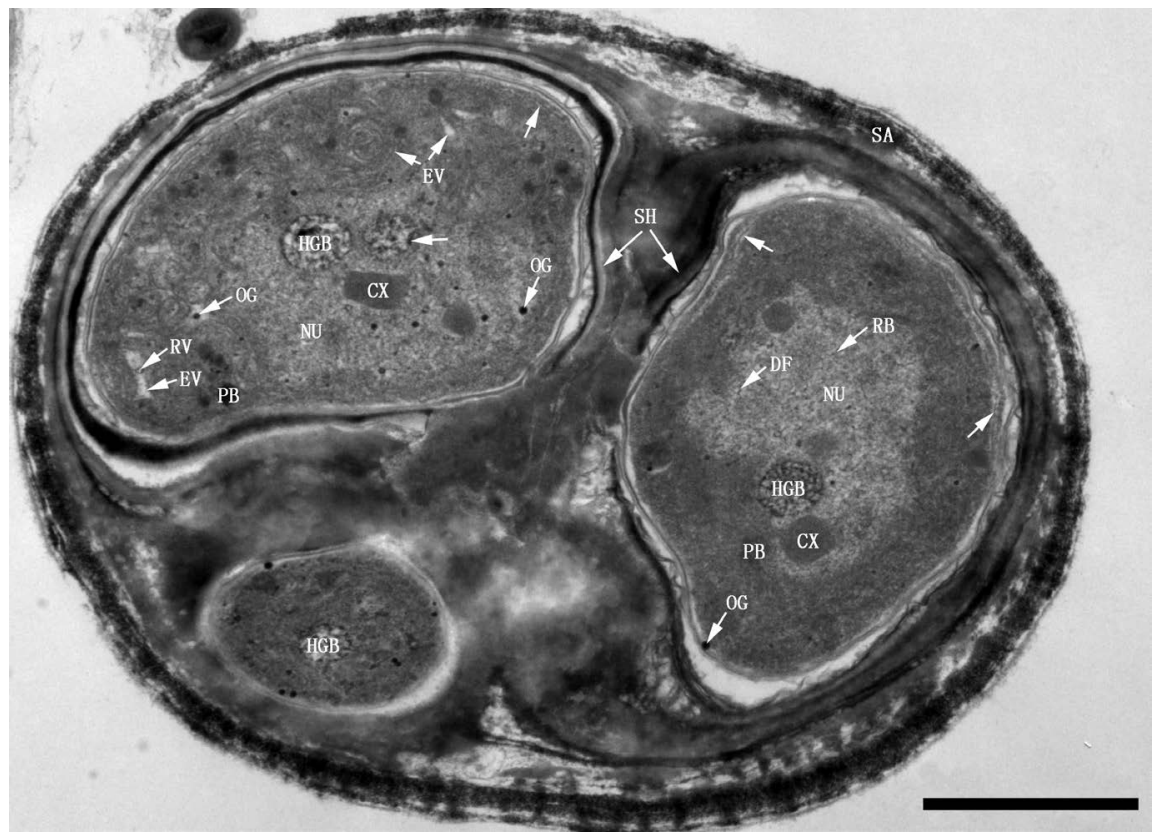

Figure 6. Three TDX16 cells within a sporangium (SA) (day 1). TDX16 cells were enclosed by thick sheaths (SH), containing no thylakoid, but heterogenous globular bodies (HGB), carboxysomes (CX), ribosomes (RB), DNA fibers (DF) and osmiophilic granules $(\mathrm{OG})$ in the nucleoids (NU) as well as polyphosphate bodies (PB) in the cytoplasm. OG also presented in the cytoplasm and some small electron-transparent vesicles (EV) with internal ring-shaped vesicles (RV) or OG were being developed in the upper left cell. Compartmentalization initiated in the two large cells (arrow). Scale bar $1 \mu \mathrm{m}$.

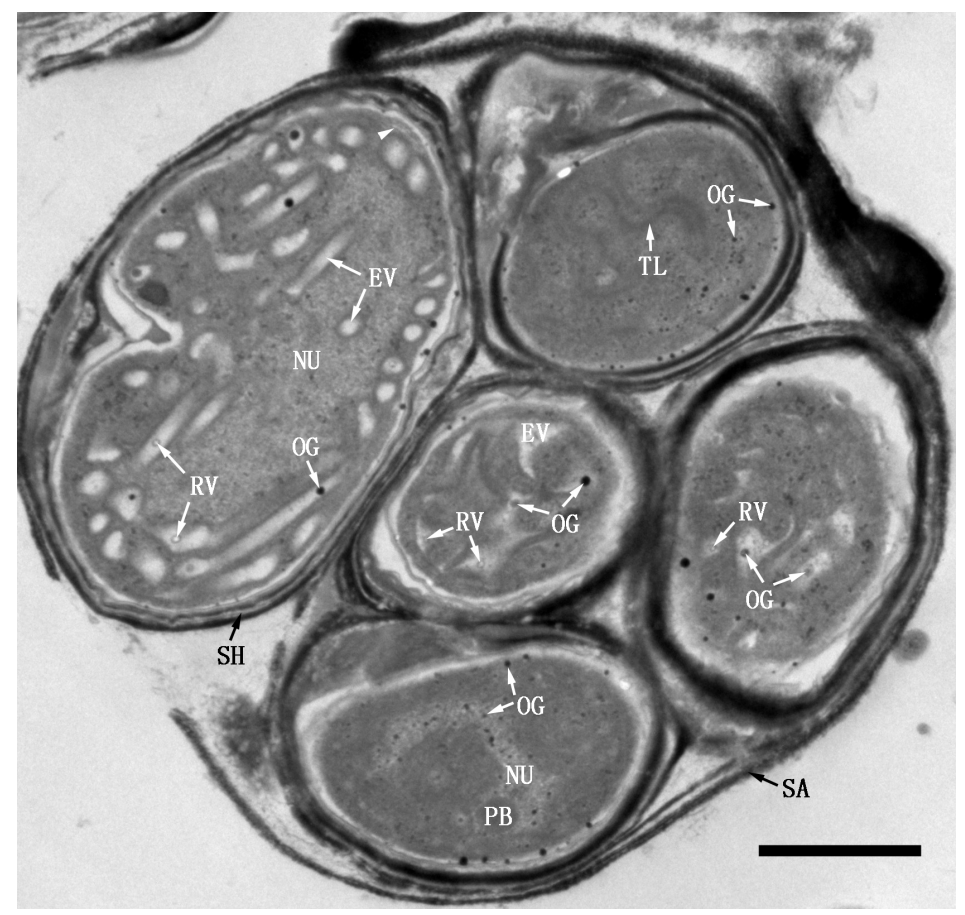

Figure 7. Five TDX16 cells within a sporangium (SA) (day 1). The bottom cell contained osmiophilic granules (OG), while electron-transparent vesicles (EV) were developed in the three middle cells, and several thylakoid-like structures (TL) were built up in the upper cell. Compartmentalization commenced in the large cell (arrowhead). Scale bar $1 \mu \mathrm{m}$. 
ring-shaped vesicles (RV) after their dense matrixes became opaque and finally transparent (Figure 6 and Figure 7). Osmiophilic granule contains triacylglycerol and tocopherol [26], while its detail composition and structure are unknown. There is a general consensus that osmiophilic granule in cyanobacteria is comparable to plastoglobule (PG) in algal and plant chloroplasts [23] [27], which contains lipids, carotenoids, enzymes, and proteins e.g., vesicle-inducing protein in plastids 1 , and structurally consists of a monolayer lipid membrane (half unit membrane) and a neutral lipid core [28] [29] [30] [31] [32]. Whereas, the formation of ring-shaped vesicles in the electron-transparent vesicles indicated that osmiophilic granules had two monolayer lipid membranes: the intermembrane space was likely filled with hydrophobic neutral lipids, while the interior monolayer membrane encased probably a hydrophilic "protein core". So, as the intermembrane space dilated, the outer monolayer membrane bulged out into an electron-transparent vesicle; while the interior monolayer membrane and protein core remained unchanged as a monolayer-membrane-bounded osmiophilic granule, which subsequently transformed into a ring-shaped vesicle after metabolizing the protein core (Figure 6 and Figure 7).

\subsubsection{Compartmentalization, Formation of Cytoplasmic Envelope and Primary Thylakoids \\ 1) Compartmentalization}

TDX16 with surrounded sheath escaped from the ruptured sporangium and changed rapidly in structures and inclusions. As shown in Figure 8(A), the cyanobacterial polyphosphate body and carboxysome vanished; the heterogenous globular bodies became nearly empty leaving only few DNA-like fibrils and electron-dense margin residues. While a startling number of osmiophilic granules and stacks of membranous elements emerged, and many small electron-transparent vesicles were being developed. The cell wall became clear, which, like those of gram-negative bacteria and other cyanobacteria [33] [34], was composed of an electron-dense outer membrane (OM), an electron-transparent intermediate space (layer) and an inner electron-dense peptidoglycan layer $(\mathrm{P})$, and separated from the cytoplasmic membrane (CM) by an electron-transparent extracytoplasmic (periplasmic) space (ES) (Figure $8(\mathrm{~A})$ ).

The most striking change was the compartmentalization of prokaryotic cytoplasm (cytoplasm) (Figure 8(A)): two intracytoplasmic membranes and an intervening peptidoglycan-like layer (PL) were being synthesized synchronously, which initiated from a start point and extended parallel to the cytoplasmic membrane. As a result, the cytoplasm was partitioned into three compartments: 1) the inner cytoplasm (ICP) delimited by the inner intracytoplasmic membrane (IIM), 2) the outer cytoplasm (OCP) bounded by the outer intracytoplasmic membrane (OIM) and cytoplasmic membrane, and 3) the sandwiched intracytoplasmic space (IS) that was further separated by the peptidoglycan-like layer into an outer intracytoplasmic space (OIS) and an inner intracytoplasmic space (IIS) (Figure 8(A)). 


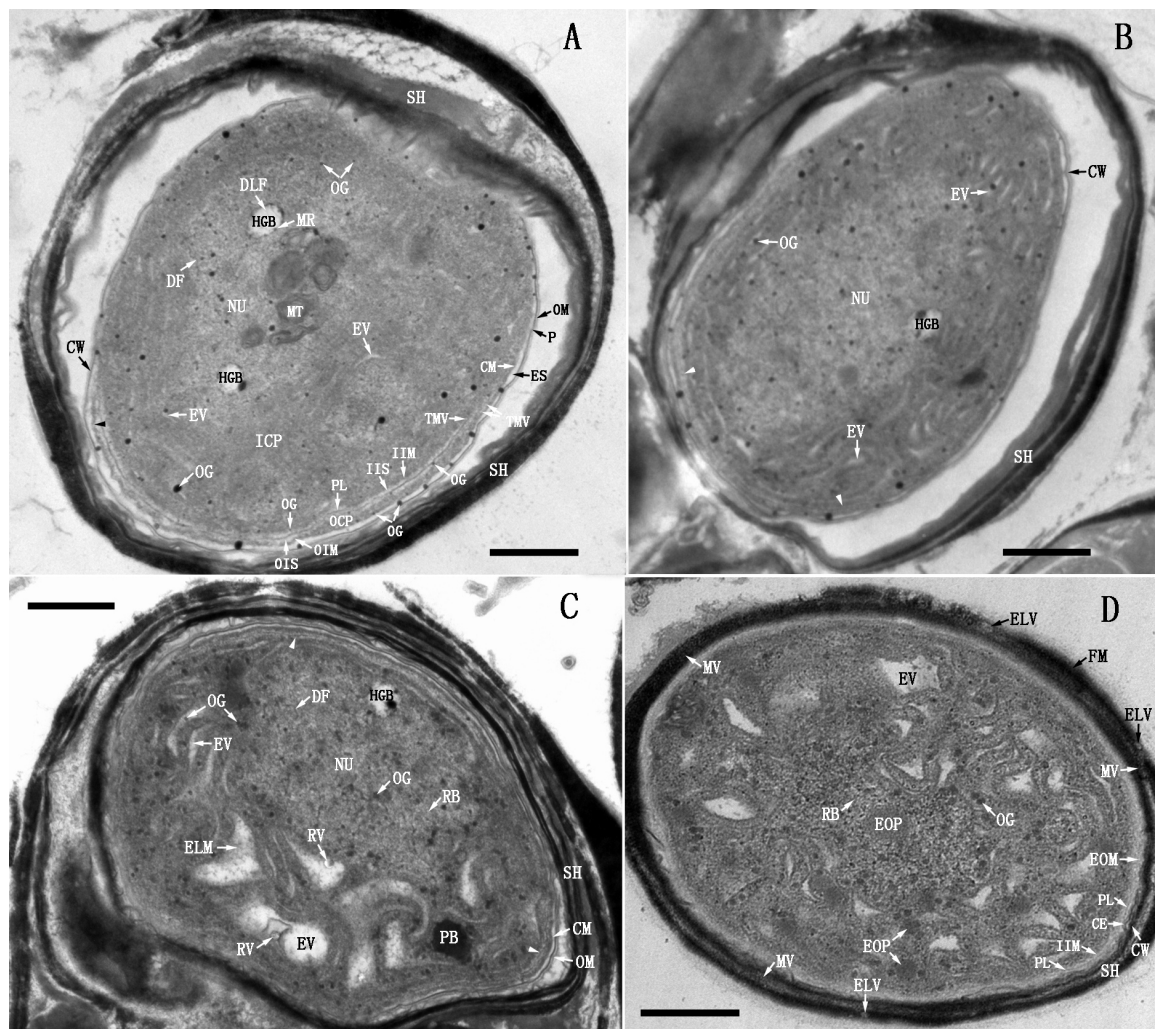

Figure 8. Compartmentalization, formation of electron-transparent vesicles and cytoplasmic envelope (day 1 - 2). (A) TDX16's cell wall (CW) comprised an outer membrane $(\mathrm{OM})$ and a peptidoglycan layer $(\mathrm{P})$, which was separated from the cytoplasmic membrane (CM) by an extracytoplasmic space (ES). Inside the cytoplasm, an inner intracytoplasmic membrane (IIM), an outer intracytoplasmic membrane (OIM) and an intervening peptidoglycan-like layer (PL) were being synthesized by fusion of the small thick margin vesicles (TMV) blistered form CM. Whereby, the cytoplasm was partitioned into three compartments: the inner cytoplasm (ICP); the outer cytoplasm (OCP), and the sandwiched intracytoplasmic space (IS) that was further separated by PL into an outer intracytoplasmic space (OIS) and an inner intracytoplasmic space (IIS). OCP began to reduce in localized region near the start point (arrowhead), such that OIM moved to CM. Osmiophilic granules (OG) budded from CM, IIM and OIM, and migrated into ICP, where many small electron-transparent vesicles (EV) were being formed and stacks of membranous elements (MT) emerged; while the heterogenous globular bodies (HGB) became nearly empty leaving only DNA-like fibrils (DLF) and electron-dense margin residues (MR). Interestingly, OG shed from the outer leaflet of CM into ES, connecting CM and CW. (B) IS became narrow (arrow), while more and more small EV were being developed. (C) EV dilated into swirling ones spiraling around the nucleoids (NU). (D) OCP vanished, OIM and CM were positioned together giving rise to a double-membraned cytoplasmic envelope (CE); NU and HGB disappeared, several electron-opaque particles (EOP) emerged; IS became widened filling with electron-opaque materials (EOM); a new sheath ( $\mathrm{SH}$ ) was formed, consisting of flocculent fibrillary materials (FM), microvesicles (MV) and electron-translucent vesicles (ELV). Scale bars $0.5 \mu \mathrm{m}$.

It was important that the outer cytoplasm began to degrade in localized regions near the start point, such that the outer intracytoplasmic membrane got closed to the cytoplasmic membrane (Figure $8(\mathrm{~A})$ ). In fact, compartmentalization also 
commenced in some of the newly inoculated cells (day 1, Figure 6 and Figure 7). The intracytoplasmic membranes and peptidoglycan-like layer were synthesized by fusion of the small thick margin vesicles (TMV) blistered form the inner leaflet of the cytoplasmic membrane (Figure 8(A)) in two probable ways: 1) if the small thick margin vesicles were delimited by a half-unit membrane, they first released their contents for synthesizing the septal peptidoglycan-like layer and then fused alternately on its two sides; 2) if the small thick margin vesicles were limited by a unit membrane, as they fused one another, the septal peptidoglycan-like layer was synthesized within the coalesced vesicles, a scenario somewhat similar to the formation of cell plate during cytokinesis [35].

\section{2) Production of osmiophilic granules}

Osmiophilic granules of various sizes blistered from the inner and outer leaflets of the cytoplasmic membrane (Figure $8(\mathrm{~A})$ ), such a scenario was also observed in the newly inoculated cells (Figure 6 and Figure 7). Importantly, some small osmiophilic granules also budded from the intracytoplasmic membranes (Figure 8(A)). These results suggested that the intracytoplasmic membranes were functionally comparable to the cytoplasmic membrane that was apparently capable of both photosynthesis and respiration just like the cytoplasmic membrane of the thylakoid-less cyanobacterium Gloeobacter violaceus [36] [37]. Osmiophilic granules appeared to play different roles: these blistered from the inner leaflet of cytoplasmic membrane and the intracytoplasmic membranes migrated into the inner cytoplasm for developing electron-transparent vesicles (Figure 8(A)); while those shed off the outer leaflet of cytoplasmic membrane contacted the cell wall, and thus served likely as transport conduits or transport vesicles to channel or transfer lipids and carotenoids from cytoplasmic membrane to cell wall (Figure 8(A)), because these compounds were synthesized on cytoplasmic membrane but deposited in outer membrane [38].

\section{3) Formation of cytoplasmic envelope}

As the intracytoplasmic membranes and peptidoglycan-like layer extended progressively (Figure $8(B)$ ) and closed up (Figure $8(C)$ ), the small electron-transparent vesicles elongated (Figure $8(\mathrm{~B})$ ) and dilated asymmetrically into swirling ones spiraling around the nucleoid (Figure $8(C)$ ). Thereafter, the outer cytoplasm vanished and thus the outer intracytoplasmic membrane and cytoplasmic membrane combined into a double-membraned cytoplasmic envelope (CE), which abutted the cell wall owing to the narrowing of extracytoplasmic space (Figure 8(D)). In parallel with these changes: 1) the heterogenous globular body and nucleoid disappeared, while electron-opaque particles (EOP) formed (Figure 8(D)); 2) the intracytoplasmic space widened, filling with electron-opaque materials (EOM) (Figure 8(D)); and 3) the old thick sheath scaled off, while a new fuzzy loosely compacted sheath external to the outer membrane formed, comprising of fibrillar materials (FM), microvesicles (MV) and electron-translucent vesicles (ELV).

\section{4) Formation of Primary Thylakoids}

As shown in Figure 9(A), the intraluminal ring-shaped vesicles swelled up 


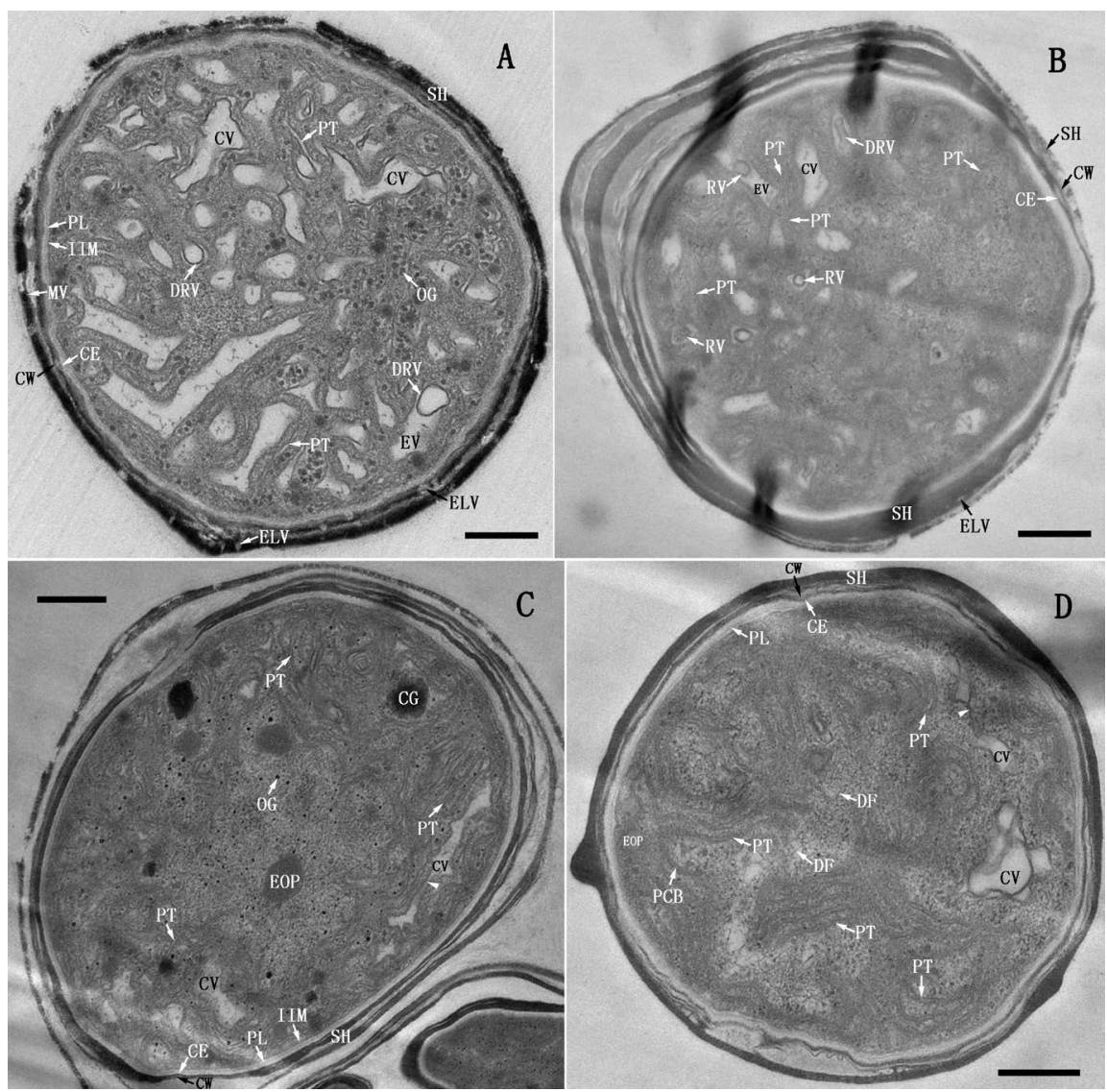

Figure 9. Formation of primary thylakoid (day 2 - 3). (A) Ring-shaped vesicles (RV) swelled up into dilated-ring-shaped vesicles (DRV), whose membranes met with the membranes of electron-transparent vesicles $(\mathrm{EV})$, and thus gave rise to unit-membrane-bounded combined vesicles (CV). Subsequently, CV coalesced into longer ones or flattened out into slender short primary thylakoids (PT). (B) The newly formed short PT distributed randomly in the inner cytoplasm (ICP), whose matrix turned opaque. Occasionally a cluster of small RV presented in a EV. (C) The short PT extended or merged end-to-end into long PT; while the long CV flattened out into PT by localized-constriction (arrowhead). Meanwhile, several cyanophycin granules (CG) were formed. (D) The extrinsic phycobilisomes (PCB) were assembled on PT. Scale bars $0.5 \mu \mathrm{m}$.

into dilated-ring-shaped vesicles (DRV), whose membranes ultimately met and combined with the electron-transparent vesicle membranes, giving rise to unitmembrane-bounded combined vesicles (CV); and then the combined vesicles coalesced into long ones or flattened out into short slender sacs, which were morphologically similar to cyanobacterial thylakoids, termed primary thylakoids (PT). In this way, the electron-transparent vesicles developed progressively into short primary thylakoids with opaque luminal matrix, distributing randomly in the inner cytoplasm (Figure 9(B)). After that, the short primary thylakoids extended or merged end-to-end into longer ones with concurrent formation of cyanophycin granules (CG) [39] and electron-opaque particles; while the long combined vesicle flattened out into primary thylakoids stepwise by localized-constriction (Figure 9(C)). Finally, extrinsic phycobilisomes (PCB) [40] were assembled on the 
irregularly-arranged primary thylakoids (Figure 9(D)). So as a result, the inner cytoplasm with primary thylakoids looked like the cyanobacterial cytoplasm, but contained no cyanobacterial inclusions.

\subsubsection{De-Compartmentalization, Disassembly of Primary Thylakoids, DNA Partition, Re-Compartmentalization and Formation of Secondary Thylakoids \\ 1) De-condensation and de-compartmentalization of inner cytoplasm, dis- assembly of primary thylakoids and DNA migration}

As shown in Figure 10(A), the inner cytoplasm de-condensed (solubilized) and became translucent with concomitant formation of less electron-dense materials (LDM), less electron-dense bodies (LDB) and cyanophycin granules; while the luminal matrix of primary thylakoids condensed, and so the membrane pair was in close apposition, seeming to be a single unit membrane with rough margin, between which short DNA fibers dispersed. In the meantime, the inner intracytoplasmic membrane disassembled into tiny vesicles (TV), such that the solubilized inner cytoplasm was de-compartmentalized and coalesced with the inner intracytoplasmic space; the less electron-dense materials diffused outward, blurring the compacted peptidoglycan-like layer, cytoplasmic envelope and cell wall (Figure 10(A)). Subsequently, the coalesced inner cytoplasm and inner intracytoplasmic space was separated into lower and upper portions by the less electron-dense materials: in the lower portion, the primary thylakoids broke up into double-layered membrane fragments (DMF, two unit membranes) with concurrent aggregation of DNA fibers; while in the upper portion, the double-layered membrane fragments began to curl and merge laterally into double-membraned vesicles (DMV) (Figure 10(B)). As such, all double-layered membrane fragments were assembled into double-membraned vesicles, which dispersed along with DNA fibers in the coalesced inner cytoplasm and inner intracytoplasmic space (Figure $10(C)$ ). Thereafter, the double-membraned vesicles moved outward quickly and attached to the peptidoglycan-like layer that was cover by electron-dense materials, while the tangled DNA fibers migrated slowly resulting in an "empty" inner space (EIS), at the border of which the recruited tiny vesicles began to fuse and elongate into double-layered membrane segments (DMS) (Figure 10(D)).

2) Re-compartmentalization, DNA partition and formation of secondary thylakoids

As the double-layered membrane segments extended into the double-membraned intracytoplasmic envelope (ICE), the coalesced inner cytoplasm and inner intracytoplasmic space was re-compartmentalized into a new inner cytoplasm (NIC) and a new inner intracytoplasmic space (NIS) (Figure 11(A)). The new inner cytoplasm was enclosed by the intracytoplasmic envelope; while the new inner intracytoplasmic space represented the space between the intracytoplasmic envelope and peptidoglycan-like layer. Most DNA fibers were allocated into the new inner intracytoplasmic space, which de-condensed into cloudlike materials (CLM) or aggregated into thick DNA threads (DT); by contrast only 


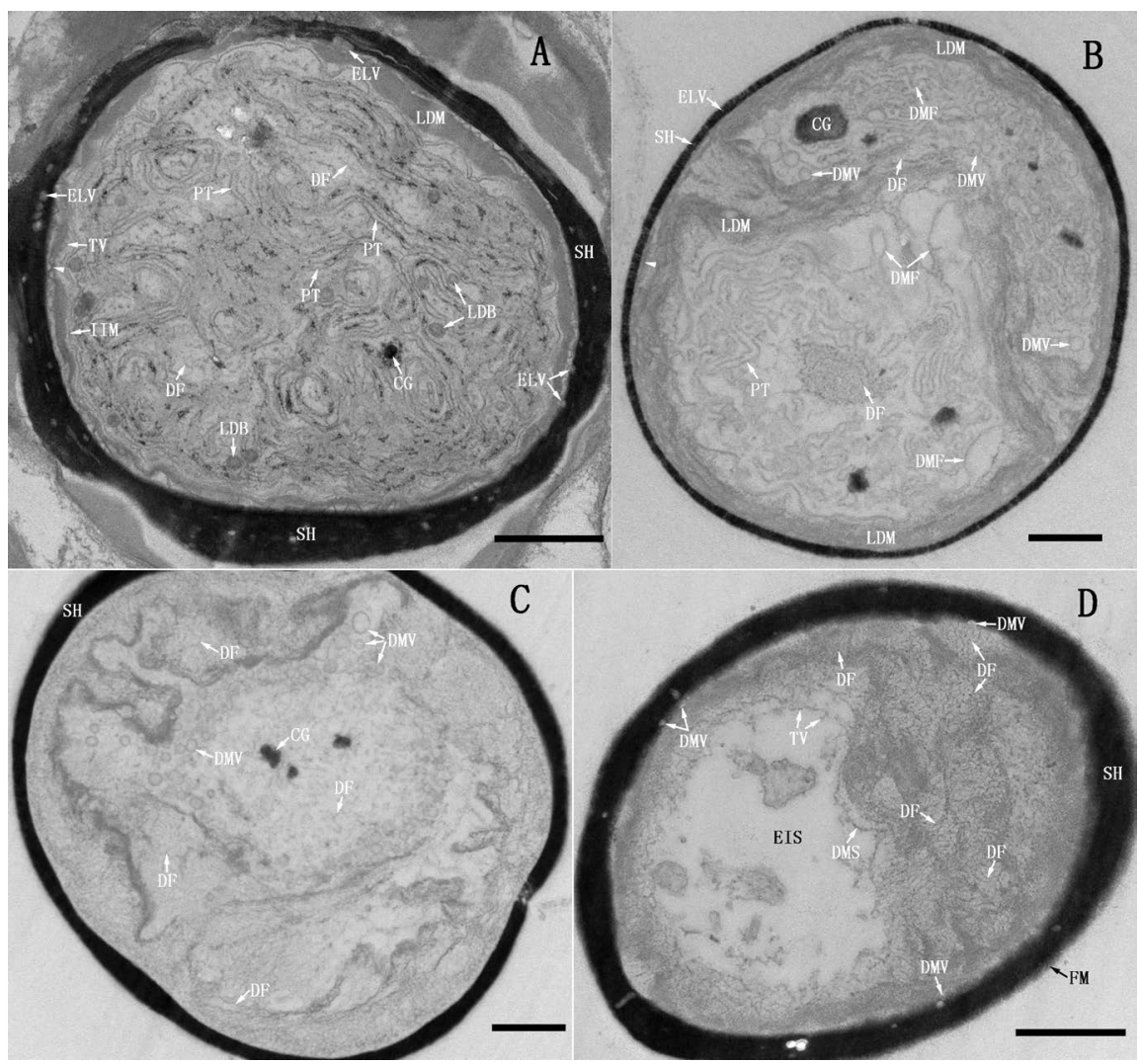

Figure 10. De-condensation and de-compartmentalization of inner cytoplasm, disassembly of primary thylakoids and DNA migration (day 4 - 5). (A) The inner cytoplasm (ICP) decondensed and became translucent, with concomitant production of less electron-dense materials (LDM), less electron-dense bodies (LDB) and cyanophycin granules (CG). The luminal matrix of primary thylakoids (PT) condensed and thus the membrane pair were in close apposition, between which short DNA fibers (DF) dispersed. The inner intracytoplasmic membrane (IIM) disassembled into tiny vesicles (TV), thus, the inner cytoplasm and inner intracytoplasmic space coalesced; LDM diffused outward blurring the compacted peptidoglycan-like layer (PL), cytoplasmic envelope (CE) and cell wall (CW) (arrowhead). (B) The primary thylakoids broke up into double-layered membrane fragments (DMF), which merged laterally into double-membraned vesicles (DMV); while DF aggregated into a cluster. (C) DMV and DF dispersed in the coalesced ICP and inner intracytoplasmic space. (D) DMV moved outward quickly and attached to PL that was cover by electron-dense materials, while the tangled DF migrated slowly resulting in an "empty" inner space (EIS), at the border of which the recruited TV began to fuse and elongate into double-layered membrane segments (DMS). Scale bars $0.5 \mu \mathrm{m}$.

few sporadic DNA fibers and electron-dense particles (EP) were partitioned into the new inner cytoplasm (Figure 11(A)). The intracytoplasmic envelope was not sealed, on the outer leaflet of which, some electron-transparent materials were synthesized, similar in appearance to the bacterial lipid [41]. Hereafter, accompanying the expansion of intracytoplasmic envelope, DNA fibers in the narrowing new inner intracytoplasmic space decondensed and likely attached to the thickened peptidoglycan-like layer (Figure 11(B)); while the double-membraned vesicles that were covered by less electron-dense materials detached from the 


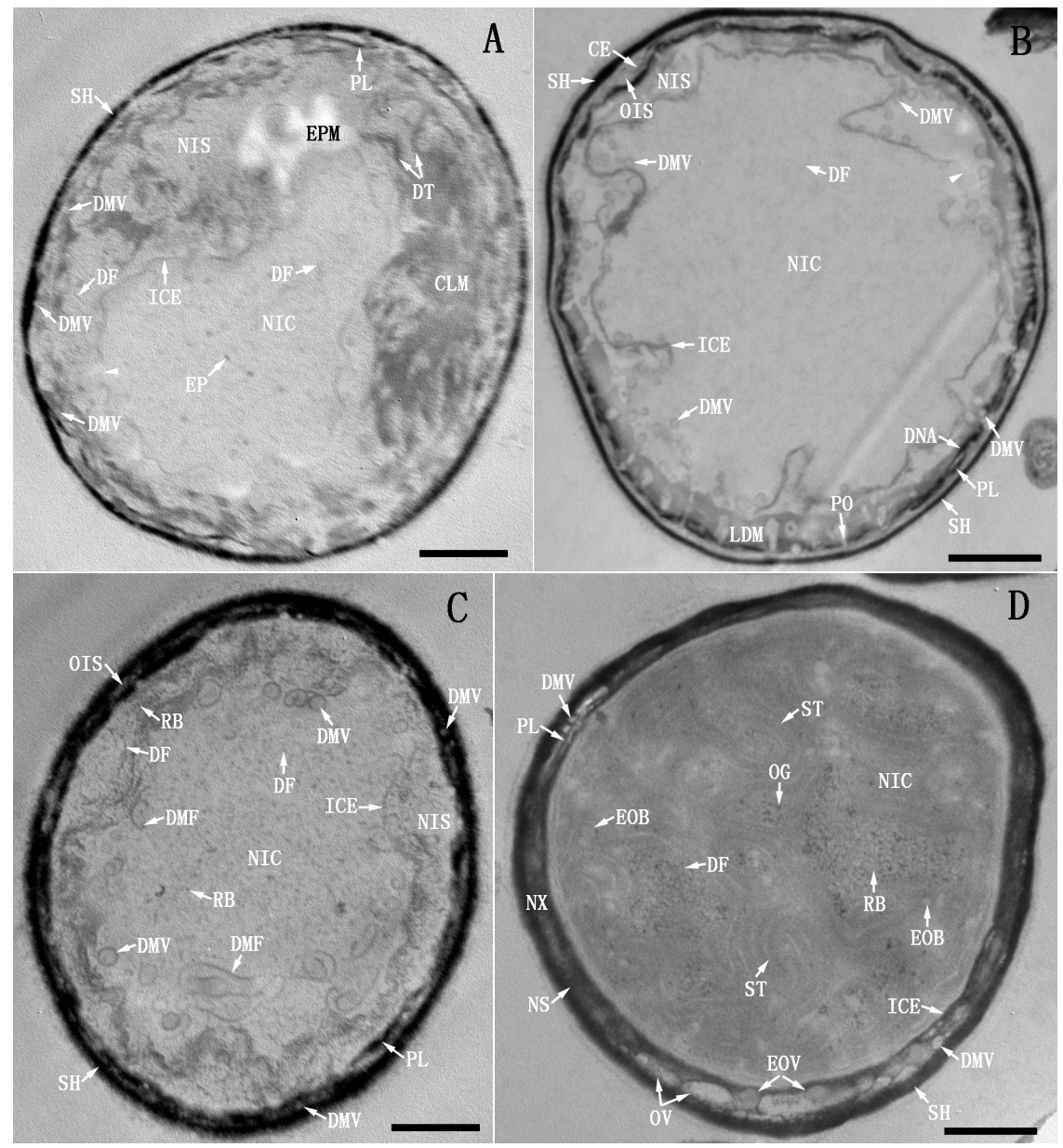

Figure 11. Re-compartmentalization, DNA partition and formation of secondary thylakoids (day 5 - 6). (A) The double-membraned intracytoplasmic envelope (ICE) re-compartmentalized the coalesced inner cytoplasm and inner intracytoplasmic space into a new inner cytoplasm (NIC) and a new inner intracytoplasmic space (NIS). Most of the DNA fibers (DF) were allocated into NIS, which decondensed into cloudlike materials (CLM) or aggregated into DNA threads (DT), while only few DF and electron-dense particles (EP) were partitioned into NIC. ICE had an opening (arrowhead), on the outer leaflet of which, some electron-transparent materials (EPM) were synthesized. (B) The doublemembraned vesicles (DMV) in NIS moved into NIC via ICE opening (arrowhead), or passed through the pores (PO) on the peptidoglycan-like layer (PL) into outer intracytoplasmic space (OIS). (C) ICE sealed, DNA in NIS condensed into a mass of DF with concomitant formation of countless ribosomes (RB); while an increased number of DF and RB were formed in NIC; DMV opened up into double-layered membrane fragments (DMF) and elongated. (D) DMF in NIC extended into secondary thylakoids (ST) with concomitant formation of osmiophilic granules (OG) and electron-opaque bodies (EOB) as well as enrichment of DF and RB. Outside of NIC, the major portion of PL was dismantled, such that NIS and OIS coalesced into a new intracytoplasmic space (NS), sequestering new intracytoplasmic matrix (NX), DMV, oblong vesicles (OV) and electron-opaque vesicles (EOV). Scale bars $0.5 \mu \mathrm{m}$.

peptidoglycan-like layer, moving inward via the opening of intracytoplasmic envelope into the new inner cytoplasm and outward through the pores on the peptidoglycan-like layer into the outer intracytoplasmic space (Figure 11(B)). 
Hence, the fenestrated peptidoglycan-like layer served not only as a mechanical and osmotic barrier, but also a platform for anchoring DNA and double-membraned vesicles. When the intracytoplasmic envelope closed up, DNA in the new inner intracytoplasmic space was assembled into thick DNA fibers resembling chromatin fibers [42] with concomitant formation of countless ribosomes (Figure 11(C)). Simultaneously, in the new inner cytoplasm an increased number of DNA fibers and many ribosomes were synthesized; the double-membraned vesicles dilated, opened up and became double-layered membrane fragments (Figure 11(C)). After that, the double-layered membrane fragments extended randomly into spiral thylakoids, which were devoid of phycobilisomes and morphologically different from the primary thylakoids, termed secondary thylakoids (ST) (Figure 11(D)). Concomitant with development of secondary thylakoids was the formation of osmiophilic granules and electron-opaque bodies as well as enrichment of DNA fibers and ribosomes in the expanded new inner cytoplasm (Figure 11(D)). The structures outside of the new inner cytoplasm were fuzzy owing to diffusion of electron-dense materials. The major portion of peptidoglycan-like layer was dismantled, and thus the new inner intracytoplasmic space and outer intracytoplasmic space coalesced into a new intracytoplasmic space (NS), sequestering the electron-opaque fluid, termed new intracytoplasmic matrix (NX). There were different vesicles in the new intracytoplasmic space, including double-membraned vesicles as well as newly formed electron-translucent oblong vesicles (OV) and electron-opaque vesicles (EOV) (Figure 11(D)).

The viability of TDX16 manifested the coordination and competence of the only two compartments in performing cellular functions. The new inner cytoplasm, like the cyanobacterial cytoplasm, performed photosynthesis and respiration on the secondary thylakoids, though it contained only a minor fraction of cellular DNA and no cyanobacterial inclusion except osmiophilic granules; while the new intracytoplasmic matrix retained the major fraction of cellular DNA and performed most if not all of other metabolic activities.

\subsubsection{Biogenesis of Primitive Chloroplast, Eukaryotic Cell Wall and Primitive Nucleus}

1) Biogenesis of primitive chloroplast and eukaryotic cell wall

As shown in Figure 12(A), the new inner cytoplasm became polarized, in which the newly formed secondary thylakoids underwent disassembly, leaving some remnants in the lower region; while parallel arrays of discrete slender sacs with transparent matrix were being developed in the upper region. These parallel-arranged slender sacs were morphologically similar to algal and plant thylakoids, termed primitive eukaryotic thylakoids (PMT), which appeared to develop from the plastoglobuli (similar in appearance to but smaller in size than osmiophilic granules) formed during disassembly of secondary thylakoids (Figure 12(A)), in a way similar to development of primary thylakoids from osmiophilic granules (Figure 9). Beneath the primitive eukaryotic thylakoids, a nascent pyrenoid (PD) with an incomplete starch plate (SP) and two starch granules (SG) were formed (Figure 12(A)), 


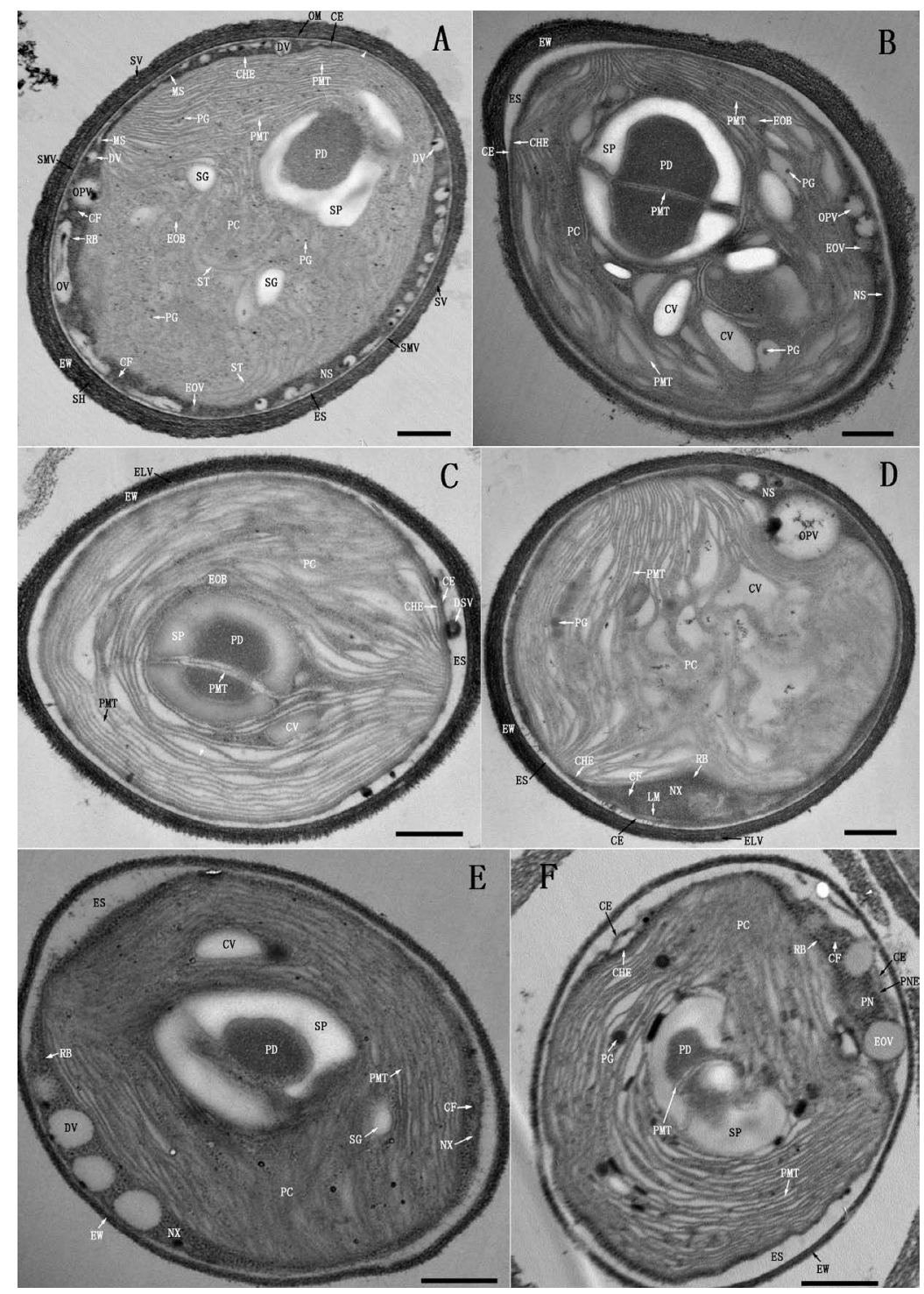

Figure 12. Biogenesis of primitive chloroplast, eukaryotic cell wall and primitive nucleus (day-7 - 9). (A) The secondary thylakoids (ST) were dismantled leaving some remnants and plastoglobuli (PG) in the lower region of new inner cytoplasm (NIC), while parallel arrays of primitive eukaryotic thylakoids (PMT) were being developed in the upper region of NIC with concomitant formation of a nascent pyrenoid (PD) surround by an incomplete starch plate (SP), and two starch granules (SG). So, NIC developed into the primitive chloroplast (PC), and the intracytoplasmic envelope became the chloroplast envelope (CHE). Inside the new intracytoplasmic space (NS), thick chromatin fibers (CF) and large ribosomes (RB) were formed; the peptidoglycan-like layer and the double-membraned vesicles disappeared; while many small dotted vesicles (DV) and opaque-periphery vesicle (OPV) emerged. Some DV began to fuse and flattened into membrane segments (MS). Outside of the new intracytoplasmic space (NS), some smaller vesicles (SMV) shed from the cytoplasmic envelope (CE) into the extracytoplasmic space (ES); the peptidoglycan layer (P) turned into an electron-dense layer (EL) (arrowhead), and a stratified SH embedded with small vesicles (SV) was formed external to the outer membrane (OM). Hence OM, EL and the sandwiched electron-transparent space constituted a trilaminar domain, which along with $\mathrm{SH}$ became the eukaryotic cell wall (EW). (B) PMT with wide luminal space were formed continuously by elongation of the combined vesicle (CV); PD was surrounded with a complete SP and bisected by two pairs of PMT; hence PC expanded and occupied most NS in the longitudinally sectioned plane; (C) PC filling with PMT occupied whole NS in longitudinally sectioned plane; CHE adhered to CE and a dense vesicle (DSV) shed off from CE into the widened ES. (D) The vertical section of a cell. The anterior portion of PC contacted CE; MS merged into the limiting membrane (LM) at the border of new intracytoplasmic matrix (NX) (E) The oblique section of a cell. The major fraction of NX converged at one side of PC. (F) The tangential section of a cell. The totally converged NX was encased by LM into the primitive nucleus (PN) containing CF, RB and electron-opaque vesicles (EOV); while LM became primitive nuclear envelope (PNE). NS vanished, and so CE shrank and wrapped PC and PN. Scale bars $0.5 \mu \mathrm{m}$. 
both of which were the characteristic bodies of green algal chloroplasts [43]. Accordingly, the new inner cytoplasm developed into a primitive chloroplast (PC) delimited by the double-membraned intracytoplasmic envelope. That was to say, the intracytoplasmic envelope became the double-membraned chloroplast envelope (CHE). The absence of mitochondrion implied that respiration took place on the primitive eukaryotic thylakoids. Thus, the primitive chloroplast was a dual-function composite organelle.

The new intracytoplasmic space became clear: the new intracytoplasmic matrix condensed, containing ribosomes and chromatin fibers (CF) [42] [44]; the peptidoglycan-like layer and double-membraned vesicles disappeared, while many small dotted vesicles (DV) blistered from the chloroplast envelope and lined up along the cytoplasmic envelope, some of which began to fuse and flatten out into membrane segments (MS) (Figure 12(A)). Such a scenario of membrane synthesis was akin to nuclear envelope assembly [45] [46]. In addition, a large coated-vesicle-like opaque-periphery vesicle (OPV) was being assembled at the primitive chloroplast envelope, which bridged the primitive chloroplast and cytoplasmic envelope probably for transferring substances.

The fuzzy electron-dense sheath external to the cell wall (Figure 11(D)) scaled off, while a stratified sheath embedded with many small vesicles (SV) formed, which adhered to the outer membrane and made the latter difficult to discern (Figure 12(A)); the peptidoglycan layer became denser and thicker indicating changes of its composition and thus was referred to as electron-dense layer (EL). In this case, the outer membrane along with the electron-dense layer and the sandwiched electron-transparent space still adopted its original configuration (Figure 8(A)), and thus constituted a trilaminar domain resembling the trilaminar sheath in the cell walls of green algae [47] [48] [49] [50] [51], which combined with the stratified sheath into a continuum similar in structure to the cell walls of green algae, termed eukaryotic cell wall (EW). Simultaneous with these changes, a large number of smaller vesicles (SMV) shed from the cytoplasmic envelope into the extracytoplasmic space, which perhaps delivered materials for or directly participated in the development of eukaryotic cell wall.

\section{2) Biogenesis of primitive nucleus}

As plastoglobuli developed progressively into combined vesicles and then flattened into primitive eukaryotic thylakoids with wide luminal space in the lower region of primitive chloroplast, the pyrenoid got matured, which was surrounded with a complete starch plate and bisected by two pairs of primitive eukaryotic thylakoids. Hence, the primitive chloroplast expanded substantially with corresponding shrinkage of the new intracytoplasmic space (Figure 12(B)). Subsequently, the primitive eukaryotic thylakoids coalesced and extended around the pyrenoid, the adjacent membranes of which were connected, seeming to be a single membrane (Figure 12(C)); the further expanded primitive chloroplast occupied whole new intracytoplasmic space in the longitudinally sectioned planes, and so the primitive chloroplast envelope fully adhered to the cytoplasmic envelope, from 
the latter of which a dense vesicle (DSV) shed off into the widened extracytoplasmic space (Figure 12(C)). Consistently, vertical profile (Figure 12(D)) showed that the anterior portion of new intracytoplasmic space disappeared owing to expansion of primitive chloroplast, as such the new intracytoplasmic matrix in the shrunken new intracytoplasmic space was concentrated by squeezing out liquid into the extracytoplasmic space, at the border of which the membrane segments coalesced into a limiting membrane (LM) (Figure 12(D)). As the expansion of primitive chloroplast continued, the stepwise-concentrated new intracytoplasmic matrix moved to (Figure 12(E)) and finally converged at one side of primitive chloroplast, which was ensheathed by the limiting membrane into a membrane-bounded organelle adhering to the primitive chloroplast (Figure 12(F)). This organelle sequestered the new intracytoplasmic matrix that retained the major fraction of cellular DNA and performed metabolic activities, and thus was also a composite organelle, termed primitive nucleus (PN). As such, the limiting membrane became the primitive nucleus envelope (PNE) that probably consisted of four unit membranes, because it was synthesized by fusion of the small dotted vesicles that were budded from the primitive chloroplast envelope (Figure 12(A)) and likely delimited by two unit membranes. Concurrent with the formation of primitive nucleus, the new intracytoplasmic space vanished, and thus the cytoplasmic envelope shrank and wrapped the only two primitive organelles, apparently to keep intercommunication via intimate membrane contacts in this vital transient state (Figure 12(F)).

\subsubsection{Formation of Eukaryotic Cytoplasmic Matrix and Biogenesis of Mitochondria}

1) Concurrent formation of eukaryotic cytoplasmic matrix and biogenesis of mitochondria

As shown in Figure 13(A), a vesicle-containing body (VB), apparently chipped off the invaginated primitive chloroplast, was being engulfed by the primitive nucleus with concomitant formation of a thin layer of electron-dense materials; and concurrently a small nascent mitochondrion $(\mathrm{M})$ was being assembled within the primitive chloroplast. The primitive nucleus envelope was contiguous with the cytoplasmic envelope at the outer side, but separated into two sets of doublemembraned envelopes inside the primitive chloroplast cavity, the inner and outer sets of which were referred to as nuclear envelope (NE) and outer nuclear envelope (OE) respectively. This result confirmed that the primitive nucleus envelope consisted of four unit membranes. The thin layer of electron-dense materials was a ribosome-containing fluid extruded from the primitive nucleus at the site where the nuclear envelope and outer nuclear envelope fused, which served as the medium connecting the primitive organelles and cytoplasmic envelope, and thus was the incipient eukaryotic cytoplasmic matrix (cytosol) (EM). After "digestion" of the vesicle-containing body, the primitive nucleus and eukaryotic cytoplasmic matrix both increased in sizes; while an oval mitochondrion with characteristic cristae (CR) emerged in the apical dome of the enlarged primitive chloroplast cavity (Figure 13(B)). The nuclear envelope and outer nuclear envelope were separated 


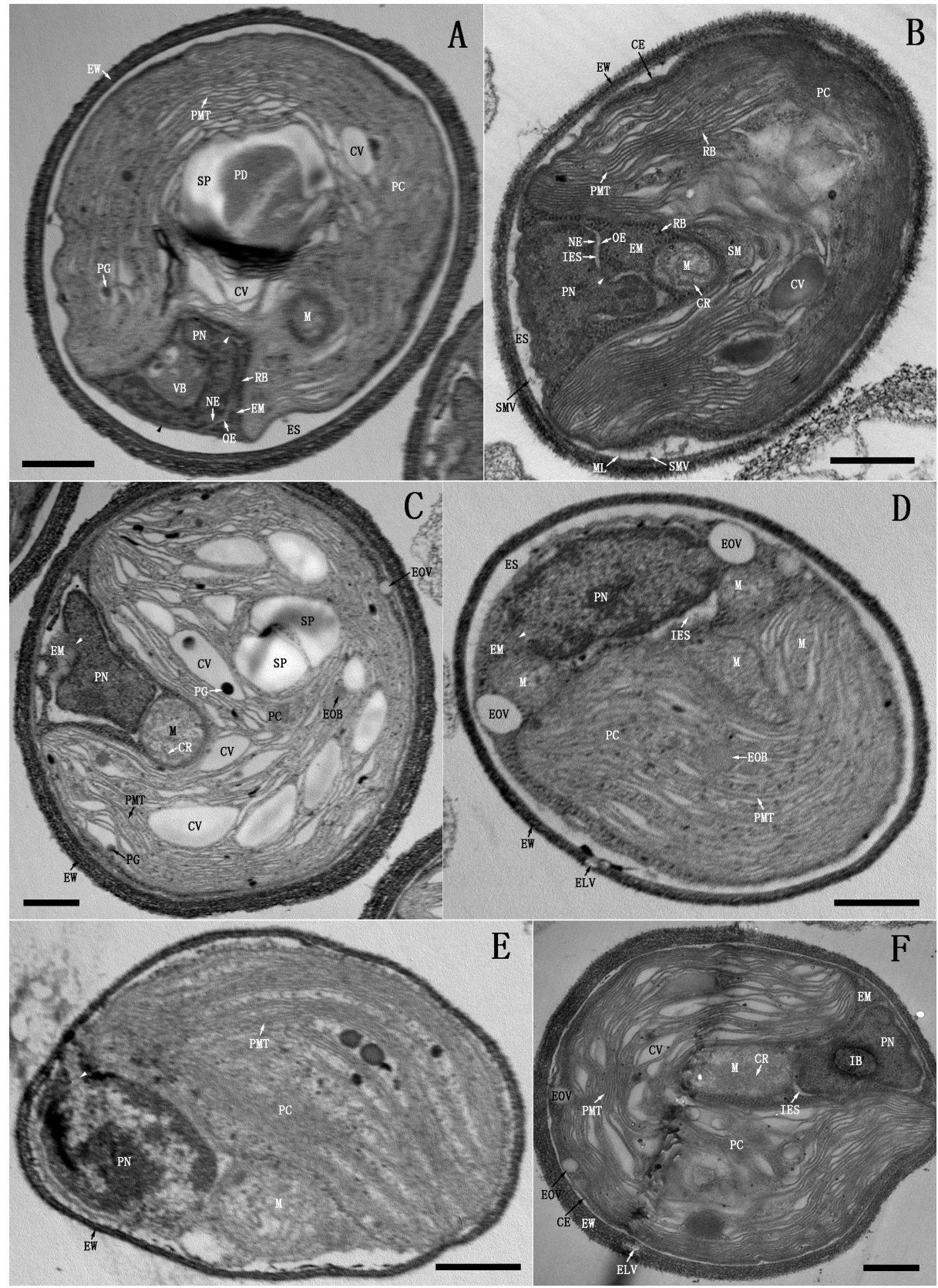

Figure 13. Concurrent formation of eukaryotic cytoplasmic matrix and biogenesis of mitochondria (day 8 - 9). (A) The primitive nucleus (PN) engulfed a vesicle-containing body (VB) and extruded nuclear matrix (white arrowhead) to build up the eukaryotic cytoplasmic matrix (EM); while a mitochondrion (M) was assembled in the primitive chloroplast (PC). The nuclear envelope (NE) and outer nuclear envelope (OE) were separated in PC cavity but contiguous with the cytoplasmic envelope (CE) at the outer side (black arrowhead). (B) PC with enriched stroma (SM) further invaginated, in the apical dome of its cavity, a mitochondrion with characteristic cristae (CR) emerged. OE and NE were separated by an inter envelope space (IES), but fused at one site into a large opening (arrowhead), from which the nuclear matrix was extruded. A number of smaller vesicles (SMV) and microfibrils (ML) budded and emanated respectively from CE into the extracytoplasmic space (ES). (C), (D) and (E) PN extruded nuclear matrix (arrowhead). (F) PN contained a membrane-delimited intranuclear body (IB). Scale bars $0.5 \mu \mathrm{m}$. 
by an interenvelope space (IES), but merged at one site resulting in a wide opening, from which the primitive nuclear matrix was extruded. Ribosomes in the eukaryotic cytoplasmic matrix were larger than those within the primitive chloroplast stroma $(\mathrm{SM})$, most of which were bound to the outer membranes of primitive organelles (Figure 13(B)). During this process, a number of smaller vesicles and microfibrils (ML) budded and emanated from the cytoplasmic envelope into the extracytoplasmic space, respectively (Figure 13(B)). Concurrent extrusion of primitive nuclear matrix and formation of mitochondrion in different cells took place in the same manner (Figures $9(C)-(E)$ ), and in one of which two spindle-shaped mitochondria were just being assembled within the primitive chloroplast (Figure 13(D)). Occasionally, an unusual membrane-delimited intranuclear body (IB) appeared in the primitive nucleus (Figure 13(F)), which seemed to be developed during engulfment and digestion of the vesicle-containing body or the like and play a role in selective extrusion of the primitive nuclear matrix to build up the eukaryotic cytoplasmic matrix.

2) Continuous biogenesis of mitochondria after formation of eukaryotic cytoplasmic matrix

After building up sufficient eukaryotic cytoplasmic matrix, bulk extrusion of primitive nuclear matrix ceased. So the primitive nucleus got matured into a nucleus $(\mathrm{N})$ and TDX16 developed into a premature eukaryote, because new mitochondria were continuously developed in the primitive chloroplast even after the formation of vacuole (V) with internal vesicle (IV), multilamellar body (MLB), lipid droplet (LD), and small opaque vesicle (SOV), leading to distortion of the primitive eukaryotic thylakoids and diminishment of the primitive chloroplast (Figure 14). As shown in Figure 14(A), a small mitochondrion was being developed in the periphery of a primitive chloroplast; and likewise a large twisting dumbbell-shaped mitochondrion was being assembled in the primitive chloroplast of another cell, one of its bulbous-end sequestering an internal body (ITB) was segregated, but another bulbous-end was under development (Figure 14(B)). Details of mitochondrion biogenesis were detected during assembly of the giant mitochondria. As shown in Figure 14(C), a giant "L-shaped" mitochondrion was in development and still continuous with the primitive chloroplast in the region around its corner point: the inner side envelope of its long arm and the corresponding portion of chloroplast envelope, as well as the interior cristae were nearly complete; while those of its short arm were just being synthesized. All these envelopes and mitochondrial cristae were synthesized by merging the small dense-margined vesicles (DGV) developed from the segmented primitive eukaryotic thylakoids (Figure $14(\mathrm{C})$ ). Similarly, in another cell a bulky mitochondrion was undergoing segregation, which was connected with the primitive chloroplast on the inner side but a small mitochondrion on the outer side (Figure 14(D)). In the inner and outer interfaces, three and two pairs of contorted membranes were being synthesized respectively by fusion of dense-margined vesicles: among the three pairs of membranes, the outer and middle ones were the segments 


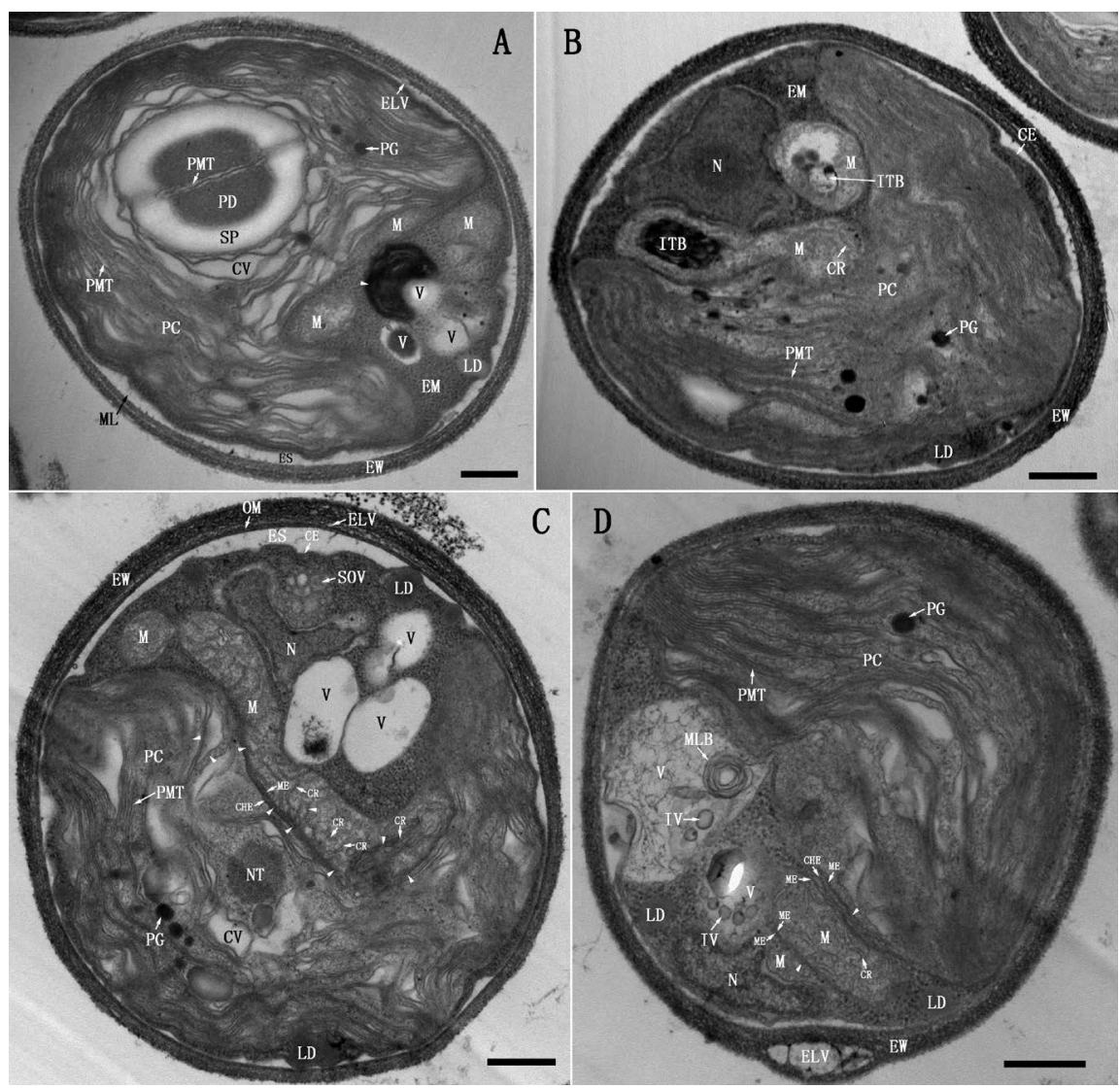

Figure 14. Biogenesis of mitochondria after building up eukaryotic cytoplasmic matrix (day 8 - 9). (A) A small mitochondrion was being developed in the primitive chloroplast (PC) in the presence of two mitochondria, three vacuoles (V), a lipid droplet (LD) and some electron-dense materials (arrowhead). (B) A twisting dumbbell-shaped mitochondrion was in development, one of its bulbous-end sequestering an internal body (ITB) was segregated, but the other end was contiguous with PC. (C) A giant "L-shaped" mitochondrion was being assembled in the presence of three vacuoles and a cluster of small opaque vesicles (SOV), which was continuous with PC in the region around its corner point. The inner side mitochondrial envelope (ME) and the corresponding portion of chloroplast envelope (CHE) as well as mitochondrial cristae (CR) were being synthesized by fusion of the dense-margined vesicles (DGV) (arrowhead) that were developed by segmentation of the primitive eukaryotic thylakoids (PMT). There was a large nucleoid-like structure (NT) in the venter side of PC. (D) After emergence of the large vacuole with internal vesicles (IV) and a multilamellar body (MLB), a bulky mitochondrion was being developed, which was connected with PC on the inner side but a small mitochondrion on the outer side. In the inner and outer interfaces, three and two pairs of contorted membranes were being synthesized respectively by merging DGV (arrowhead). In addition, several large electron-translucent vesicles (ELV) were embedded in the eukaryotic cell wall (EW). Scale bars $0.5 \mu \mathrm{m}$.

of mitochondria envelope and chloroplast envelope respectively, while the inner one was likely the envelope of the next mitochondrion that appeared to be in preparation; likewise the two pairs of membranes were the outer side and inner side mitochondria envelope of the bulky and small mitochondria respectively (Figure 14(D)). 
The above results indicated that mitochondria were assembled in the periphery of primitive chloroplast by encapsulating selected components with the membranes derived from the primitive eukaryotic thylakoids. As the assembly nearly finished, the chloroplast envelope opened up at the ventral side allowing mitochondria to detach by twisting, and then resealed by incorporating the membrane segment concurrently synthesized with the mitochondrial envelope. Since mitochondria were always assembled in the ventral side of primitive chloroplast where a large nucleoid-like structure situated (Figure 14(C)), it seemed likely that DNA was synthesized in the nucleoid-like structure and subsequently sorted into the mitochondria.

\subsubsection{Transition of Mitochondria into Vacuoles and Degradation of Primitive Eukaryotic Thylakoids-Derived Vesicles \\ 1) Transition of mitochondria into double-membraned vacuoles}

Following the emergence of new mitochondrion, the opaque matrix of previously formed mitochondria began to self-degrade into electron-transparent material (Figure 15(A)), such that, the mitochondria turned into double-membraned vacuoles $(V)$ with electron-transparent matrix, containing incompletely degraded internal body, vesicle and cristae (Figure 15(B)). Most of the residual inclusions were further degraded into electron-dense debris (ED) (Figure 15(C)) and released into the eukaryotic cytoplasmic matrix (Figure 15(D)); while some internal bodies themselves also contained small internal bodies, so after degradation of their contents, the residual membranes (Figure 15(D)) were collected into multilamellar bodies [52] (Figure 15(E) and Figure 15(F)). Accompanying the development of vacuoles, a new mitochondrion was assembled at the edge of primitive chloroplast (Figure 15(B)); a piece of chloroplast debris (CD) emerged in the eukaryotic cytoplasmic matrix (Figure 15(B)); and lipid droplets formed intensively on the inner membrane of cytoplasmic envelope and the outer membrane of primitive chloroplast envelope (Figures 15(B)-(F)).

2) Formation and degradation of primitive eukaryotic thylakoids-derived vesicles and coalescence of vacuoles

After vacuoles came into being, the short fragmented primitive eukaryotic thylakoids that were generated during assembly of mitochondria curled and "rolled up" into "vesicle within vesicle" like compound vesicles (CPV) (Figures 16(A)-(C)), which were internalized by vacuoles directly as they segregated from the primitive chloroplast (Figure $16(\mathrm{C})$ ), or after they shed into the eukaryotic cytoplasmic matrix (Figure 16(A) and Figure 16(B)). And then contents of the internalized compound vesicles were degraded, while the remaining membranes stacked up into multilamellar bodies within the vacuoles (Figures 16(D)-(F)), which began to fuse with each other by membrane protrusion. As shown in Figure 16(C) and Figure 16(D), a vacuole protruded into another one and fused at the contact sites, such that the membrane protrusion pinched off and became an internal vesicle (Figure 16(E)) or shed as membrane fragments (Figure 16(D) and Figure $16(\mathrm{~F})$ ). When the primitive chloroplast dwindled to a normal size, no more 


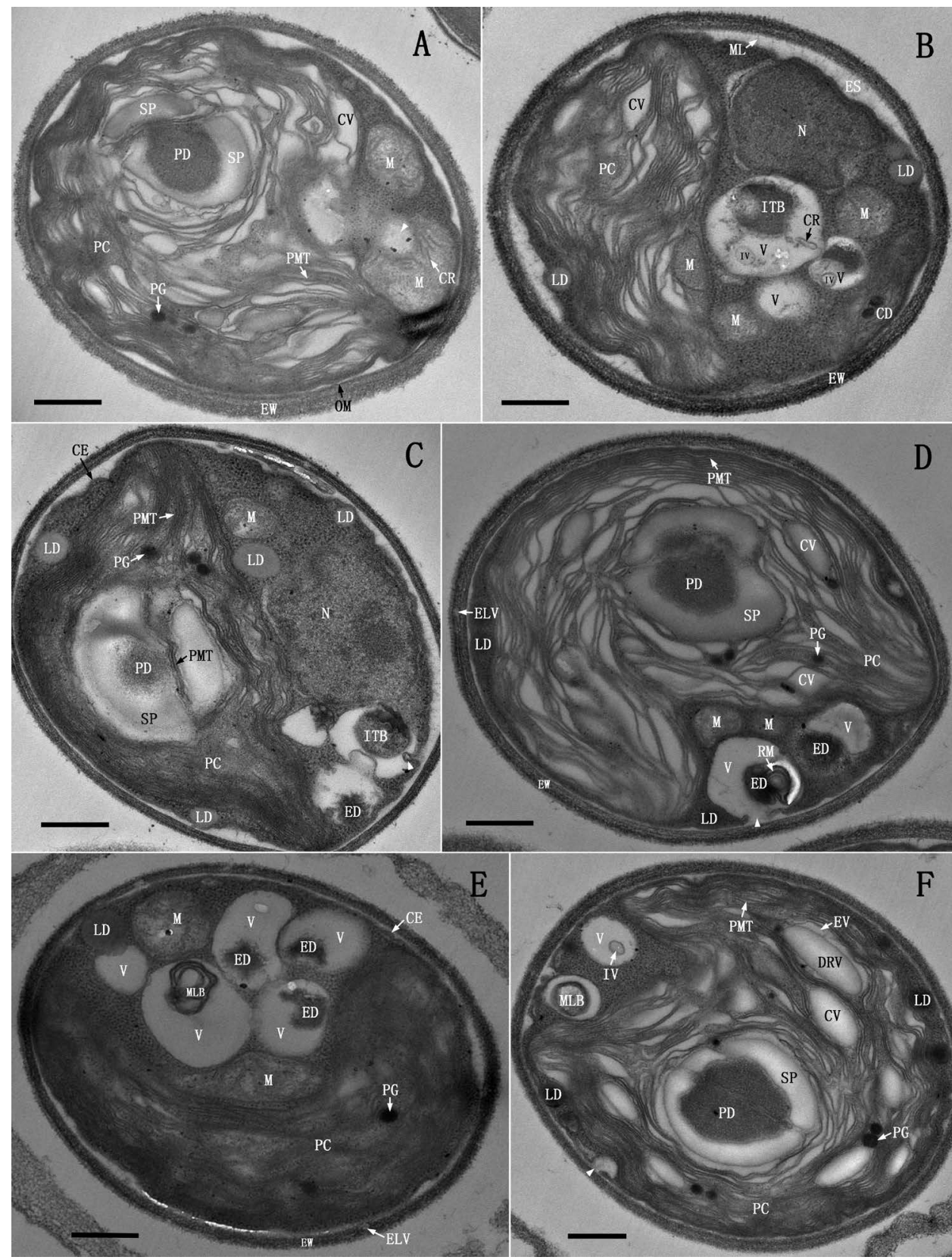

Figure 15. Transition of mitochondria into double-membraned vacuoles (day 8 - 9). (A) The matrix of a mitochondrion was being degraded (arrowhead). (B) After matrix degradation, the mitochondria turned into vacuoles (V) containing internal body (ITB), internal vesicle (IV) and remnant cristae (CR) or only electron-transparent matrix. Meanwhile, a new mitochondrion was developed in the primitive chloroplast (PC), two lipid droplets (LD) were formed at the inner leaflet of cytoplasmic envelope (CE) and a piece of chloroplast debris (CD) emerged in the eukaryotic cytoplasmic matrix (EM). (C) ITB in two small vacuoles degraded into electron-dense debris (ED); while ITB in the large vacuole remained intact, the vacuolar membranes fused with CE and invaginated (arrowhead). (D) A small vacuole expelled ED into EM; while a large vacuole sequestered some residual membranes (RM) and fused with $\mathrm{CE}$, resulting in an opening (arrowhead). (E) A large vacuole contained a multilamellar body (MLB). (F) Two vacuoles contained a MLB and an IV respectively. A small vacuole fused with CE, resulting in an opening (arrowhead); and several dilated ring-shaped vesicles (DRV) emerged in the electron-transparent vesicles (EV) in PC. Scale bars $0.5 \mu \mathrm{m}$. 


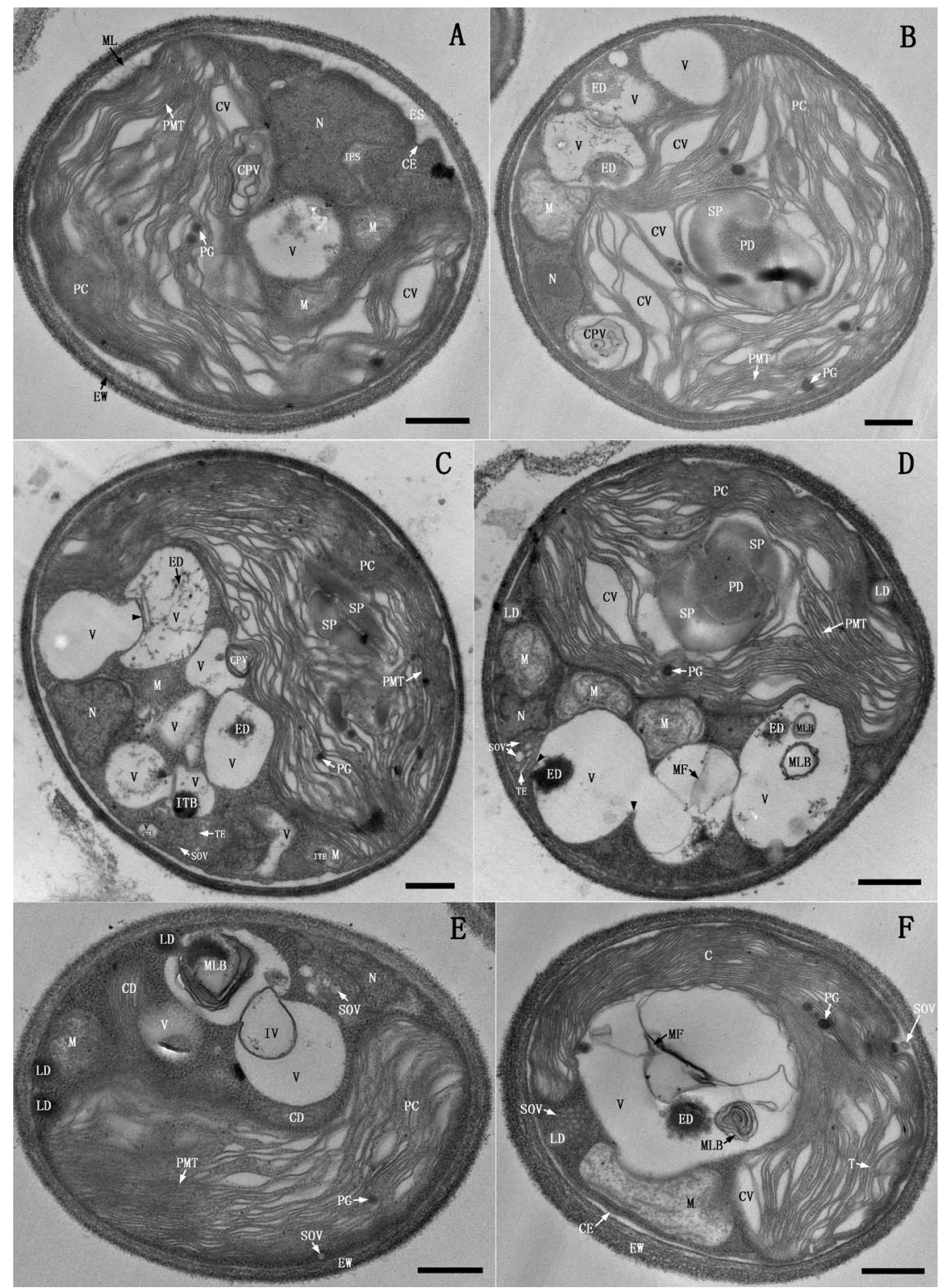

Figure 16. Formation and degradation of primitive eukaryotic thylakoids-derived vesicles and coalescence of vacuoles (day 8 - 9). (A) A collection of short primitive eukaryotic thylakoids (PMT) "rolled up" into "vesicle within vesicle" like compound vesicle (CPV) in the margin of primitive chloroplast (PC). (B) A CPV was segregating from PC into the eukaryotic cytoplasmic matrix (EM). (C) A CPV was detaching from PC into a vacuole; while a large vacuole protruded into another one (arrowhead). (D) Membranes of the protruded vacuole and the vacuole that contained membranous fragments (MF) fused at their contact site (arrowhead). (E) Two vacuoles were merging; while a conspicuous piece of chloroplast debris (CD) presented in EM. (F) PC matured into a chloroplast (C); all vacuoles coalesced into a single vacuole containing electron-dense debris (ED), MF and MLB. Scale bars $0.5 \mu \mathrm{m}$.

mitochondria and compound vesicles were produced and all vacuoles coalesced into a large one (Figure 16(F)). Accordingly, the primitive chloroplast got matured into a chloroplast $(\mathrm{C})$, and thus the primitive eukaryotic thylakoids became eukaryotic thylakoids (T). 


\subsubsection{Vacuole Mediated Unconventional Exocytosis and Endocytosis}

\section{1) Vacuole-mediated unconventional exocytosis}

Vacuoles came into contact with the cytoplasmic envelope, and then the contacted membranes fused or broke up into fragments resulting in openings, from which a small quantity (Figure 15(D), Figure 15(F) and Figure 17(A)) or a large amount of vacuolar contents and small opaque vesicles that seemed to be internalized from the neighboring vesicle clusters were expelled into the extracytoplasmic space (Figure 17(B)). Apparently, vacuole-mediated exocytosis was unconventional exocytosis [53] [54], as the exocytotic proteins were not sorted through Golgi apparatus.

\section{2) Vacuole-mediated unconventional endocytosis}

The vacuolar membranes merged with cytoplasmic envelope at two distant sites and then invaginated, resulting in a large invaginated space (IVS), entrapping some electron-dense fibrils (EF) and globular particles (GP); while cytoplasmic envelope between the two merged sites disrupted and coiled into membranous structures (Figure 17(C)). Upon the invaginated space reaching a certain size, the membrane invagination pinched off into the vacuole lumen and became a large internal vesicle (vacuole?), whose content was degraded in situ or discharged into the vacuole lumen (Figure 17(D)). In the same way, the nascent vacuoles also mediated small episodes of endocytosis (Figure 14(D) and Figure 15(C)). Evidently, vacuole-mediated endocytosis was unconventional endocytosis, as there was no other organelle involved.

\subsubsection{Transition of the Cyanobacterium TDX16 into a New Alga TDX16-DE}

After bulk exocytosis and endocytosis, the large vacuoles vanished and no other organelle was formed. Thus, the prokaryotic cyanobacterium TDX16 (Figure 6 and Figure 7) turned into a stable new eukaryotic alga TDX16-DE with unique structure (Figures 18(A)-(C)). TDX16-DE cell has an eukaryotic cell wall, an extracytoplasmic space and a double-membraned cytoplasmic envelope, contains a chloroplast, a nucleus with two set of envelopes, two mitochondria, and no or several double-membraned vacuoles, but lacks endoplasmic reticulum, Golgi apparatus and peroxisome.

The nucleus still retains ribosomes (Figures $18(\mathrm{~A})-(\mathrm{C})$ ), indicating its capability of protein synthesis. The nuclear envelope and outer nuclear envelope have no visible pores and usually connect with the cytoplasmic envelope at the opening of chloroplast cavity (Figure 18(A)). When they are separated, a number of electron-dense vesicles (EDV) bud form the nuclear envelope into the interenvelope space, which fuse with and re-bud from the outer nuclear envelope and ultimately migrate to the two sides of chloroplast envelope and cytoplasmic envelope (Figure 18(B)), probably transferring nucleus-synthesized proteins for membrane renewal. Meanwhile, several openings are formed on the outer nuclear envelope, one of which is at the site where it merges with the cytoplasmic envelope. Such that, the eukaryotic cytoplasmic matrix and extracytoplasmic space is connected 


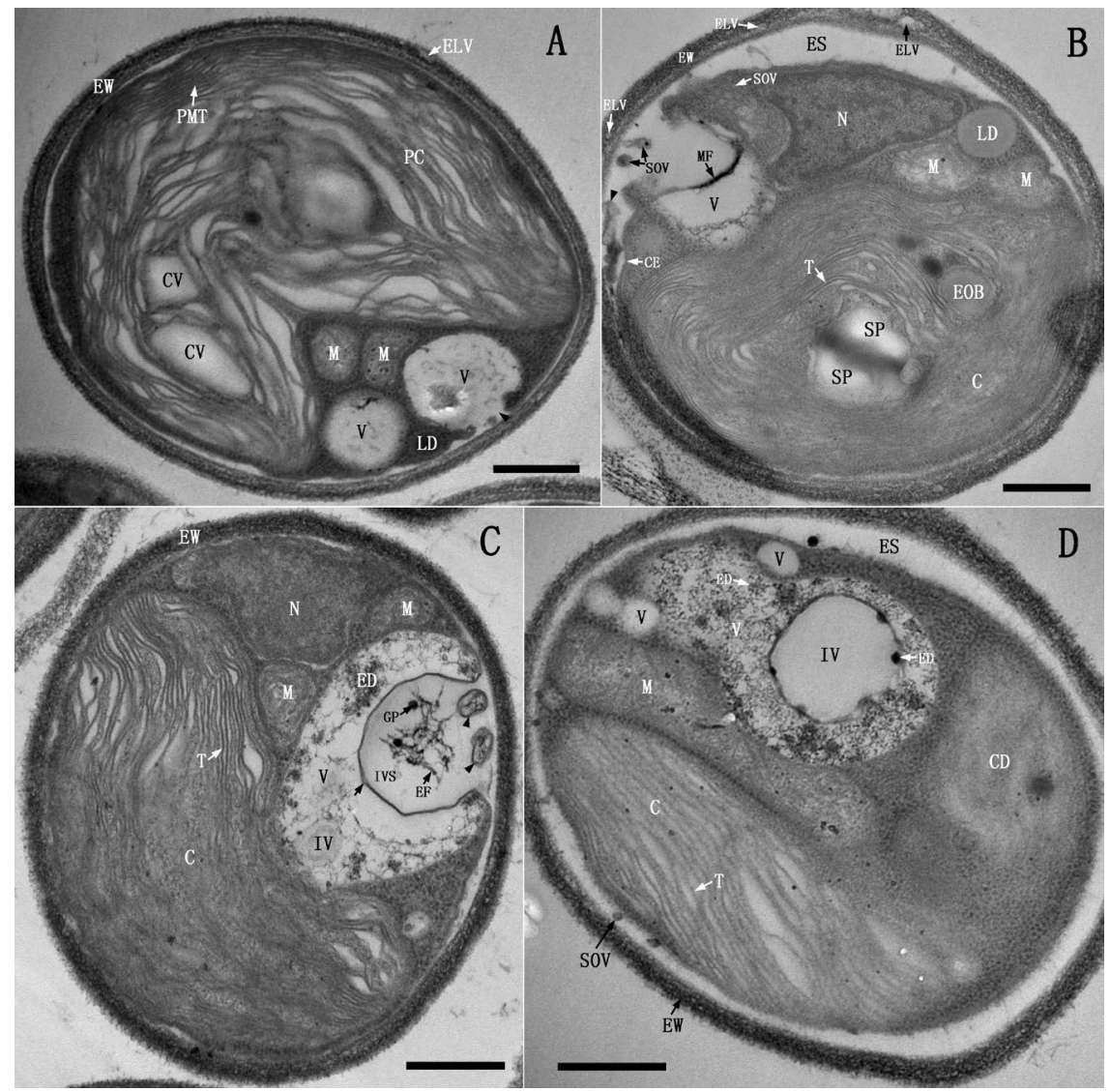

Figure 17. Vacuole mediated unconventional exocytosis and endocytosis (day 8 - 9). (A) An opening was formed at the contact site of the vacuolar membranes and cytoplasmic envelope (CE) (arrowhead), from which the vacuolar content was released. (B) The contacted vacuolar membranes and CE broke up into fragments (arrowhead), resulting in a wide opening, from which the soluble contents and small opaque vesicle (SOV) were expelled outside into the extracytoplasmic space (ES). (C) The vacuolar membranes merged with $\mathrm{CE}$ at two distant sites and then invaginated, resulting in a large invaginated space (IVS) entrapping some electron-dense fibrils (FB) and globular particles (GP); while CE between the two merged sites disrupted and coiled into membranous structures (arrowhead). It was clear that the vacuolar membranes consisted of two unit membranes (arrow). (D) A vacuole contained a large internal vesicle (IV). Scale bars $0.5 \mu \mathrm{m}$.

through the interenvelope space, enabling the exchange of metabolites between these two compartments (e.g., protein secretion) (Figure 18(B)). By contrast, when the outer nuclear envelope and nuclear envelope come into contact, they disrupt at several sites and result in openings, allowing nucleocytoplasmic transport (Figure 18(C)), and fuse with the cytoplasmic envelope at one site resulting in a fusion pore, enabling the direct communication between nucleus and extracytoplasmic space.

TDX16-DE multiplies via autosporulation. As shown in Figure 18(D), four autospores (TDX16-DE cells) within an autosporangium (AUG) are in different developmental stages and more or less similar in arrangement to TDX16 (endospores) in the sporangium (Figure 6). 


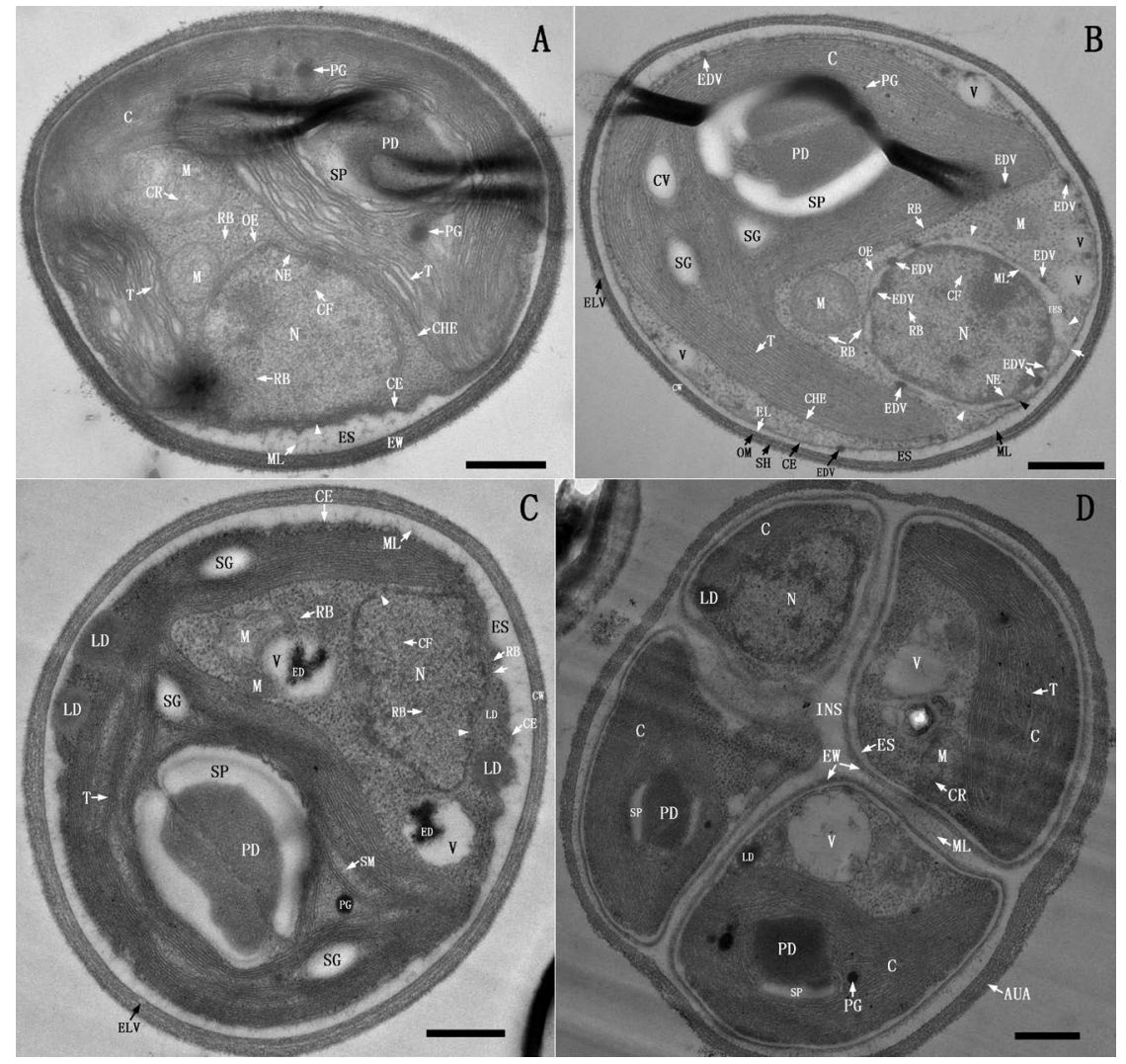

Figure 18. Structure and reproduction of TDX16-DE (day 9 - 10). (A), (B) and (C). Three TDX16-DE cells contain chloroplasts $(\mathrm{C})$, nuclei $(\mathrm{N})$ with chromatin fibers $(\mathrm{CF})$ and ribosomes (RB), mitochondria (M) and vacuoles (v) ((A) had no vacuole). (A) The nuclear envelope (NE) and outer nuclear envelope (OE) contact the cytoplasmic envelope (CE) at the opening of chloroplast cavity (arrowhead). (B) Electron-dense vesicles (EDV) bud form NE (black arrowhead) into inter envelope space (IES), and then fuse with and re-bud from OE, ultimately reach the two sides of chloroplast envelope (CHE) and CE. There are several openings on OE (white arrowhead), and one opening at the contact site of OE and CE (arrow). (C) OE and NE contact intimately, on which large openings (arrowhead) are formed, and also a fusion pore is developed at the contact site of NE, OE and CE (arrow). (D) Four autospores in an autosporangium (AUA) are segregated from each other by the wide interspace (INS). Scale bars $0.5 \mu \mathrm{m}$.

\subsection{Photosynthetic Pigments of TDX16 and TDX16-DE}

In vivo absorption spectra (Figure 19(A)) showed that apart from the absorption maxima of chlorophyll a (Chl a) at 440 and $680 \mathrm{~nm}$, TDX16 displayed a prominent peak at $630 \mathrm{~nm}$, corresponding to phycocyanin [55]; while TDX16-DE cell lacked phycocyanin peak but exhibited a conspicuous shoulder peak of chlorophyll b (Chl b) at $653 \mathrm{~nm}$ [56], and a merged peak of carotenoids around $485 \mathrm{~nm}$. Consistently, fluorescence emission spectroscopy indicated that the water soluble pigment extract of TDX16 (Figure 19(E)) and lipid soluble pigment extract of TDX16-DE (Figure 19(F)) displayed an emission peak of phycocyanin at $646 \mathrm{~nm}$ [57] and an emission peak of Chl b at $658 \mathrm{~nm}$ [58] respectively, but no emission peak was detected in the water soluble pigment extract of TDX16-DE (Figure 19(E)) and lipid soluble pigment extract of TDX16 (Figure 19(F)). The separated 


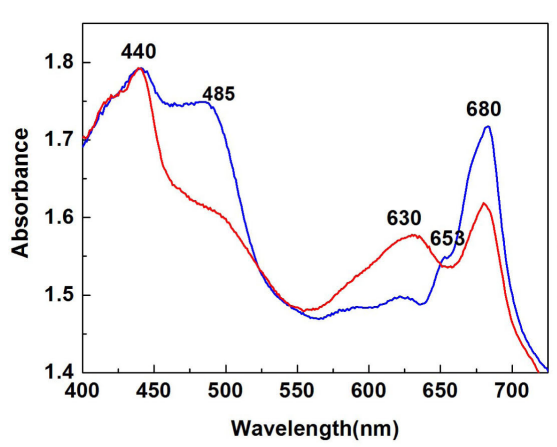

(A)

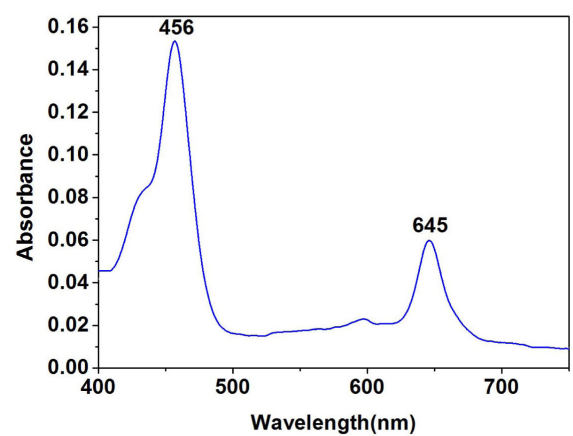

(C)

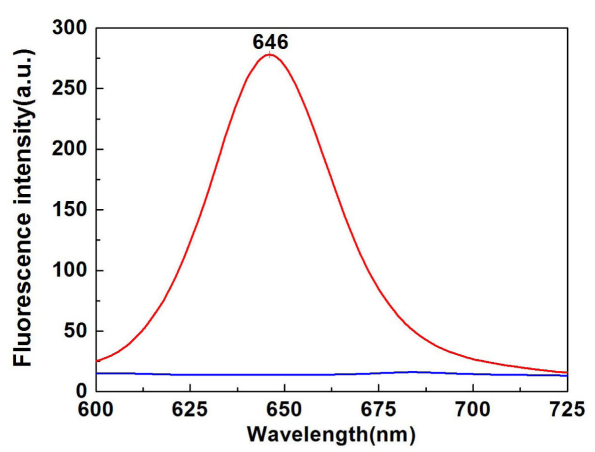

(E)

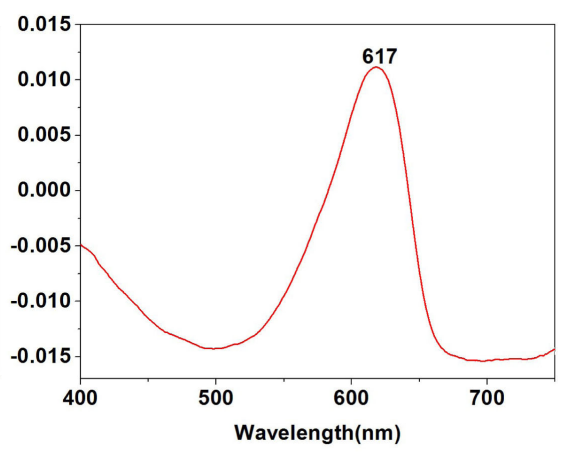

(B)

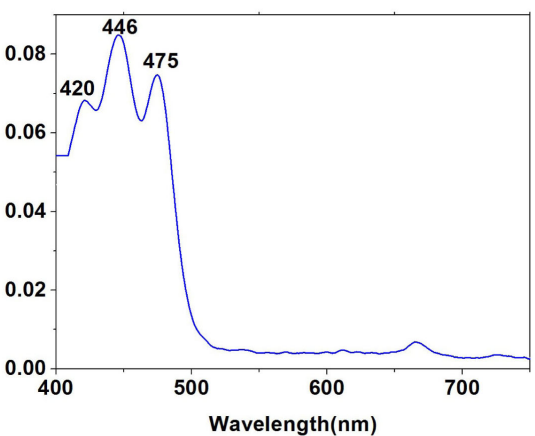

(D)

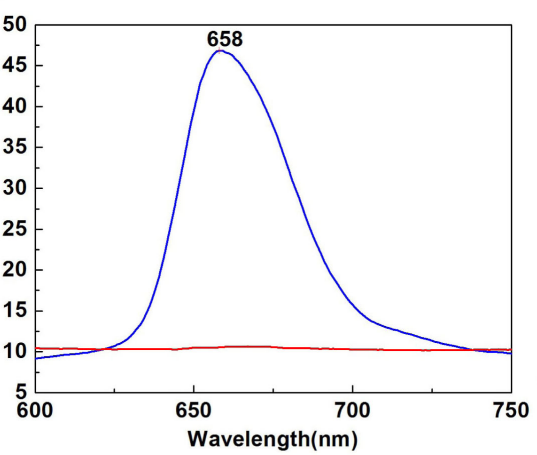

(F)

Figure 19. Absorption and fluorescence emission spectra. (A) In vivo absorption spectra of TDX16 (red) and TDX16-DE cell (blue). Absorption spectra of the isolated and purified phycocyanin (B), chlorophyll b (C) and lutein (D). Fluorescence emission spectra of water soluble pigment extracts (E) and lipid soluble pigment extracts (F) of TDX16 (red) and TDX16-DE cell (blue).

phycocyanin of TDX16 showed an absorption peak at 617nm (Figure 19(B)), nearly the same as that of C-phycocyanin [57]; the purified Chl b and lutein of TDX16-DE displayed absorption peaks at 456 and $645 \mathrm{~nm}$ (Figure 19(C)), 420, 446 and $475 \mathrm{~nm}$ (Figure 18(D)) respectively, identical to those of plant pigments [15]. These results demonstrate that TDX16 contains phycocyanin but no Chl b, while TDX16-DE has Chl b but no phycocyanin.

\subsection{S rRNAs of TDX16 and TDX16-DE Chloroplast}

16S rRNAs of TDX16 (GenBank KJ599678.2) and TDX16-DE chloroplast (Gen- 
Bank KJ612008.1) share a low identity of $83 \%$, but show the highest similarities of $98 \%$ and $99 \%$ to that of Chroococcidiopsis thermalis (GenBank NR102464.1) and those of the chloroplasts of Auxenochlorella protothecoides (GenBank AY553213.1) and Chlorella vulgaris (GenBank AB001684.1) respectively.

\subsection{TDX16 Genome}

TDX16 genome is $15,333,193$ bp in size with an average GC content of $55.2 \%$ containing 15,894 genes (CDS 15,756; RNA 138). This Whole Genome Shotgun project has been deposited at DDBJ/ENA/GenBank under the accession NDGV00000000. The version described in this paper is version NDGV01000000.

\section{Discussion}

\subsection{The Reason for Organelle Biogenesis in TDX16}

The formation of organelles in cyanobacterium TDX16 is the first case of organelle biogenesis in prokaryotes observed so far, which contradicts the assumption of only once organelle biogenesis in prokaryotes in ancient times and occurs in a complex manner completely different from the simple hypothetical ways (discussion is in the following section), and thus may be surprising, not easily understood, but easily suspected as an artifact of contamination. Whereas, the possibility of contamination by other microorganisms can be completely excluded in this study. Because: 1) TDX16 used in the experiments was prepared from the pure and axenic colony (Figure 4); 2) light microscopic observation confirmed the absence of other microorganisms in TDX16 cultures (Figure 5); and 3) the intermediate states and cell structures in the course of organelle biogenesis (Figures 5-17) are unprecedented and coherent, which cannot be generated by any other microorganisms; and more importantly the resultant TDX16-DE (Figure 18) is a new green alga [59], distinct from all the algae documented so far, including $A$. protothecoides and $C$. vulgaris though their 16S rRNAs (GenBank AY553213.1 and GenBank AB001684.1) show the highest similarity to that of TDX16-DE (GenBank KJ612008.1). Therefore, organelle biogenesis in TDX16 is an undoubted fact but not an artifact. In truth, organelle biogenesis in TDX16 is not affected by other microorganisms, because TDX16-to-TDX16-DE transition occurs unaffectedly in non-axenic cultures in our previous studies [12]. Such that, a key question arises as to why organelles form in TDX16?

The consistent results of cell color and morphology (Figure 2 and Figure 5(A)), structure (Figure 3 and Figure 6 and Figure 7), pigmentation (Figure 19) and 16S rRNA (GenBank KJ599678.2) indicate that TDX16 is a phycocyanin-containing cyanobacterium resembling $C$. thermalis [20]. However, the size, gene number and GC content of TDX16 genome (GenBank NDGV00000000) are 2.4, 2.8 and 1.2 times those of $C$. thermalis genome (6,315,792 bp, 5593 genes and 44.4\% GC, GenBank CP003597.1), respectively. These results demonstrated that TDX16 had obtained a huge number of eukaryotic genes that have higher GC contents than the prokaryotic ones. Because: 1) TDX16 multiplied in the senescent/necrotic $H$. 
pluvialis cell at the expense of host's degraded organelles and cytoplasmic matrix (Figure 3), and 2) $\mathrm{Chl} \mathrm{b}$ and lutein, the typical pigments of green algae, are absent in TDX16 but present in TDX16-DE (Figure 19), it is certain that TDX16 had acquired 9,017,401 bp DNAs with 10,301 genes from its dead green algal host H. pluvialis. Accordingly, organelle biogenesis in TDX16 resulted from hybridizing the acquired DNAs with its own ones and expressing the hybrid genome. Since this study focuses on the cellular mechanism of organelle biogenesis in TDX16, we are unable to elucidate the molecular mechanism in detail here, but infer the molecular process based on the changes of cellular structure:

1) When the bloated H. pluvialis cells underwent senescence/necrosis (Figure 2), the tiny dormant endosymbiotic cyanobacterium TDX16 was activated, which took up its host's DNAs and retained the acquired DNAs most likely in the unique replicable heterogenous globular body so as to keep from degradation (Figure 3). After the small TDX16 cells were liberated from the ruptured host cell (Figure 2), the heterogenous globular body with electron-dense DNA-like materials situated in the nucleoid and seemed to be a "micronuleus" (Figure 6).

2) Upon compartmentalization, the obtained DNAs were released gradually from the heterogenous globular body into the nucleoid (Figure 8), most of which kept inactive because the initially formed primary thylakoids were cyanobacterial ones (Figure 9) similar to those of $C$. thermalis [20] owing to expression of TDX16's own genes that were suppressed within the host cell and in the dim light.

3) During de-compartmentalization the total DNAs in the solubilized inner cytoplasm fragmented and intermingled (hybridized) (Figure 10), which was then partitioned into the new intracytoplasmic space (major fraction) and new inner cytoplasm (minor fraction) during re-compartmentalization (Figure 11), and subsequently gave rise to nuclear genome (Figure 12 and Figure 13) and primitive chloroplast genome (Figure 12) respectively. Hereafter, the primitive chloroplast genome partitioned into chloroplast genome and mitochondrial genome during assembly of mitochondria (Figures 13-15). The disappearance of phycocyanin (Figure 19) and TDX16 16S rRNA, but appearance of chlorophyll b, lutein (Figure 19) and new 16S rRNA of TDX16-DE chloroplast indicated that DNA hybridization resulted in the loss of prokaryotic genes, retention of eukaryotic genes and synthesis of new (hybrid) genes.

\subsection{Organelle Biogenesis in TDX16 Sheds Light on Eukaryotes}

Organelle biogenesis in the prokaryote TDX16 (Figures 6-17) resulted in its transition into an eukaryote TDX16-DE (Figure 18). That is to say, organelles in the eukaryote TDX16-DE were originally formed in the prokaryote TDX16 (the first place). So, the biogenesis of organelles in TDX16 provides the first example for improving our current understanding of the development, structure, function and association of organelles and other compartments in eukaryotes and the reasons behind them, which is unachievable by studying eukaryotes themselves only. 


\subsubsection{Formation of Different DNA-Containing Organelles All at Once}

With the initial compartmentalization (Figure 8) and subsequent de-and re-compartmentalization (Figure 10 and Figure 11), the whole cellular content of TDX16 was allocated into the only two compartments: the new intracytoplasmic space and the new inner cytoplasm (Figure 11), from which nucleus, chloroplast and mitochondrion were developed respectively (Figures 12-15). Therefore, different DNA-containing organelles in TDX-DE were formed all at once in a single development event with concurrent establishment of interorganellar metabolic link and communication as evidenced by the viability of TDX16-DE. So, the interorganellar signaling (control) in eukaryotes is a multilateral system, encompassing not only anterograde signaling (nucleus-to-chloroplast/mitochondrion) and retrograde signaling (chloroplast/mitochondrion-to-nucleus) [60] [61] [62], but also chloroplast-to-mitochondrion signaling [63] and mitochondrion-to-chloroplast signaling.

\subsubsection{The Number of Membranes Enclosing the DNA-Containing Organelles}

Chloroplast, nucleus and mitochondrion were all formed in TDX16 by encapsulating the relevant components with the membranes synthesized by fusion, flatten and extension of the small vesicles (Figures 10-14). Such that, the envelopes of these DNA-containing organelles in eukaryotes inevitably comprise two unit membranes if the vesicles are bounded by one unit membrane, but four unit membranes, such as the nuclear envelop of TDX16-DE (Figure 18) and the chloroplast envelopes of some algae [64] [65] [66], if the vesicles are bounded by two unit membranes.

\subsubsection{Uneven DNA Distribution and Promiscuous DNA Sequences among Organelles}

During de-and re-compartmentalization the total DNAs in TDX16 aggregated (hybridized) and were partitioned into the new intracytoplasmic space (major fraction) and the new inner cytoplasm (minor fraction) (Figure 10 and Figure 11). The former's matrix was then encapsulated into the nucleus (Figure 12), while the latter subsequently gave rise to chloroplast and mitochondrion (Figures 12-16). So, nucleus sequestered most of the cellular DNAs, while chloroplast and mitochondrion contained only a handful of DNAs. Accordingly, DNA partition during organelle biogenesis in prokaryotes is the cause for the uneven DNA distribution among organelles in eukaryotes, and likely also the cause for promiscuous DNA sequences (genes): chloroplast and mitochondrial genes in nucleus [67], nuclear and chloroplast genes in mitochondrion [68] [69] [70], and nuclear and mitochondrial genes in chloroplast [71] [72] [73] [74] [75], which are usually interpreted as the results of interorganellar, intracellular or horizontal (DNA/gene) sequence transfers.

\subsubsection{The Common Origin of Eukaryotic Cytoplasmic Matrix and Nuclear Matrix}

After formation of the only two transitional composite organelles, the eukaryotic 
cytoplasmic matrix was built up from the matrix extruded by the primitive nucleus (Figure 13), indicating that the eukaryotic cytoplasmic matrix is different and not developed from the cytoplasm of prokaryotes, but shares the common origin with the nuclear matrix (nucleoplasm). Therefore, it is not surprising that: 1) most of nucleus-encoded proteins are synthesized in the eukaryotic cytoplasmic matrix, 2) some nucleus-encoded proteins are synthesized locally in the nuclear matrix of TDX16-DE as indicated by the presence of ribosome (Figure 18) and the nuclei of other cells (nuclear translation) [76]-[81], and 3) during open mitosis, a) nucleus but not mitochondrion or chloroplast disassembles, b) nuclear matrix and eukaryotic cytoplasmic matrix coalesce into one compartment (the reverse process of their formation), and c) daughter nuclei form by de novo assembly of nuclear envelop (in this regard, daughter nuclei form de novo). Accordingly, the eukaryotic cytoplasmic matrix and nuclear matrix is in essence a dynamic entity, and thus we define them as the nucleocytoplasmic matrix.

\subsubsection{Development of Mitochondria in the Primitive Chloroplasts}

Mitochondria were assembled in and segregated from the primitive chloroplast in TDX16 (Figures 13-15), demonstrating that mitochondria and chloroplasts developed from the same intermediate organelle, which is the reason why: 1) chloroplast and mitochondrial genomes share similar features [82], and have widespread homologies or the same DNA sequences [83] [84] and even a high degree of sequence identity of $85 \%$ [85], 2) mitochondria contain specific chloroplast proteins [86], and 3) chloroplasts possess respiratory electron transfer chains for chlororespiration [87] [88].

The presence of mitochondria in chloroplasts [89]-[94] and detachment of mitochondria or mitochondrion-like bodies from chloroplasts [95] [96] [97] have been observed frequently in plant cells. However, these phenomena have largely been overlooked and whether the chloroplast-localized mitochondria were developed in or engulfed by the chloroplast remains controversial. In light of the assembly of mitochondria in the primitive chloroplast of TDX16, it is likely that the impaired mitochondria entered the chloroplast and dismantled, allowing the mixture of mitochondrial matrix and chloroplast stroma (the reverse process of their formation). Such that the chloroplast became a primitive-chloroplast-like composite organelle, in and from which new mitochondria were assembled and segregated. Thus, assembly of mitochondria in chloroplast in eukaryotic cells is, in principle, similar to development of daughter nuclei in nucleocytoplasmic matrix during open mitosis, which occurs in the plant cells that probably contain only impaired mitochondria under stress conditions.

\subsubsection{Transition of Mitochondria into Double-Membraned Vacuoles}

Mitochondria in TDX16 turned into double-membraned vacuoles after matrix degradation (Figure 15). Currently, mitochondrion in plant cells is thought to be degraded only by autophagy (mitophagy), which is selectively enclosed by the phagophore (isolation membrane) into a double-membraned autophagosome, and then delivered into the single-membraned vacuole for degradation [98]. 
This way of mitochondrion degradation is, however, unachievable in TDX16, because: 1) autophagosome cannot be formed owing to the lack of endoplasmic reticulum, which is proposed to be the membrane source for phagophore synthesis in plant cells [99], and 2) there is no vacuole, which is also developed from scratch.

The cellular mechanism of vacuole biogenesis in plant cell is unclear, while the vacuolar membrane is presumably sourced from Golgi apparatus [100] or endoplasmic reticulum [9], both of which are devoid in TDX16 and TDX16-DE. So, mitochondrion-to-vacuole transition in TDX16 is an alternative way of mitochondrion degradation and vacuole formation, while the hydrolytic enzymes were probably stored in and released from mitochondria' internal bodies (Figure 14 and Figure 15). Since double-membraned vacuoles also present in plant cells [101] [102], it is certain that transition of mitochondria or other organelles (e.g., autophagosomes) into double-membraned vacuoles occur in plant cells under specific conditions.

Different from the single-membraned vacuoles in plant cells, the double-membraned vacuoles in TDX16-DE serve both as a degradative and as a secretory compartment, similar in function to the secretory lysosomes in animal cells [5] [6]. Since mitochondria-produced vesicles contribute to the generation of peroxisomes [4], it is possible that the mitochondria-derived double-membraned vacuoles in TDX16-DE also play the roles of peroxisomes.

\subsubsection{Formation of Different Thylakoids}

Thylakoids are photosynthetic apparatus and vital for cell maintenance and organelle development. So, concomitant with compartmentalization, de-and re-compartmentalization were the assembly/disassembly of primary and secondary thylakoids in the transitional compartments and finally development of primitive eukaryotic thylakoids in the primitive chloroplast (Figures 8-12).

1) The primary thylakoids developed from the electron-transparent vesicles formed by "germination" of osmiophilic granules (Figure 8 and Figure 9). Thus: a) osmiophilic granules are the precursors (seeds) of thylakoids in cyanobacteria, which is why there is no osmiophilic granule in the thylakoid-less cyanobacterium $G$. violaceus [36]; b) osmiophilic granules consist of two rather than one half unit membrane; and c) the confusing interthylakoidal vesicles of cyanobacteria [103] [104] [105] are premature thylakoids developed from osmiophilic granules.

2) The secondary thylakoids developed from the primary thylakoid-derived vesicles (Figure 11), in a manner similar to re-development of thylakoids from the former thylakoid-derived vesicles or segments in the stress-experienced cyanobacterial cells and germinated akinetes [23] [106]. Nevertheless, the absence of phycobilisomes in secondary thylakoids suggested that the primary thylakoid-derived vesicles were modified in composition.

3) The primitive eukaryotic thylakoids developed from the plastoglobuli produced during disassembly of secondary thylakoids in the same way as the development of primary thylakoids from the osmiophilic granules (Figure 12). There- 
fore: 1) plastoglobuli are identical to osmiophilic granules in structure but different in composition, and 2) plastoglobuli are the precursors of chloroplast thylakoids, which is why their number increases during thylakoid breakdown but decreases during thylakoid development [31] [107].

\subsubsection{The Double-Membraned Cytoplasmic Envelope of TDX16-DE}

TDX16-DE's double-membraned cytoplasmic envelope was formed in TDX16 by combination of the outer intracytoplasmic membrane with the cytoplasmic membrane after degradation of the outer cytoplasm (Figure 8), the two membranes of which were closely appressed in most cases and thus difficult to distinguish without being aware of the developmental process.

As a matter of fact, double membraned cytoplasmic envelopes seem also present in other unicellular algae, particularly picoalgae (cell size less than $3 \mu \mathrm{m}$ ), which are ignored or thought to be the two layers of a unit membrane. For examples, Nanochlorum eucaryotum, Nannochloris coccoides [108], Chlorella fusca [48] and Chloroparva pannonica [109] apparently have double-membraned cytopalsmic envelops akin to that of TDX16-DE, while Pseudochloris wilhelmii [110], Nannochloropsis oceanic [111], and Chlorella sp [112] [113] [114] also seem to be the case. Picoalgae are very simple in structure, containing a minimal set of organelles. For examples, the picoalgae [115]-[123] all lack endoplasmic reticulum, most of which also lack Golgi apparatus [115] [116] [117] [120] [121], and few of which lack endoplasmic reticulum, Golgi apparatus and peroxisome [122] [123] and even vacuole [123]. These results suggest that endoplasmic reticulum, Golgi apparatus and peroxisome are not essential and their functions can be performed in other compartments, similar to performance of mitochondrial function in cytoplasmic matrix of the mitochondrion-less eukaryote Monocercomonoides $s p$ [124].

TDX16-DE is very small $(2.9-3.6 \mu \mathrm{m})$ and bears strong resemblances to picoalgae in cell morphology, structure, organelle number and arrangement, though $16 \mathrm{~S}$ rRNA sequence of its chloroplast shows the highest similarity to those of the chloroplasts of $A$. protothecoides and $C$. vulgaris. In TDX16-DE cells, the attachment of ribosomes to and assembly of lipid droplets on the inner membrane of cytoplasmic envelop (Figures 14-18) indicate that the cytoplasmic envelop serves the functions of endoplasmic reticulum for synthesizing proteins and lipids. And the proteins synthesized on the inner membrane can be used locally for remodeling the cytoplasmic envelop without sorting and secreted into the extracytoplasmic space directly with no need for vesicular transport, and thus the cytoplasmic envelop serves the functions of Golgi apparatus as well.

\subsubsection{The Outer Membrane in the Eukaryotic Cell Wall of TDX16-DE}

The eukaryotic cell wall of TDX16-DE (Figures 12-18) was developed on the base of TDX16's prokaryotic cell wall (Figure 8) by forming sheath over the outer membrane and modifying the peptidoglycan layer into the electron-dense layer (Figures 8(D)-12(A)), and so, the outer membrane remains in the eukaryotic cell 
wall of TDX16-DE. Since the sheath scaled off and re-formed continuously until formation of the stratified one, the outer membrane where enzymes anchored was remodeled to accommodate the above changes, which along with the electron-dense layer and the sandwiched electron-transparent space constituted a trilaminar domain resembling the trilaminar sheaths [47] [48] [49] [50] [51] [112] in algal and plant cell walls. The trilaminar domain and the trilaminar sheaths are equivalent structures, because like cyanobacterial cell walls, algal and plant cell walls also contain lipids [49] [125] [126] [127] [128], enzymes [49] [50] [129] [130] [131] [132] and carotenoids [133] [134]. Accordingly, the out layers of trilaminar sheaths in algal and plant cell walls are membranes, which serve as platforms for anchoring enzymes to assemble the primary and secondary cell walls (corresponding to the sheath and the extended part of electron-dense layer in the eukaryotic cell wall of TDX-DE, respectively) and barriers for constraining lateral diffusion of cytoplasmic membrane proteins [135]; while the intermediate layers are aqueous spaces and the inner layers are porous mechanical structures.

\subsubsection{The Extracytoplasmic Space Is a Membrane-Surrounded Compartment}

TDX16 had an extracytoplasmic space between the cytoplasmic membrane and the outer membrane (Figure 8(A)), equivalent to the periplasmic space of other prokaryotic cells [33] [136]. The extracytoplasmic space remains in TDX16-DE (Figure 18), which is surrounded by the cytoplasmic envelope and the outer membrane within the eukaryotic cell wall, and thus a genuine membrane-surrounded compartment. During biogenesis of the primitive nucleus the liquid of new intracytoplasmic matrix was squeezed out into the extracytoplasmic space (Figure 12), and later vacuoles expelled their contents into and internalized substances from it (Figure 17). So, the extracytoplasmic space plays indispensable roles and metabolically links to the eukaryotic cell wall, cytoplasmic envelope, eukaryotic cytoplasmic matrix, nucleus and vacuoles.

Likewise, the extracytoplasmic spaces (interspaces) between the cytoplasmic membrane and the trilaminar-sheath-containing cell wall in algal cells [47] [48] [50] are also membrane-surrounded compartments, rather than the extracellular spaces (apoplasts) [137] as usually considered.

\subsubsection{Generation of Different Small Bodies from the Primitive Chloroplast}

The oversized primitive chloroplast in TDX16 was the source of energy and materials for organelle development and cell maintenance, from which different small bodies generated during it dwindled into a large chloroplast.

1) The vesicle-containing body was firstly developed from the primitive chloroplast and engulfed by the primitive nucleus (Figure 13(A)), which delivered materials for primitive nucleus maturation and formation of eukaryotic cytoplasmic matrix. The absence of visible enclosing-membrane and rectangular-shape of the vesicle-containing body suggested that it was formed most likely by incision, but not by budding or protrusion. 
2) The chloroplast debris with fragmented primitive thylakoids (Figure 15(B), Figure 16(E) and Figure 17(D)) was irregular in shape and devoid of enclosing-membrane, and thus seemed to be chipped off the primitive chloroplast during assembly of mitochondria and degraded by vacuoles as they formed concurrently with or after the development of vacuoles, or directly in the eukaryotic cytoplasmic matrix.

3) The compound vesicles detached from the primitive chloroplast in a way similar to that of mitochondria and transferred principally the segmented primitive eukaryotic thylakoids into vacuoles for degradation and formation of multilamellar bodies (Figure 16).

These small bodies played roles in primitive chloroplast maturation, the mechanisms by which they formed apparently differed from those for developing the small bodies during the piecemeal-degradation of chloroplast, including $\mathrm{Ru}$ bisco-containing body [138], ATI1-PS body [139] and SSGL body [140], as well as senescence-associated vacuole [141] and CV-containing vesicle [142]. Hence, generating different small bodies through different mechanisms is a strategy for both chloroplast development and chloroplast degradation.

\subsection{Implications of Organelle Biogenesis in TDX16}

The formation of organelles in cyanobacterium TDX16 demonstrates that organelle biogenesis in prokaryotes occurs not only once in ancient times but continues at the present time- "evolution in action" [143]. Hence, it is reasonable that organelles can also form de novo in bacteria, the close relatives of cyanobacteria, in the similar situations. In light of organelle biogenesis in TDX16, we postulate that organelles (no chloroplast) form in the eukaryotic-DNA-acquired bacteria by enclosing the cytoplasm into one versatile organelle-the primitive nucleus, from which mitochondria and eukaryotic cytoplasmic matrix develop. This postulation is supported by the facts that in heterotrophic eukaryotes: 1) mitochondria present in the nucleus [144]-[149], 2) nuclear genomes contain intact mitochondrial DNA copies [150] [151] [152], and 3) most mitochondrial proteins are descendants of nuclear genes with no bacterial antecedents [153] [154] [155], and present in the nucleus [156]. Therefore, organelle biogenesis in TDX16 has broad implications on biology, particularly cancer biology and evolutionary biology.

\subsubsection{Implications on Cancer Biology}

The origin of cancer cells is the most fundamental yet unresolved problem in cancer biology. Cancer cells are thought to be transformed from normal cells, however, recent studies reveal that the small nascent primary cancer cells (PCCs) for cancer initiation [157] [158] [159] [160] [161] and secondary cancer cells (SCCs) for cancer progression [159] [162]-[170] are formed in and but not transformed from the senescent normal cells and cancer cells, respectively. These nascent PCCs/SCCs are very small, undifferentiated [162] [169] [171] [172] and absent of organelles, which mature into eukaryotic PCCs/FCCs after being released from the ruptured senescent normal/cancer cells. Nevertheless, the cellular mechanisms of how the 
small nascent PCCs/SCCs formed, and how organelles developed in PCCs/SCCs are unclear. In the light of TDX16-to-TDX16-DE transition, it is most likely that PCCs/SCCs arise from bacteria [173]: the intracellular bacteria take up the senescent normal/cancer cells' DNAs and become small nascent organelle-less PCCs/SCCs, which develop into eukaryotic PCCs/SCCs by hybridizing the acquired DNAs with their own ones and expressing the hybrid genomes to guide organelle biogenesis.

\subsubsection{Implications on Evolutionary Biology}

The origin and diversification of organelles are two different problems in evolutionary biology. The origin of organelles is coupled to origin of eukaryotes concerning how the ancestral organelles formed in the first and last eukaryotic common ancestors. This problem is difficult to make clear owing to the lack of direct evidence. Now, the endosymbiotic hypothesis [174] [175] is widely accepted that an endosymbiotic eubacterium and an endosymbiotic cyanobacterium within an eukaryotic cell turned into the ancestral mitochondrion and chloroplast respectively, while an endosymbiotic archaebacterium within an eubacterium transformed into the ancestral nucleus [176] [177] [178]. By contrast, the diversification of organelles is coupled to formation of new single-celled eukaryotes (the progenitors of multicellular eukaryotes) regarding how the new organelles form in the new single-celled eukaryotes after appearance of the first and last eukaryotic common ancestors. This problem has received little attention and also remains unclear.

Organelle biogenesis in TDX16: 1) uncovers a way of organelle diversification and new single-celled eukaryote formation: the endosymbiotic prokaryote acquires and hybridizes its eukaryotic host's DNA with its own one and then develops into a new single-celled eukaryote by de novo biogenesis of new organelles; 2) provides clues for inferring the origin of organelles and modifying the endosymbiotic hypothesis. In light of organelle biogenesis in TDX16, it is more reasonably that the ancestral nucleus, mitochondrion and chloroplast were de novo formed in but not transformed from the endosymbiotic prokaryotes that had acquired their senescent/necrotic hosts' DNAs. Such that, the modified endosymbiotic theory unifies the endosymbiotic theory and autogenous theory [179] [180], and accounts for both the origin and the diversification of organelles.

\section{Conclusion}

This study unravels the cellular mechanism of organelle biogenesis in cyanobacterium TDX16 that had acquired its eukaryotic host's DNA, which provides an unprecedented insight into the origin, structure and function of eukaryotes and their links to prokaryotes, and thus has broad and profound implications on biology.

\section{Acknowledgements}

This research was funded by the Natural Science Foundation of Hebei Province (B2008000029). 


\section{Authors' Contributions}

Q.L.D. and X.Y.X. performed the experiments and wrote the manuscript with the participation of Y.H. in partial electron microscopic observation and 16S rRNA sequencing, X.L.W. and S. Z. in pigment analyses.

\section{Conflicts of Interest}

The authors declare no conflicts of interest regarding the publication of this paper.

\section{References}

[1] Bevis, B.J., Hammond, A.T., Reinke, C.A. and Glick, B.S. (2002) De Novo Formation of Transitional ER Sites and Golgi Structures in Pichia pastoris. Nature Cell Biology, 4, 750-756. https://doi.org/10.1038/ncb852

[2] South, S.T. and Gould, S.J. (1999) Peroxisome Synthesis in the Absence of Preexisting Peroxisomes. Journal of Cell Biology, 144, 255-266. https://doi.org/10.1083/jcb.144.2.255

[3] van der Zand, A., Gent, J., Braakman, I. and Tabak, H.F. (2012) Biochemically Distinct Vesicles from the Endoplasmic Reticulum Fuse to Form Peroxisomes. Cell, 149, 397-409. https://doi.org/10.1016/j.cell.2012.01.054

[4] Sugiura, A., Mattie, S., Prudent, J. and McBride, H.M. (2017) Newly Born Peroxisomes Are a Hybrid of Mitochondrial and ER-Derived Pre-Peroxisomes. Nature, 542, 251-254. https://doi.org/10.1038/nature21375

[5] Stinchcombe, J.C., Page, L.J. and Griffiths, G.M. (2000) Secretory Lysosome Biogenesis in Cytotoxic T Lymphocytes from Normal and Chediak-Higashi Syndrome Patients. Traffic, 1, 435-444. https://doi.org/10.1034/j.1600-0854.2000.010508.x

[6] Liu, D.F., Xu, L., Yang, F., Li, D.D., Gong, F.L. and Xu, T. (2005) Rapid Biogenesis and Sensitization of Secretory Lysosomes in NK Cells Mediated by Target-Cell Recognition. Proceedings of the National Academy of Sciences of the United States of America, 102, 123-127. https://doi.org/10.1073/pnas.0405737102

[7] Li, Y., Xu, M., Ding, X., Yan, C., Song, Z., Chen, L., Huang, X., Wang, X., Jian, Y., Tang, G., et al. (2016) Protein Kinase C Controls Lysosome Biogenesis Independently of mTORC1. Nature Cell Biology, 18, 1065-1077. https://doi.org/10.1038/ncb3407

[8] Hoh, B., Hinz, G., Jeong, B.K. and Robinson, D.G. (1995) Protein Storage Vacuoles Form De Novo during Pea Cotyledon Development. Journal of Cell Science, 108 299-310.

[9] Viotti, C., Krüger, F., Krebs, M., Neubert, C., Fink, F., Lupanga, U., Scheuring, D., Boutté, Y., Frescatada-Rosa, M., Wolfenstetter, S., Sauer, N., Hillmer, S., Grebe, M. and Schumacher, K. (2013) The Endoplasmic Reticulum Is the Main Membrane Source for Biogenesis of the Lytic Vacuole in Arabidopsis. Plant Cell, 25, 3434-3449. https://doi.org/10.1105/tpc.113.114827

[10] Dong, Q.L., Zhao, X.M., Ma, H.W., Xing, X.Y. and Sun, N.X. (2006) Metabolic Flux Analysis of the Two Astaxanthin-Producing Microorganisms Haematococcus pluvialis and Phaffia rhodozyma in the Pure and Mixed Cultures. Biotechnology Journal, 1, 1283-1292. https://doi.org/10.1002/biot.200600060

[11] Dong, Q.L., Li, Z.W., Xing, X.Y. and Chen, B. (2011) Discovery of an Endophytic 
Cyanobacterium in Haematococcus pluvialis. Journal of Hebei University of Technology, 40, 1-5. https://doi.org/10.3969/j.issn.1007-2373.2011.03.001

[12] Dong, Q.L., Xing, X.Y., Wu, H.X., Han, Y., Wei, X.L. and Zhang, S. (2016) Transition of a Prokaryotic Endosymbiotic Cyanobacterium into a Eukaryotic Green Alga. Chemical Engineering (China), 44, 1-6. https://doi.org/10.3969/j.issn.1005-9954.2016.01.001

[13] Stanier, R.Y., Kunisawa, R., Mandel, M. and Cohen-Bazire, G. (1971) Purification and Properties of Unicellular Blue-Green Algae (Order Chroococcales). Bacteriological Reviews, 35, 171-205. https://doi.org/10.1128/MMBR.35.2.171-205.1971

[14] Ferris, M.J. and Hirsch, C.F. (1991) Method for Isolation and Purification of Cyanobacteria. Applied and Environmental Microbiology, 57, 1448-1452. https://doi.org/10.1128/AEM.57.5.1448-1452.1991

[15] Lichtenthaler, H.K. (1987) Chlorophylls and Carotenoids: Pigments of Photosynthetic Biomembranes. Methods in Enzymology, 148, 350-382. https://doi.org/10.1016/0076-6879(87)48036-1

[16] Adams, S.M., Kao, O.W. and Berns, D.S. (1979) Psychrophile C-Phycocyanin. Plant Physiology, 64, 525-527. https://doi.org/10.1104/pp.64.4.525

[17] Garcia-Pichel, F., Nübel, U. and Muyzer, G. (1998) The Phylogeny of Unicellular, Extremely Halotolerant Cyanobacteria. Archives of Microbiology, 169, 469-482. https://doi.org/10.1007/s002030050599

[18] Moore, L.R., Rocap, G. and Chisholm, S.W. (1998) Physiology and Molecular Phylogeny of Coexisting Prochlorococcus Ecotypes. Nature, 393, 464. https://doi.org/10.1038/30965

[19] Caiola, M.G., Friedmann, R.O. and Friedmann, E.I. (1993) Cytology of Long-Term Desiccation in the Desert Cyanobacterium Chroococcidiopsis (Chroococcales). Phycologia, 32, 315-322. https://doi.org/10.2216/i0031-8884-32-5-315.1

[20] Gonzalez-Esquer, C.R., Smarda, J., Rippka, R., Axen, S.D., Guglielmi, G., Gugger, M. and Kerfeld, C.A. (2016) Cyanobacterial Ultrastructure in Light of Genomic Sequence Data. Photosynthesis Research, 129, 147-157. https://doi.org/10.1007/s11120-016-0286-2

[21] Yeates, T.O., Kerfeld, C.A., Heinhorst, S., Cannon, G.C. and Shively, J.M. (2008) Protein-Based Organelles in Bacteria: Carboxysomes and Related Microcompartments. Nature Reviews Microbiology, 6, 681-691.

https://doi.org/10.1038/nrmicro1913

[22] Allen, M.M. (1984) Cyanobacterial Cell Inclusions. Annual Review of Microbiology, 38, 1-25. https://doi.org/10.1146/annurev.mi.38.100184.000245

[23] Lang, N.J. (1968) The Fine Structure of Blue-Green Algae. Annual Review of Microbiology, 22, 15-46. https://doi.org/10.1146/annurev.mi.22.100168.000311

[24] Eltsov, M. and Zuber, B. (2006) Transmission Electron Microscopy of the Bacterial Nucleoid. Journal of Structural Biology, 156, 246-254. https://doi.org/10.1016/j.jsb.2006.07.007

[25] van de Meene, A.M., Hohmann-Marriott, M.F., Vermaas, W.F. and Roberson, R.W. (2006) The Three-Dimensional Structure of the Cyanobacterium Synechocystis sp. PCC 6803. Archives of Microbiology, 184, 259-270. https://doi.org/10.1007/s00203-005-0027-y

[26] Peramuna, A. and Summers, M.L. (2014) Composition and Occurrence of Lipid Droplets in the Cyanobacterium Nostoc punctiforme. Archives of Microbiology, 196, 881-890. https://doi.org/10.1007/s00203-014-1027-6 
[27] Bréhélin, C., Kessler, F. and van Wijk, K.J. (2007) Plastoglobules: Versatile Lipoprotein Particles in Plastids. Trends in Plant Science, 12, 260-266. https://doi.org/10.1016/j.tplants.2007.04.003

[28] Austin II, J.R., Frost, E., Vidi, P.A., Kessler, F. and Staehelin, L.A. (2006) Plastoglobules Are Lipoprotein Subcompartments of the Chloroplast That Are Permanently Coupled to Thylakoid Membranes and Contain Biosynthetic Enzymes. Plant Cell, 18, 1693-1703. https://doi.org/10.1105/tpc.105.039859

[29] Ytterberg, A.J., Peltier, J. and van Wijk, K.J. (2006) Protein Profiling of Plastoglobules in Chloroplasts and Chromoplasts. A Surprising Site for Differential Accumulation of Metabolic Enzymes. Plant Physiology, 140, 984-997.

https://doi.org/10.1104/pp.105.076083

[30] Vidi, P., Kanwischer, M., Baginsky, S., Austin, J.R., Csucs, G., Dörmann, P., Kessler, F. and Bréhélin, C. (2006) Tocopherol Cyclase (VTE1) Localization and Vitamin E Accumulation in Chloroplast Plastoglobule Lipoprotein Particles. Journal of Biological Chemistry, 281, 11225-11234. https://doi.org/10.1074/jbc.M511939200

[31] Lichtenthaler, H.K. (2013) Plastoglobuli, Thylakoids, Chloroplast Structure and Development of Plastids. In: Biswal, B., Krupinska, K. and Biswal, U.C., Eds., Plastid Development in Leaves during Growth and Senescence Advances in Photosynthesis and Respiration, Springer, Berlin, 337-361.

https://doi.org/10.1007/978-94-007-5724-0_15

[32] Davidi, L., Levin, Y., Ben-Dor, S. and Pick, U. (2015) Proteome Analysis of Cytoplasmatic and Plastidic $\beta$-Carotene Lipid Droplets in Dunaliella bardawil. Plant Physiology, 167, 60-79. https://doi.org/10.1104/pp.114.248450

[33] Hobot, J.A., Carlemalm, E., Villiger, W. and Kellenberger, E. (1984) Periplasmic Gel: New Concept Resulting from the Reinvestigation of Bacterial Cell Envelope Ultrastructure by New Methods. Journal of Bacteriology, 160, 143-152. https://doi.org/10.1128/JB.160.1.143-152.1984

[34] Liberton, M., Berg, R.H., Heuser, J., Roth, R. and Pakrasi, H.B. (2006) Ultrastructure of the Membrane Systems in the Unicellular Cyanobacterium Synechocystis sp Strain PCC 6803. Protoplasma, 227, 129-138.

https://doi.org/10.1007/s00709-006-0145-7

[35] Samuels, A.L., Giddings, T.H. and Staehelin, L.A. (1995) Cytokinesis in Tobacco BY-2 and Root Tip Cells: A New Model of Cell Plate Formation in Higher Plants. Journal of Cell Biology, 130, 1345-1357. https://doi.org/10.1083/jcb.130.6.1345

[36] Rippka, R., Waterbury, J. and Cohen-Bazire, G. (1974) A Cyanobacterium Which Lacks Thylakoids. Archives of Microbiology, 100, 419-436.

https://doi.org/10.1007/BF00446333

[37] Rexroth, S., Mullineaux, C.W., Ellinger, D., Sendtko, E., Rögner, M. and Koenig, F. (2011) The Plasma Membrane of the Cyanobacterium Gloeobacter violaceus Contains Segregated Bioenergetic Domains. Plant Cell, 23, 2379-2390. https://doi.org/10.1105/tpc.111.085779

[38] Hoiczyk, E. and Hansel, A. (2000) Cyanobacterial Cell Walls: News from an Unusual Prokaryotic Envelope. Journal of Bacteriology, 182, 1191-1199. https://doi.org/10.1128/JB.182.5.1191-1199.2000

[39] Simon, R.D. (1971) Cyanophycin Granules form the Blue-Green Alga Anabaena cylindrica: A Reserve Material Consisting of Copolymers of Aspartic Acid and Arginine. Proceedings of the National Academy of Sciences of the United States of America, 68, 265-267. https://doi.org/10.1073/pnas.68.2.265

[40] Gantt, E. and Conti, S.F. (1969) Ultrastructure of Blue-Green Algae. Journal of Bacteriology, 97, 1486-1493. https://doi.org/10.1128/JB.97.3.1486-1493.1969 
[41] Alvarez, H.M., Mayer, F., Fabritius, D. and Steinbüchel, A. (1996) Formation of Intracytoplasmic Lipid Inclusions by Rhodococcus opacus Strain PD630. Archives of Microbiology, 165, 377-386. https://doi.org/10.1007/s002030050341

[42] Woodcock, C.L.F., Frado, L.L.Y. and Rattner, J.B. (1984) The Higher Order Structure of Chromatin: Evidence for a Helical Ribbon Arrangement. Journal of Cell Biology, 99, 42-52. https://doi.org/10.1083/jcb.99.1.42

[43] Gibbs, S.P. (1962) The Ultrastructure of the Pyrenoids of Green Algae. Journal of Ultrastructure Research, 7, 262-272. https://doi.org/10.1016/S0022-5320(62)90022-9

[44] Hay, E.D. and Revel, J.P. (1963) The Fine Structure of the DNP Component of the Nucleus. Journal of Cell Biology, 16, 29-51. https://doi.org/10.1083/jcb.16.1.29

[45] Forbes, D.J., Kirschner, M.W. and Newport, J.W. (1983) Spontaneous Formation of Nucleus-Like Structures around Bacteriophage DNA Microinjected into Xenopus Eggs. Cell, 34, 13-23. https://doi.org/10.1016/0092-8674(83)90132-0

[46] Lohka, M.J. and Masui, Y. (1984) Roles of Cytosol and Cytoplasmic Particles in Nuclear Envelope Assemble and Sperm Pronuclear Formation in Cell-Free Preparations from Amphibian Eggs. Journal of Cell Biology, 98, 1222-1230. https://doi.org/10.1083/jcb.98.4.1222

[47] Hagen, C., Siegmund, S. and Braune, W. (2002) Ultrastructural and Chemical Changes in the Cell Wall of Haematococcus pluvialis (Volvocales, Chlorophyta) during Aplanospore Formation. European Journal of Phycology, 37, 217-226. https://doi.org/10.1017/S0967026202003669

[48] Burczyk, J. and Hesse, M. (1981) The Ultrastructure of the Outer Cell Wall-Layer of Chlorella Mutants with and without Sporopollenin. Plant Systematics and Evolution, 138, 121-137. https://doi.org/10.1007/BF00984613

[49] Scholz, M.J., Weiss, T.L., Jinkerson, R.E., Jing, J., Roth, R., Goodenough, U., Posewitz, M.C. and Gerken, H.G. (2014) Ultrastructure and Composition of the Nannochloropsis gaditana Cell Wall. Eukaryotic Cell, 13, 1450-1464. https://doi.org/10.1128/EC.00183-14

[50] Baudelet, P.H., Ricochon, G., Linder, M. and Muniglia, L. (2017) A New Insight into Cell Walls of Chlorophyta. Algal Research, 25, 333-371. https://doi.org/10.1016/j.algal.2017.04.008

[51] Damiani, M.C., Leonardi, P.I., Pieroni, O. and Cáceres, E.J. (2006) Ultrastructure of the Cyst Wall of Haematococcus pluvialis (Chlorophyceae): Wall Development and Behaviour during Cyst Germination. Phycologia, 45, 616-623. https://doi.org/10.2216/05-27.1

[52] Paquet, V.E., Lessire, R., Domergue, F., Fouillen, L., Filion, G., Sedighi, A. and Charette, S.J. (2013) Lipid Composition of Multilamellar Bodies Secreted by Dictyostelium discoideum Reveals Their Amoebal Origin. Eukaryotic Cell, 12, 1326-1334. https://doi.org/10.1128/EC.00107-13

[53] Nickel, W. and Rabouille, C. (2009) Mechanisms of Regulated Unconventional Protein Secretion. Nature Reviews Molecular Cell Biology, 10, 234-255. https://doi.org/10.1038/nrm2645

[54] Zhang, M. and Schekman, R. (2013) Cell Biology. Unconventional Secretion, Unconventional Solutions. Science, 340, 559-561. https://doi.org/10.1126/science.1234740

[55] Lemasson, C., Marsac, N.T. and Cohen-Bazire, G. (1973) Role of Allophycocyanin as a Light-Harvesting Pigment in Cyanobacteria. Proceedings of the National Academy of Sciences of the United States of America, 70, 3130-3133.

https://doi.org/10.1073/pnas.70.11.3130 
[56] Govindjee and Rabinowitch, E. (1960) Two Forms of Chlorophyll a in Vivo with Distinct Photochemical Functions. Science, 132, 355-356. https://doi.org/10.1126/science.132.3423.355

[57] Gantt, E., Lipschultz, C.A., Grabowski, J. and Zimmerman, B.K. (1979) Phycobilisomes from Blue-Green and Red Algae: Isolation Criteria and Dissociation Characteristics. Plant Physiology, 63, 615-620. https://doi.org/10.1104/pp.63.4.615

[58] Thorne, S.W., Newcomb, E.H. and Osmond, C.B. (1977) Identification of Chlorophyll b in Extracts of Prokaryotic Algae by Fluorescence Spectroscopy. Proceedings of the National Academy of Sciences of the United States of America, 74, 575-578. https://doi.org/10.1073/pnas.74.2.575

[59] Dong, Q.L. and Xing, X.Y. (2020) Chroococcidiorella tianjinensis, gen. et sp. nov. (Trebouxiophyceae, Chlorophyta), a Green Alga Arises from the Cyanobacterium TDX16. bioRxiv. https://doi.org/10.1101/2020.01.09.901074

[60] Bradbeer, J.W., Atkinson, Y.E., Borner, T. and Hagemann, R. (1979) Cytoplasmic Synthesis of Plastid Polypeptdes May Be Controlled by Plastid-Synthesised RNA. Nature, 279, 816-817. https://doi.org/10.1038/279816a0

[61] Chan, K.X., Phua, S.Y., Crisp, P., McQuinn, R. and Pogson, B.J. (2016) Learning the Languages of the Chloroplast: Retrograde Signaling and Beyond. Annual Review of Plant Biology, 67, 25-53. https://doi.org/10.1146/annurev-arplant-043015-111854

[62] De Souza, A., Wang, J.Z. and Dehesh, K. (2017) Retrograde Signals: Integrators of Interorganellar Communication and Orchestrators of Plant Development. Annual Review of Plant Biology, 68, 1.1-1.24.

https://doi.org/10.1146/annurev-arplant-042916-041007

[63] Hedtke, B., Wagner, I., Börner, T. and Hess, W.R. (1999) Inter-Organellar Crosstalk in Higher Plants: Impaired Chloroplast Development Affects Mitochondrial Gene and Transcript Levels. The Plant Journal, 19, 635-643. https://doi.org/10.1046/j.1365-313x.1999.00554.x

[64] Gibbs, S.P. (1962) Nuclear Envelope-Chloroplast Relationships in Algae. Journal of Cell Biology, 14, 433-444. https://doi.org/10.1083/jcb.14.3.433

[65] Bouck, G.B. (1965) Fine Structure and Organelle Associations in Brown Algae. Journal of Cell Biology, 26, 523-537. https://doi.org/10.1083/jcb.26.2.523

[66] Gantt, E., Edwards, M.R. and Provasoli, L. (1971) Chloroplast Structure of the Cryptophyceae. Evidence for Phycobiliproteins within Intrathylakoidal Spaces. Journal of Cell Biology, 48, 280-290. https://doi.org/10.1083/jcb.48.2.280

[67] Timmis, J.N., Ayliffe, M.A., Huang, C.Y. and Martin, W. (2004) Endosymbiotic Gene Transfer: Organelle Genomes Forge Eukaryotic Chromosomes. Nature Reviews Genetics, 5, 123-135. https://doi.org/10.1038/nrg1271

[68] Unseld, M., Marienfeld, J.R., Brandt, P. and Brennicke, A. (1997) The Mitochondrial Genome of Arabidopsis thaliana Contains 57 Genes in 366,924 Nucleotides. Nature Genetics, 15, 57-61. https://doi.org/10.1038/ng0197-57

[69] Notsu, Y., Masood, S., Nishikawa, T., Kubo, N., Akiduki, G., Nakazono, M., Hirai, A. and Kadowaki, K. (2002) The Complete Sequence of the Rice (Oryza sativa L.) Mitochondrial Genome: Frequent DNA Sequence Acquisition and Loss during the Evolution of Flowering Plants. Molecular Genetics and Genomics, 268, 434-445. https://doi.org/10.1007/s00438-002-0767-1

[70] Alverson, A.J., Wei, X.X., Rice, D.W., Stern, D.B., Barry, K. and Palmer, J.D. (2010) Insights into the Evolution of Mitochondrial Genome Size from Complete Sequences of Citrullus lanatus and Cucurbita pepo (Cucurbitaceae). Molecular Biology and Evolution, 27, 1436-1448. https://doi.org/10.1093/molbev/msq029 
[71] Knox, E.B. (2014) The Dynamic History of Plastid Genomes in the Campanulaceae Sensu Lato Is Unique among Angiosperms. Proceedings of the National Academy of Sciences of the United States of America, 111, 11097-11102. https://doi.org/10.1073/pnas.1403363111

[72] Spooner, D.M., Ruess, H., Iorizzo, M., Senalik, D. and Simon, P. (2017) Entire Plastid Phylogeny of the Carrot Genus (Daucus, Apiaceae): Concordance with Nuclear Data and Mitochondrial and Nuclear DNA Insertions to the Plastid. American Journal of Botany, 104, 296-312. https://doi.org/10.3732/ajb.1600415

[73] Goremykin, V.V., Salamini, F., Velasco, R. and Viola, R. (2009) Mitochondrial DNA of Vitis vinifera and the Issue of Rampant Horizontal Gene Transfer. Molecular Biology and Evolution, 26, 99-110. https://doi.org/10.1093/molbev/msn226

[74] Iorizzo, M., Grzebelus, D., Senalik, D., Szklarczyk, M., Spooner, D. and Simon, P. (2012) Against the Traffic: The First Evidence for Mitochondrial DNA Transfer into the Plastid Genome. Mobile Genetic Elements, 2, 261-266.

https://doi.org/10.4161/mge.23088

[75] Straub, S.C.K., Cronn, R.C., Edwards, C., Fishbein, M. and Liston, A. (2013) Horizontal Transfer of DNA from the Mitochondrial to the Plastid Genome and Its Subsequent Evolution in Milkweeds (Apocynaceae). Genome Biology and Evolution, 5, 1872-1885. https://doi.org/10.1093/gbe/evt140

[76] Allfrey, V.G., Mirsky, A.E. and Osawa, S. (1955) Protein Synthesis in Isolated Cell Nuclei. Nature, 176, 1042-1049. https://doi.org/10.1038/1761042a0

[77] Iborra, F.J., Jackson, D.A. and Cook, P.R. (2001) Coupled Transcription and Translation within Nuclei of Mammalian Cells. Science, 293, 1139-1142.

https://doi.org/10.1126/science.1061216

[78] Dolan, B.P., Knowlton, J.J., David, A., Bennink, J.R. and Yewdell, J.W. (2010) RNA Polymerase II Inhibitors Dissociate Antigenic Peptide Generation from Normal Viral Protein Synthesis: A Role for Nuclear Translation in Defective Ribosomal Product Synthesis? The Journal of Immunology, 185, 6728-6733. https://doi.org/10.4049/jimmunol.1002543

[79] David, A., Dolan, B.P., Hickman, H.D., Knowlton, J.J., Clavarino, G., Pierre, P., Bennink, J.R. and Yewdell, J.W. (2012) Nuclear Translation Visualized by Ribosome-Bound Nascent Chain Puromycylation. Journal of Cell Biology, 197, 45-57. https://doi.org/10.1083/jcb.201112145

[80] Apcher, S., Millot, G., Daskalogianni, C., Scherl, A., Manoury, B. and Fåhraeus, R. (2013) Translation of Pre-Spliced RNAs in the Nuclear Compartment Generates Peptides for the MHC Class I Pathway. Proceedings of the National Academy of Sciences of the United States of America, 110, 17951-17956. https://doi.org/10.1073/pnas.1309956110

[81] Baboo, S., Bhushan, B., Jiang, H., Grovenor, C.R., Pierre, P., Davis, B.G. and Cook, P.R. (2014) Most Human Proteins Made in Both Nucleus and Cytoplasm Turn over within Minutes. PLoS ONE, 9, e99346.

https://doi.org/10.1371/journal.pone.0099346

[82] Smith, D.R. and Keeling, P.J. (2015) Mitochondrial and Plastid Genome Architecture: Reoccurring Themes, But Significant Differences at the Extremes. Proceedings of the National Academy of Sciences of the United States of America, 112, 10177-10184. https://doi.org/10.1073/pnas.1422049112

[83] Stern, D.B. and Lonsdale, D.M. (1982) Mitochondrial and Chloroplast Genomes of Maize Have a 12-Kilobase DNA Sequence in Common. Nature, 299, 698-702. https://doi.org/10.1038/299698a0 
[84] Stern, D.B. and Palmer, J.D. (1984) Extensive and Widespread Homologies between Mitochondrial DNA and Chloroplast DNA in Plants. Proceedings of the National Academy of Sciences of the United States of America, 81, 1946-1950. https://doi.org/10.1073/pnas.81.7.1946

[85] Zhang, X., Bauman, N., Brown, R., Richardson, T.H., Akella, S., Hann, E., Morey, R. and Smith, D.R. (2019) The Mitochondrial and Chloroplast Genomes of the Green Alga Haematococcus Are Made up of Nearly Identical Repetitive Sequences. Current Biology, 29, R715-R737. https://doi.org/10.1016/j.cub.2019.06.040

[86] Lacoste-Royal, G. and Gibbs, S.P. (1985) Ochromonas Mitochondria Contain a Specific Chloroplast Protein. Proceedings of the National Academy of Sciences of the United States of America, 82, 1456-1459. https://doi.org/10.1073/pnas.82.5.1456

[87] Bennoun, P. (1982) Evidence for a Respiratory Chain in the Chloroplast. Proceedings of the National Academy of Sciences of the United States of America, 79, 4352-4356. https://doi.org/10.1073/pnas.79.14.4352

[88] Peltier, G., Ravenel, J. and Vermeglio, A. (1987) Inhibition of a Respiratory Activity by Short Saturating Flashes in Chlamydomonas: Evidence for a Chlororespiration. Biochimica et Biophysica Acta, 893, 83-90. https://doi.org/10.1016/0005-2728(87)90151-4

[89] Vesk, M., Mercer, F.V. and Possingham, J.V. (1965) Observations on the Origin of Chloroplast and Mitochondria in the Leaf Cells of Higher Plants. Australian Journal of Botany, 13, 161-169. https://doi.org/10.1071/BT9650161

[90] Ballantine, J.E.M. and Forde, B.J. (1970) The Effect of Light Intensity and Temperature on Chloroplast Ultrastructure in Soybean. American Journal of Botany, 52, 1150-1159. https://doi.org/10.1002/j.1537-2197.1970.tb09919.x

[91] Montes, G. and Bradbeer, J.W. (1976) An Association of Chloroplasts and Mitochondria in Zea mays and Hyptis suaveolens. Plant Science Letters, 6, 35-41. https://doi.org/10.1016/0304-4211(76)90176-0

[92] Brown, R.H., Bouton, J.H., Rigsby, L. and Rigler, M. (1983) Photosynthesis of Grass Species Differing in Carbon Dioxide Fixation Pathways. VIII. Ultrastructural Characteristics of Panicum Species in the Laxa Group. Plant Physiology, 71, 425-431. https://doi.org/10.1104/pp.71.2.425

[93] Brown, R.H., Rigsby, L.L. and Akin, D.E. (1983) Enclosure of Mitochondria by Chloroplasts. Plant Physiology, 71, 437-439. https://doi.org/10.1104/pp.71.2.437

[94] Carvalho, A.O., Da Cunha, M., Rodrigues, R., Sudré, C.P., Santos, I.S., Fernandes, K.V.S., Rabelo, G.R. and Gomes, V.M. (2011) Ultrastructural Changes during Early Infection of Vigna unguiculata and Phaseolus vulgaris Leaves by Xanthomonas axonopodis pv. Phaseoli and an Unexpected Association between Chloroplast and Mitochondrion. Acta Physiologiae Plantarum, 33, 2025-2033. https://doi.org/10.1007/s11738-011-0726-8

[95] Wildman, S.G., Hongladarom, T. and Honda, S.I. (1962) Chloroplasts and Mitochondria in Living Plant Cells: Cinephotomicrographic Studies. Science, 138, 434-435. https://doi.org/10.1126/science.138.3538.434

[96] Valanne, N. and Valanne, T. (1972) Structure of Plastids of Variegated Betula pubescens Mutant. Canadian Journal of Botany, 50, 1835-1839. https://doi.org/10.1139/b72-230

[97] Bonzi, L.M. and Fabbri, F. (1975) Chloroplast Protrusions in Arisarum proboscideum (L.) Savi. Caryologia, 28, 407-426. https://doi.org/10.1080/00087114.1975.10796628 
[98] Zachari, M., Gudmundsson, S.R., Li, Z., Manifava, M., Shah, R., Smith, M., Ktistakis, N.T., et al. (2019) Selective Autophagy of Mitochondria on a Ubiquitin-Endoplasmic Reticulum Platform. Developmental Cell, 5, 627-643. https://doi.org/10.1016/j.devcel.2019.06.016

[99] Zhuang, X., Chung, K.P., Cui, Y., Lin, W., Gao, C., Kang, B.H. and Jiang, L. (2017) ATG9 Regulates Autophagosome Progression from the Endoplasmic Reticulum in Arabidopsis. Proceedings of the National Academy of Sciences of the United States of America, 114, E426-E435. https://doi.org/10.1073/pnas.1616299114

[100] Marty, F. (1999) Plant Vacuoles. Plant Cell, 11, 587-600. https://doi.org/10.1105/tpc.11.4.587

[101] Ragetli, H.W.J., Weintraub, M. and Lo, E. (1970) Degeneration of Leaf Cells Resulting from Starvation after Excision. I. Electron Microscope Observations. Canadian Journal of Botany, 48, 1913-1922. https://doi.org/10.1139/b70-281

[102] Aubert, S., Gout, E., Bligny, R., Marty-Mazars, D., Barrieu, F., Alabouvette, J., Marty, F. and Douce, R. (1996) Ultrastructural and Biochemical Characterization of Autophagy in Higher Plant Cells Subjected to Carbon Deprivation: Control by the Supply of Mitochondria with Respiratory Substrates. Journal of Cell Biology, 133, 1251-1263. https://doi.org/10.1083/jcb.133.6.1251

[103] Ris, H. and Singh, R.N. (1961) Electron Microscope Studies on Blue-Green Algae. The Journal of Biophysical and Biochemical Cytology, 9, 63-80. https://doi.org/10.1083/jcb.9.1.63

[104] Peat, A. and Whitton, B.A. (1967) Environmental Effects on the Structure of the Blue-Green Alga Chlorogloea fritschii. Archiv für Mikrobiologie, 57, 155-180. https://doi.org/10.1007/BF00408699

[105] Edwards, M.R., Berns, D.S., Ghiorse, W.C. and Holt, S.C. (1968) Ultrastructure of the Thermophiic Blue-Green Alga, Synechococcus lividus Copeland. The Journal of Phycology, 4, 283-298. https://doi.org/10.1111/j.1529-8817.1968.tb04697.x

[106] Miller, M.M. and Lang, N.J. (1968) The Fine Structure of Akinete Formation and Germination in Cylindrospermum. Archiv für Mikrobiologie, 60, 303-313. https://doi.org/10.1007/BF00408551

[107] van Wijk, K.J. and Kessler, F. (2017) Plastoglobuli: Plastid Microcompartments with Integrated Functions in Metabolism, Plastid Developmental Transitions, and Environmental Adaptation. Annual Review of Plant Biology, 68, 11.1-11.37. https://doi.org/10.1146/annurev-arplant-043015-111737

[108] Menzel, K. and Wild, A. (1989) A Comparative Ultrastructural Investigation of Some Nannochloris Species (Chlorococcales) with Particular References to the Systematic Position of Nanochlorum eucaryotum. Botanica Acta, 102, 152-158. https://doi.org/10.1111/j.1438-8677.1989.tb00084.x

[109] Somogyi, B., Felföldi, T., Solymosi, K., Makk, J., Homonnay, Z.G., Horváth, G., Turcsi, E., Böddi, B., Márialigeti, K. and Vörös, L. (2011) Chloroparva pannonica gen. et sp. nov. 15 (Trebouxiophyceae, Chlorophyta): A New Picoplanktonic Green Alga from a Turbid, Shallow Soda Pan. Phycologia, 50, 1-10.

https://doi.org/10.2216/10-08.1

[110] Somogyi, B., Felföldi, T., Solymosi, K., Flieger, K., Márialigeti, K., Böddi, B. and Vörös, L. (2013) One Step Closer to Eliminating Nomenclatural Problems of Minute Coccoid Green Algae: Pseudochloris wilhelmii gen. et sp. nov. (Trebouxiophyceae, Chlorophyta). European Journal of Phycology, 48, 427-436. https://doi.org/10.1080/09670262.2013.854411

[111] Vieler, A., et al. (2012) Genome, Functional Gene Annotation, and Nuclear Trans- 
formation of the Heterokont Oleaginous Alga Nannochloropsis oceanica CCMP1779. PLOS Genetics, 8, e1003064. https://doi.org/10.1371/journal.pgen.1003064

[112] Atkinson, A.W., Gunning, B.E. and John, P.C.L. (1972) Sporopollenin in the Cell Wall of Chlorella and Other Algae: Ultrastructure, Chemistry, and Incorporation of 14C-Acetate, Studied in Synchronous Cultures. Planta, 107, 1-32. https://doi.org/10.1007/BF00398011

[113] Pyliotis, N.A., Goodchild, D.J. and Grimme, L.H. (1975) The Regreening of Nitrogen Deficient Chlorella fusca. II. Structural Changes during Synchronous Regreening. Archives of Microbiology, 103, 259-270. https://doi.org/10.1007/BF00436359

[114] Gärtner, G., Uzunov, B., Ingolic, E., Kofler, W., Gacheva, G., Pilarski, P., Zagorchev, L., Odjakova, M. and Stoyneva, M. (2015) Microscopic Investigations (LM, TEM and SEM) and Identification of Chlorella Isolate R-06/2 from Extreme Habitat in Bulgaria with Strong Biological Activity and Resistance to Environmental Stress Factors. Biotechnology \& Biotechnological Equipment, 29, 536-540. https://doi.org/10.1080/13102818.2015.1013283

[115] Zahn, R.K. (1984) A Green Alga with Minimal Eukaryotic Features: Nanochlorum eucaryotum. Origins of Life, 13, 289-303. https://doi.org/10.1007/BF00927178

[116] Eikrem, W. and Throndsen, J. (1990) The Ultrastructure of Bathycoccus gen. nov. and B. prasinos sp. nov., a Non-Motile Picoplanktonic Alga (Chlorophyta, Prasinophyceae) from the Mediterranean and Atlantic. Phycologia, 29, 344-350. https://doi.org/10.2216/i0031-8884-29-3-344.1

[117] Chretiennot-Dinet, M.J., Courties, C., Vaquer, A., Neveux, J., Claustre, H., Lautier, J. and Machado, M.C. (1995) A New Marine Picoeucaryote: Ostreococcus tauri gen. et sp. nov. (Chlorophyta, Prasinophyceae). Phycologia, 34, 285-292. https://doi.org/10.2216/i0031-8884-34-4-285.1

[118] Krienitz, L., Huss, V.A.R. and Hummer, C. (1996) Picoplanktonic Choricystis Species (Chlorococcales, Chlorophyta) and Problems Surrounding the Morphologically Similar “Nannochloris-Like Algae”. Phycologia, 35, 332-341. https://doi.org/10.2216/i0031-8884-35-4-332.1

[119] Krienitz, L., Takeda, H. and Hepperle, D. (1999) Ultrastructure, Cell Wall Composition and Phylogenetic Position of Pseudodictyosphaerium jurisii (Chlorophyta, Chlorococcales) Including a Comparison with Other Picoplanktonic Green Algae. Phycologia, 38, 100-107. https://doi.org/10.2216/i0031-8884-38-2-100.1

[120] Lewin, R.A., Krienitz, L., Goericke, R., Takeda, H. and Hepperle, D. (2000) Picocystis salinarum gen. et sp. nov. (Chlorophyta)-A New Picoplanktonic Green Alga. Phycologia, 39, 560-565. https://doi.org/10.2216/i0031-8884-39-6-560.1

[121] Belykh, O.I., Semenova, E.A., Kuznedelov, K.D., Zaika, E.I. and Guselnikova, N.E. (2000) A Eukaryotic Alga from Picoplankton of Lake Baikal: Morphology, Ultrastructure and rDNA Sequence Data. Hydrobiologia, 435, 83-90. https://doi.org/10.1023/A:1004056604534

[122] Hanagata, N., Malinsky-Rushansky, M. and Dubinsky, Z. (1999) Eukaryotic Picoplankton, Mychonastes homosphaera (Chlorophyceae, Chlorophyta), in Lake Kinneret, Israel. Phycological Research, 47, 263-269. https://doi.org/10.1111/j.1440-1835.1999.tb00307.x

[123] Henley, W.J., Hironaka, J.L., Guillou, L., Buchheim, M.A., Buchheim, J.A., Fawley, M.W. and Fawley, K.P. (2004) Phylogenetic Analysis of the "Nannochloris-Like" Algae and Diagnoses of Picochlorum oklahomensis gen. et sp. nov. (Trebouxiophyceae, Chlorophyta). Phycologia, 43, 641-652.

https://doi.org/10.2216/i0031-8884-43-6-641.1 
[124] Karnkowska, A., Vacek, V., Zubáčová, Z., Treitli, S.C., Petrželková, R., Eme, L., Novák, L., Žárský, V., Barlow, L.D., Herman, E.K., et al. (2016) A Eukaryote without a Mitochondrial Organelle. Current Biology, 26, 1274-1284. https://doi.org/10.1016/j.cub.2016.03.053

[125] Allard, B., Rager, M. and Templier, J. (2002) Occurrence of High Molecular Weight Lipids (C80+) in the Trilaminar Outer Cell Walls of Some Freshwater Microalgae. A Reappraisal of Algaenan Structure. Organic Geochemistry, 33, 789-801. https://doi.org/10.1016/S0146-6380(02)00029-3

[126] Gelin, F., Volkman, J.K., Largeau, C., Derenne, S., Damste, J.S.S. and De Leeuw, J.W. (1999) Distribution of Aliphatic, Nonhydrolyzable Biopolymers in Marine Microalgae. Organic Geochemistry, 30, 147-159. https://doi.org/10.1016/S0146-6380(98)00206-X

[127] Kodner, R.B., Surnmons, R.E. and Knoll, A.H. (2009) Phylogenetic Investigation of the Aliphatic, Non-Hydrolyzable Biopolymer Algaenan, with a Focus on Green Algae. Organic Geochemistry, 40, 854-862. https://doi.org/10.1016/j.orggeochem.2009.05.003

[128] Rashidi, B. and Trindade, L.M. (2018) Detailed Biochemical and Morphologic Characteristics of the Green Microalga Neochloris oleoabundans Cell Wall. Algal Research, 35, 152-159. https://doi.org/10.1016/j.algal.2018.08.033

[129] Burczyk, J. and Loos, E. (1995) Cell Wall-Bound Enzymatic Activities in Chlorella and Scenedesmus. Journal of Plant Physiology, 146, 748-750. https://doi.org/10.1016/S0176-1617(11)81943-7

[130] Matagne, R.F., Loppes, R. and Deltour, R. (1976) Phosphatases of Chlamydomonas reinhardtii: Biochemical and Cytochemical Approach with Specific Mutants. Journal of Bacteriology, 126, 937-950. https://doi.org/10.1128/JB.126.2.937-950.1976

[131] Loos, E. and Meindle, D. (1985) Cell-Wall-Bound Lytic Activity in Chlorella fusca: Function and Characterization of an Endomannanase. Planta (Bed.), 166, 557-562. https://doi.org/10.1007/BF00391282

[132] Satoh, H. and Takeda, H. (1989) Detection and First Characterisation of a Cell Wall Lytic Activity in Chlorella ellipsoidea C-27. Physiologia Plantarum, 77, 20-26. https://doi.org/10.1111/j.1399-3054.1989.tb05972.x

[133] Burczyk, J., Szkawran, H., Zontek, I. and Czygan, F.C. (1981) Carotenoids in the Outer Cell Wall Layer of Scenedesmus (Chlorophyceae). Planta, 151, 247-250. https://doi.org/10.1007/BF00395176

[134] Burczyk, J. (1987) Cell Wall Carotenoids in Green Algae That Form Sporopollenin. Phytochemistry, 26, 121-128. https://doi.org/10.1016/S0031-9422(00)81494-6

[135] Martinière, A., et al. (2012) Cell Wall Constrains Lateral Diffusion of Plant Plasma-Membrane Proteins. Proceedings of the National Academy of Sciences of the United States of America, 109, 12805-12810.

https://doi.org/10.1073/pnas.1202040109

[136] Beveridge, T.J. (1999) Structures of Gram-Negative Cell Walls and Their Derived Membrane Vesicles. Journal of Bacteriology, 181, 4725-4733. https://doi.org/10.1128/JB.181.16.4725-4733.1999

[137] Guerra-Guimaraes, L., Pinheiro, C., Chaves, I., Barros, D.R. and Ricardo, C.P. (2016) Protein Dynamics in the Plant Extracellular Space. Proteomes, 4, 22. https://doi.org/10.3390/proteomes4030022

[138] Chiba, A., Ishida, H., Nishizawa, N.K., Makino, A. and Mae, T. (2003) Exclusion of Ribulose-1,5-bisphosphate Carboxylase/Oxygenase from Chloroplasts by Specific 
Bodies in Naturally Senescing Leaves of Wheat. Plant and Cell Physiology, 44, 914-921. https://doi.org/10.1093/pcp/pcg118

[139] Honig, A., Avin-Wittenberg, T., Ufaz, S. and Galili, G. (2012) A New Type of Compartment, Defined by Plant-Specific Atg8-Interacting Proteins, Is Induced upon Exposure of Arabidopsis Plants to Carbon Starvation. Plant Cell, 24, 288-303. https://doi.org/10.1105/tpc.111.093112

[140] Wang, Y., Yu, B., Zhao, J., Guo, J., Li, Y., Han, S., Huang, L., Du, Y., Hong, Y., Tang, D. and Liu, Y. (2013) Autophagy Contributes to Leaf Starch Degradation. Plant Cell, 25, 1383-1399. https://doi.org/10.1105/tpc.112.108993

[141] Otegui, M.S., Noh, Y.S., Martínez, D.E., Vila Petroff, M.G., Staehelin, L.A., Amasino, R.M. and Guiamet, J.J. (2005) Senescence-Associated Vacuoles with Intense Proteolytic Activity Develop in Leaves of Arabidopsis and Soybean. The Plant Journal, 41, 831-844. https://doi.org/10.1111/j.1365-313X.2005.02346.x

[142] Wang, S. and Blumwald, E. (2014) Stress-Induced Chloroplast Degradation in Arabidopsis Is Regulated via a Process Independent of Autophagy and Senescence-Associated Vacuoles. Plant Cell, 26, 4875-4888. https://doi.org/10.1105/tpc.114.133116

[143] Gantt, E. (2011) Oxygenic Photosynthesis and the Distribution of Chloroplasts. Photosynthesis Research, 107, 1-6. https://doi.org/10.1007/s11120-010-9605-1

[144] Hoffman, H. and Grigg, G.W. (1958) An Electron Microscopic Study of Mitochondria Formation. Experimental Cell Research, 15, 118-131. https://doi.org/10.1016/0014-4827(58)90068-5

[145] Brandes, D., Schofield, B.H. and Anton, E. (1965) Nuclear Mitochondria? Science, 149, 1373-1374. https://doi.org/10.1126/science.149.3690.1373

[146] Matsuyama, M. and Suzuki, H. (1972) Seizing Mechanism and Fate of Intranuclear Mitochondria. Experientia, 28, 1347-1348. https://doi.org/10.1007/BF01965337

[147] Oliva, H., Valle, A., Díaz Flores, L. and Rivas, M.C. (1973) Intranuclear Mitochondriae in Hodgkin's Disease. Virchows Archiv B Cell Pathology, 12, 189-194.

[148] Jensen, H., Engedal, H. and Selmer Satersdal, T. (1976) Ultrastructure of Mitochondria-Containing Nuclei in Human Myocardial Cells. Virchows Archiv B Cell Pathology, 21, 1-12.

[149] Bakeeva, L.E., Skulachev, V.P., Sudarikova, Yu.V. and Tsyplenkova, V.G. (2001) Mitochondria Enter the Nucleus (One Further Problem in Chronic Alcoholism). Biochemistry, 66, 1335-1341. https://doi.org/10.1023/A:1013374410540

[150] Kristensen, T. and Prydz, H. (1986) The Presence of Intact Mitochondrial DNA in HeLa Cell Nuclei. Nucleic Acids Research, 14, 2597-2609. https://doi.org/10.1093/nar/14.6.2597

[151] Hirano, T., Shiraishi, K., Adachi, K., Miura, S., Watanabe, H. and Utiyama, H. (1999) Co-Localization of Mitochondrial and Double Minute DNA in the Nuclei of HL-60 Cells But Not Normal Cells. Mutation Research, 425, 195-204. https://doi.org/10.1016/S0027-5107(99)00037-8

[152] Hazkani-Covo, E., Zeller, R.M. and Martin, W. (2010) Molecular Poltergeists: Mitochondrial DNA Copies (Numts) in Sequenced Nuclear Genomes. PLOS Genetics, 6, e1000834. https://doi.org/10.1371/journal.pgen.1000834

[153] Karlberg, O., Canbäck, B., Kurland, C.G. and Andersson, S.G.E. (2000) The Dual Origin of the Yeast Mitochondrial Proteome. Yeast, 17, 170-187. https://doi.org/10.1002/1097-0061(20000930)17:3<170::AID-YEA25>3.0.CO;2-V

[154] Gabaldón, T. and Huynen, M.A. (2003) Reconstruction of the Proto-Mitochondrial Metabolism. Science, 301, 609. https://doi.org/10.1126/science.1085463 
[155] Gray, M.W. (2015) Mosaic Nature of the Mitochondrial Proteome: Implications for the Origin and Evolution of Mitochondria. Proceedings of the National Academy of Sciences of the United States of America, 112, 10133-10138. https://doi.org/10.1073/pnas.1421379112

[156] Tang, B.L. (2015) Mitochondrial Protein in the Nucleus. CellBio, 4, 23-29. https://doi.org/10.4236/cellbio.2015.42003

[157] Walen, K.H. (2002) The Origin of Transformed Cells: Studies of Spontaneous and Induced in Cell Cultures from Marsupials, a Snail and Human Amniocytes. Cancer Genetics and Cytogenetics, 133, 45-54. https://doi.org/10.1016/S0165-4608(01)00572-6

[158] Walen, K.H. (2004) Spontaneous Cell Transformation: Karyoplasts Derived from Multinucleated Cells Produce New Cell Growth in Senescent Human Epithelial Cell Cultures. In Vitro Cellular \& Developmental Biology-Animal, 40, 150-158. https://doi.org/10.1290/1543-706X(2004)40<150:SCTKDF>2.0.CO;2

[159] Sundaram, M., Guerrnsey, D.L., Rajaraman, M.M. and Rajaraman, R.R. (2004) Neosis: A Novel Type of Cell Division in Cancer. Cancer Biology \& Therapy, 3, 207-218. https://doi.org/10.4161/cbt.3.2.663

[160] Leikam, C., Hufnagel, A.L., Otto, C., Murphy, D.J., Mühling, B., Kneitz, S., Nanda, I., Schmid, M., Wagner, T.U., Haferkamp, S., Bröcker, E.B., Schartl, M. and Meierjohann, S. (2015) In Vitro Evidence for Senescent Multinucleated Melanocytes as a Source for Tumor-Initiating Cells. Cell Death \& Disease, 6, e1711. https://doi.org/10.1038/cddis.2015.71

[161] Zhang, S., Mercado-Uribe, I., Sood, A., Bast, R.C. and Liu, J. (2016) Coevolution of Neoplastic Epithelial Cells and Multilineage Stroma via Polyploid Giant Cells during Immortalization and Transformation of Mullerian Epithelial Cells. Genes Cancer, 7, 60-72.

[162] Buikis, I., Harju, L. and Freivalds, T. (1999) Origin of Microcells in Human Sarcoma Cell Line HT1080. Analytical Cellular Pathology, 18, 73-85. https://doi.org/10.1155/1999/461805

[163] Erenpreisa, J., Cragg, M., Fringes, B., Sharakhov, I. and Illidge, T. (2000) Release of Mitotic Descendents by Giant Cells from Irradiated Burkitt's Lymphoma Cell Line. Cell Biology International, 24, 635-648. https://doi.org/10.1006/cbir.2000.0558

[164] Puig, P.E., Guilly, M.N., Bouchot, A., Droin, N., Cathelin, D., Bouyer, F., et al. (2008) Tumor Cells Can Escape DNA-Damaging Cisplatin through DNA Endoreduplication and Reversible Polyploidy. Cell Biology International, 32, 1031-1043. https://doi.org/10.1016/j.cellbi.2008.04.021

[165] Ianzini, F., Kosmacek, E.A., Nelson, E.S., Napoli, E., Erenpreisa, J., Kalejs, M. and Mackey, M.A. (2009) Activation of Meiosis-Specific Genes Is Associated with Depolyploidization of Human Tumor Cells Following Radiation-Induced Mitotic Catastrophe. Cancer Research, 69, 2296-2304. https://doi.org/10.1158/0008-5472.CAN-08-3364

[166] Weihua, Z., Lin, Q., Ramoth, A.J., Fan, D. and Fidler, I.J. (2011) Formation of Solid Tumors by a Single Multinucleated Cancer Cell. Cancer, 117, 4092-4099. https://doi.org/10.1002/cncr.26021

[167] Zhang, S., Mercado-Uribe, I. and Liu, J. (2013) Generation of Erythroid Cells from Fibroblasts and Cancer Cells in Vitro and in Vivo. Cancer Letters, 333, 205-212. https://doi.org/10.1016/j.canlet.2013.01.037

[168] Niu, N., Zhang, J., Zhang, N., Mercado-Uribe, I., Tao, F., Han, Z., et al. (2016) Linking Genomic Reorganization to Tumor Initiation via the Giant Cell Cycle. Oncogenesis, 5, e281. https://doi.org/10.1038/oncsis.2016.75 
[169] Niu, N., Mercado-Uribe, I. and Liu, J. (2017) Dedifferentiation into Blastomere-Like Cancer Stem Cells via Formation of Polyploid Giant Cancer Cells. Oncogene, 36, 4887-4900. https://doi.org/10.1038/onc.2017.72

[170] Zhang, D., Yang, X., Yang, Z., Fei, F., Li, S., Qu, J., Zhang, M., Li, Y., Zhang, X. and Zhang, S. (2017) Daughter Cells and Erythroid Cells Budding from Pgccs and Their Clinicopathological Significances in Colorectal Cancer. Journal of Cancer, 8, 469-478. https://doi.org/10.7150/jca.17012

[171] Woodworth, C.D., Bowden, P.E., Doninger, J., Pirisi, L., Barnes, W., Lancaster, W.D. and DiPaolo, J.A. (1988) Characterization of Normal Human Exocervical Epithelial Cells Immortalized in Vitro by Papillomavirus Types 16 and 18 DNA. Cancer Research, 48, 4620-4628.

[172] Romanov, S.R., Kozakiewics, B.K., Hoist, C.R., Stampfei, M.R., Haupt, L.M. and Tlsty, T.D. (2001) Normal Human Mammary Epithelial Cells Spontaneously Escape Senescence and Acquire Genomic Changes. Nature, 409, 633-637.

https://doi.org/10.1038/35054579

[173] Dong, Q.L. and Xing, X.Y. (2018) Cancer Cells Arise from Bacteria. Cancer Cell International, 18, 205. https://doi.org/10.1186/s12935-018-0699-4

[174] Sagan, L. (1967) On the Origin of Mitosing Cells. Journal of Theoretical Biology, 14, 225-274. https://doi.org/10.1016/0022-5193(67)90079-3

[175] Martin, W. and Kowallik, K. (1999) Annotated English Translation of Mereschkowsky's 1905 Paper “über Natur und Ursprung der Chromatophoren im Pflanzenreiche”. European Journal of Phycology, 34, 287-295. https://doi.org/10.1017/S0967026299002231

[176] Zillig, W., Klenk, H.-P., Palm, P., Leffers, H., Pühler, G., Gropp, F. and Garrett, R.A. (1989) Did Eukaryotes Originate by a Fusion Event? Endocytobiosis and Cell Research, 6, 1-25.

[177] Lake, J.A. and Rivera, M.C. (1994) Was the Nucleus the First Endosymbiont? Proceedings of the National Academy of Sciences of the United States of America, 91, 2880-2881. https://doi.org/10.1073/pnas.91.8.2880

[178] Gupta, R.S. and Golding, G.B. (1996) The Origin of the Eukaryotic Cell. Trends in Biochemical Sciences, 21, 166-171. https://doi.org/10.1016/S0968-0004(96)20013-1

[179] Harish, A. and Kurland, C.G. (2017) Mitochondria Are Not Captive Bacteria. The Journal of Theoretical Biology, 434, 88-98. https://doi.org/10.1016/j.jtbi.2017.07.011

[180] Baum, D.A. (2015) A Comparison of Autogenous Theories for the Origin of Eukaryotic Cells. American Journal of Botany, 102, 1954-1965.

https://doi.org/10.3732/ajb.1500196 


\section{Abbreviations}

AUG: Autosporangium

C: Chloroplast

CD: Chloroplast debris

CE: Cytoplasmic envelope

CF: Chromatin fibers

CG: Cyanophycin granules

CHE: Chloroplast envelope

CLM: Cloudlike materials

CM: Cytoplasmic membrane

CPV: Compound vesicles

CR: Cristae

CV: Combined vesicles

CW: Cell wall

CX: Carboxysomes

DF: DNA Fibers

DGV: Dense-margined vesicles

DLF: DNA-like fibrils

DMF: Double-layered membrane fragment

DMS: Double-layered membrane segment

DMV: Double-membraned vesicles

DRV: Dilated ring-shaped vesicles

DSV: Dense vesicle

DT: DNA threads

DV: Dotted vesicles

ED: Electron-dense debris

EDV: Electron-dense vesicles

EF: Electron-dense fibrils

EG: Electron-dense granules

EIS: Empty Inner space

EL: Electron-dense layer

ELM: Electron-translucent materials

ELV: Electron-translucent vesicles

EM: Eukaryotic cytoplasmic matrix

EOB: Electron-opaque bodies

EOP: Electron-opaque particles

EOM: Electron-opaque materials

EOV: Electron-opaque vesicles

EP: Electron-dense particles

EPM: Electron-transparent materials

ER: Endoplasmic reticulum

ES: Extracytoplasmic space

EV: Electron-transparent vesicle 
EW: Eukaryotic cell wall

FM: Fibrillar materials

GA: Golgi apparatus

GP: Globular particles

HGB: Heterogenous globular bodies

IB: Intranuclear body

ICE: Intracytoplasmic envelope

ICP: Inner cytoplasm

IES: Inter envelope space

IIM: Inner intracytoplasmic membrane

IIS: Inner intracytoplasmic space

INS: Interspace

IS: Intracytoplasmic space

ITB: Internal body

IV: Internal vesicle

IVS: Invaginated space

LD: Lipid droplet

LDB: Less electron-dense bodies

LDM: Less electron-dense materials

LM: Limiting membrane

M: Mitochondrion

ME: Mitochondrial envelope

MF: Membrane fragments

ML: Microfibrils

MLB: Multilamellar body

MR: Margin residues

MS: Membrane segments

MT: Membranous elements

MV: Microvesicles

$\mathrm{N}$ : Nucleus

NE: Nuclear envelope

NIC: New inner cytoplasm

NIS: New inner intracytoplasmic space

NS: New intracytoplasmic space

NT: Nucleoid-like structure

NU: Nucleoid

NX: New intracytoplasmic matrix

OCP: Outer cytoplasm

OE: Outer nuclear envelope

OG: Osmiophilic granules

OIM: Outer intracytoplasmic membrane

OIS: Outer intracytoplasmic space

OPV: Opaque-periphery vesicle

OM: Outer membrane 
OV: Oblong vesicles

P: Peptidoglycan layer

PB: Polyphosphate bodies

PC: Primitive chloroplast

PCB: Phycobilisomes

PD: Pyrenoids

PG: Plastoglobuli

PL: Peptidoglycan-like layer

PMT: Primitive thylakoids

PN: Primitive nucleus

PNE: Primitive nuclear envelope

PO: Pores

PT: Primary thylakoids

RB: Ribosomes

RM: Residual membranes

RV: Ring-shaped vesicles

SA: Sporangium

SG: Starch granules

SH: Sheath

SMV: Smaller vesicles

SM: Stroma

SOV: Small opaque vesicle

SP: Starch plate

ST: Secondary thylakoids

SV: Small vesicles

T: Thylakoids

TL: Thylakoid-like structure

TMF: Two-layered membrane fragment

TMV: Thick margin vesicle

TV: Tiny vesicles

V: Vacuole

VB: Vesicle-containing body 